THE INFLUENCE OF ROLE MODELS ON TRANS

MEN'S IDENTITY DEVELOPMENT

A Dissertation
presented to
the Faculty of the Graduate School
at the University of Missouri-Columbia
In Partial Fulfillment
of the Requirements for the Degree
JENNAH STRATHAUSEN
Doctor of Philosophy

Dr. Francisco J. Sánchez, Dissertation Supervisor

JULY 2020 
The undersigned, appointed by the dean of the Graduate School, have examined the dissertation entitled: THE INFLUENCE OF ROLE MODELS ON TRANS MEN'S IDENTITY

\section{DEVELOPMENT}

presented by Jennah Strathausen, a candidate for the degree of Doctor of Philosophy, and hereby certify that, in their opinion, it is worthy of acceptance.

Francisco J. Sánchez. Ph.D. (chair)

Lisa Y. Flores, Ph.D.

Shannon E. McClain, Ph.D.

Emily R. Crawford-Rossi, Ph.D. 
Trans Men's Role Models

\section{DEDICATION}

For Carsten, Coen, and Lena. Love you to pieces! 


\section{ACKNOWLEDGMENTS}

I am deeply grateful for the support of many friends, family members, colleagues, and mentors throughout my graduate training. I would like to thank Dr. Francisco J. Sánchez for his support, recommendations, and thoughtful advising. I would also like to thank Dr. Lisa Y. Flores who fostered me as her mentee and encouraged me in both of my roles as a student and as a mother. Finally, I would like to thank Dr. Roger L. Worthington who initially believed in me, provided me the opportunity to publish, and who is ultimately responsible for my pursuing a doctoral degree in Counseling Psychology. 


\section{TABLE OF CONTENTS}

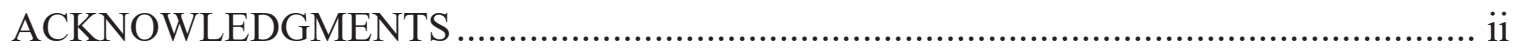

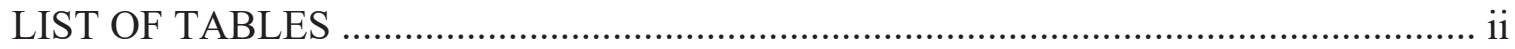

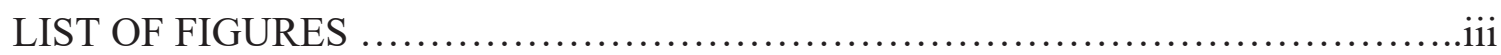

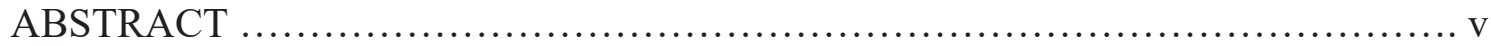

Chapter 1 ...................................................................

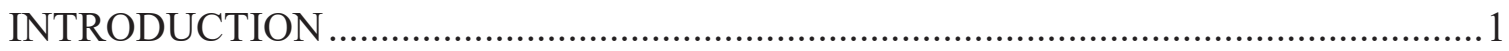

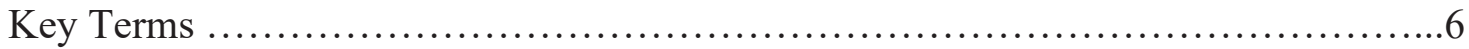

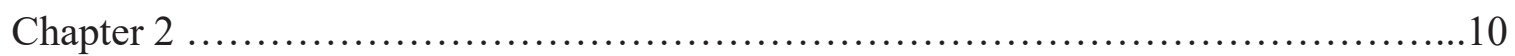

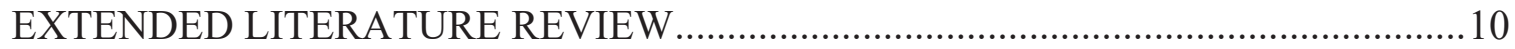

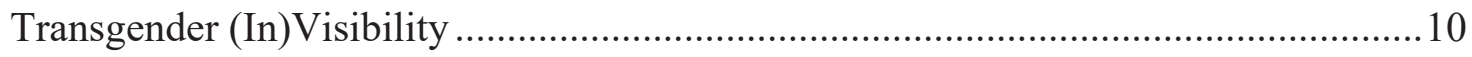

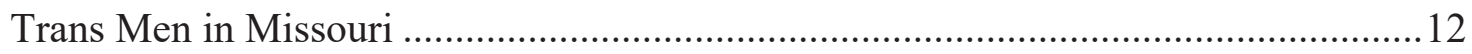

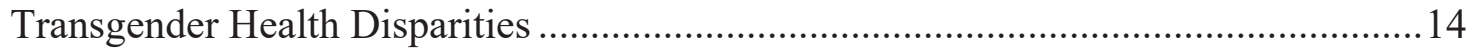

Gender Minority Stress Model ............................................................................ 15

Social Learning Theory \& Gender Identity Development .................................... 17

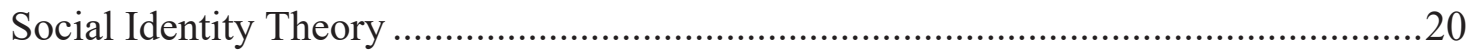

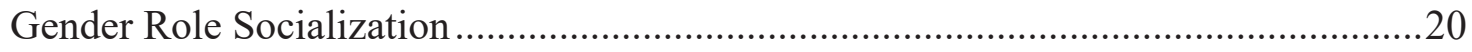

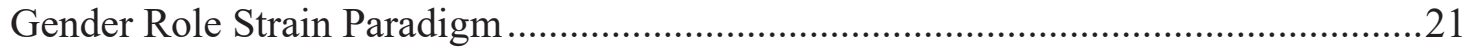

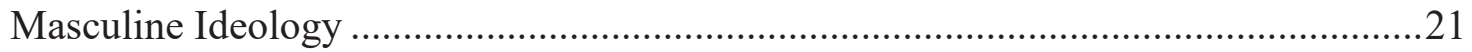




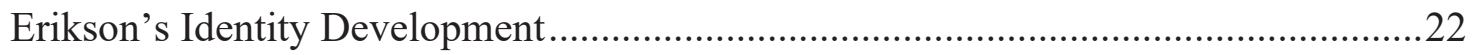

Transgender Identity Development ...................................................................22

Devor's Model of Transsexual Identity Formation .................................................23

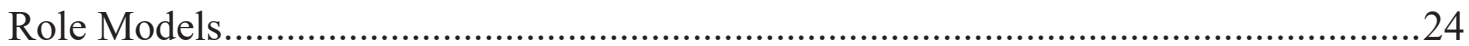

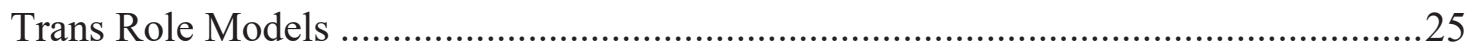

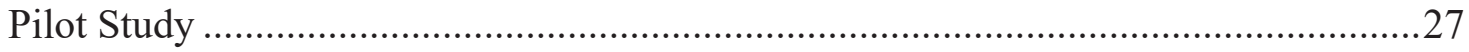

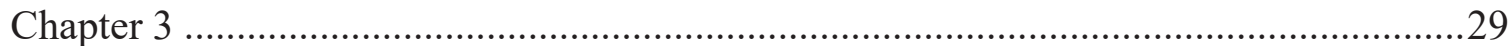

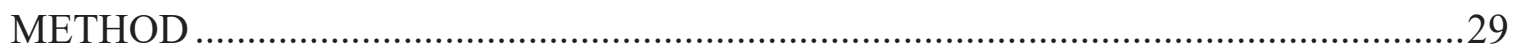

Rational For Qualitative Design............................................29

Researcher Background and Potential Bias ........................................................... 30

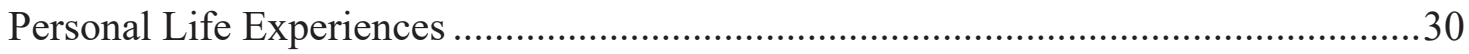

Social Constructivism Central to My Worldview ....................................31

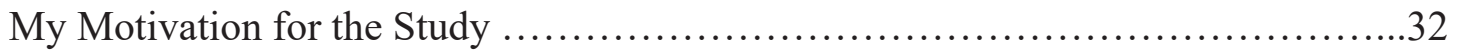

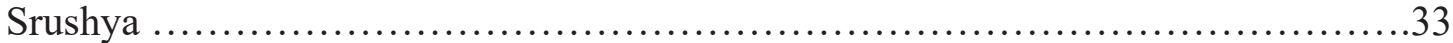

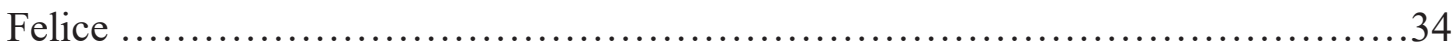

Community Based Participatory Research ..................................... 34

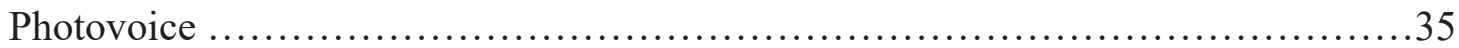

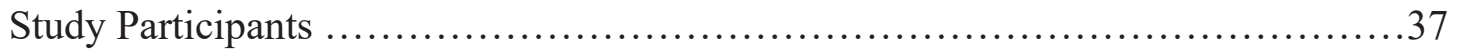

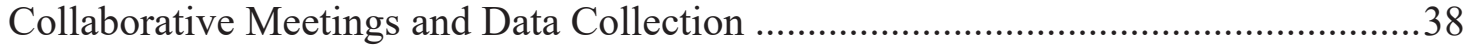

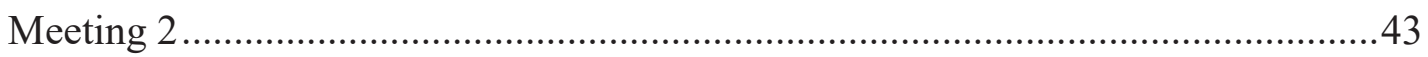

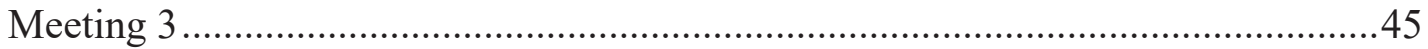




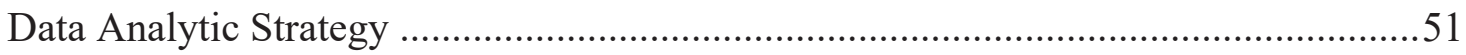

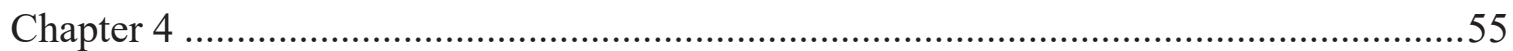

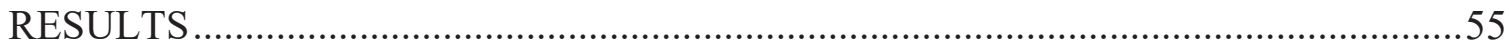

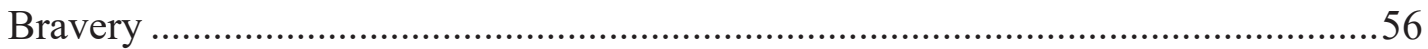

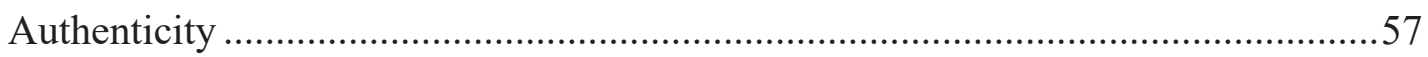

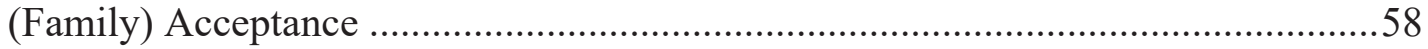

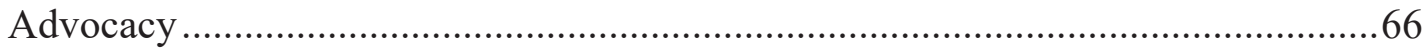

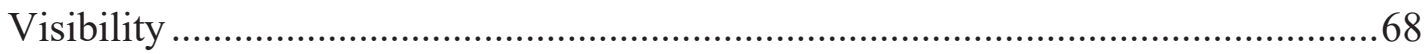

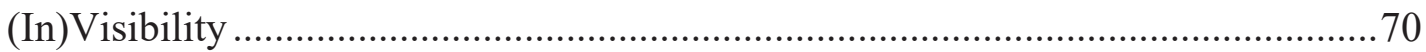

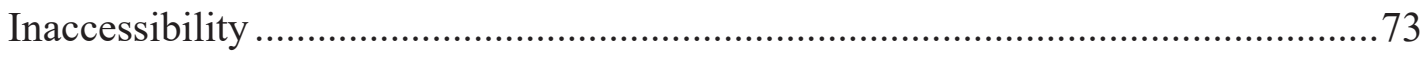

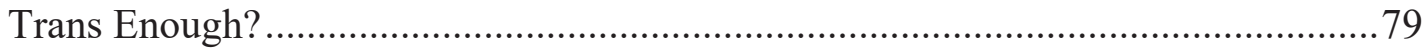

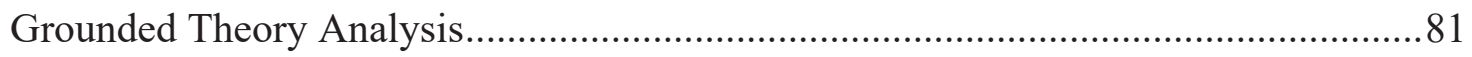

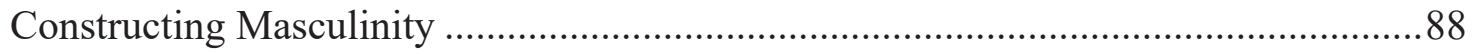

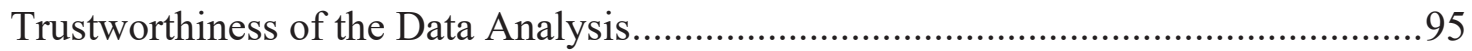

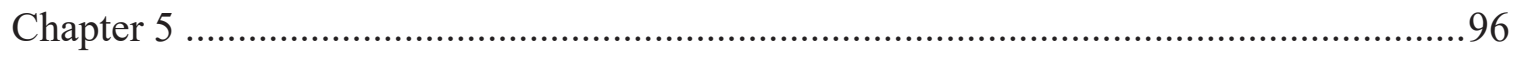

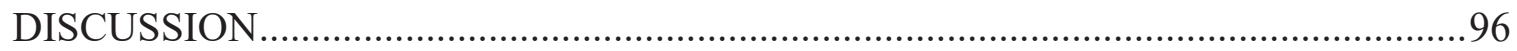

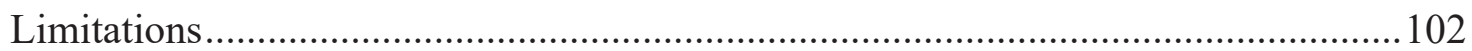

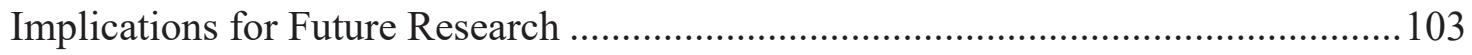

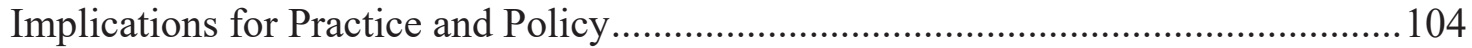

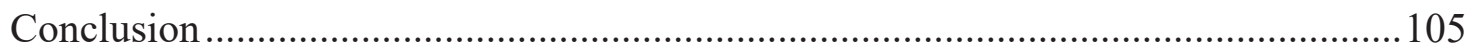

References ........................................................... 107 


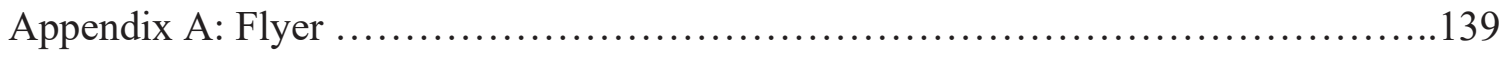

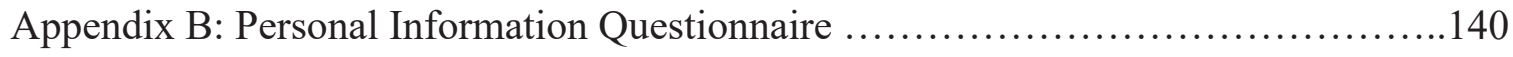

Appendix C: Informed Consent .......................................... 142

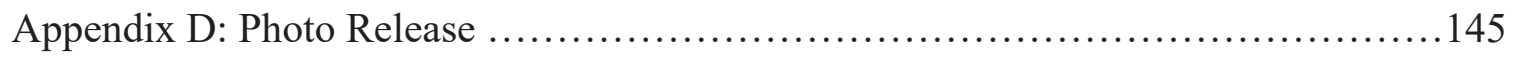

Appendix E: Consent to Use Photographs ................................... 146

Appendix F: Photovoice Brochure (Front Side) ................................ 148

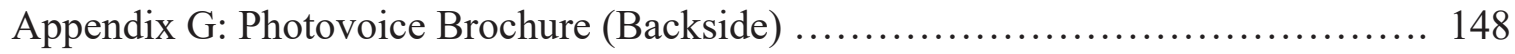

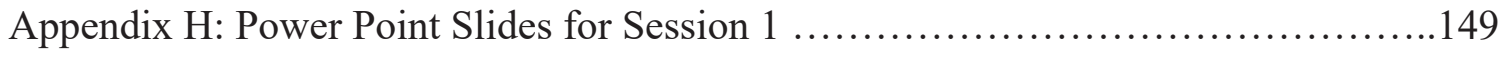

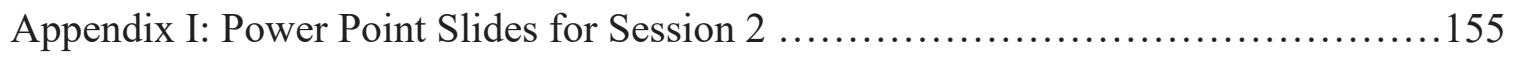

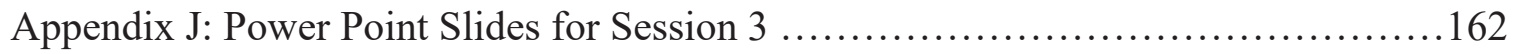

Appendix K: Researchers Statement of Reflexivity ......................... 174

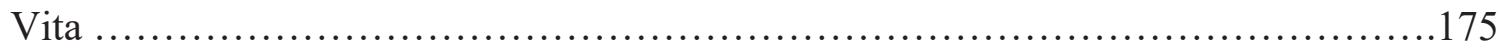




\section{LIST OF TABLES}

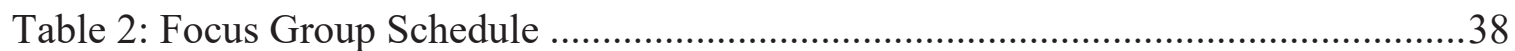

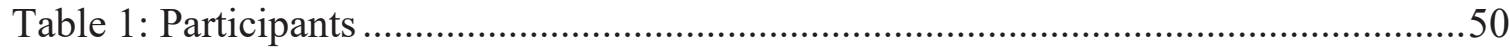




\section{LIST OF FIGURES}

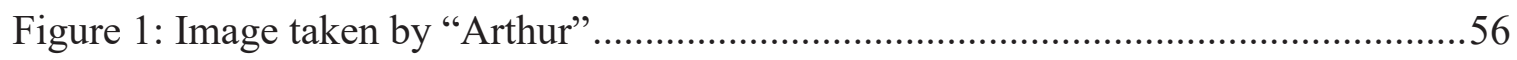

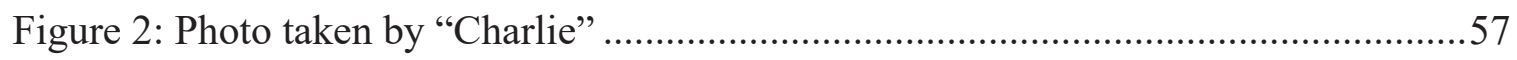

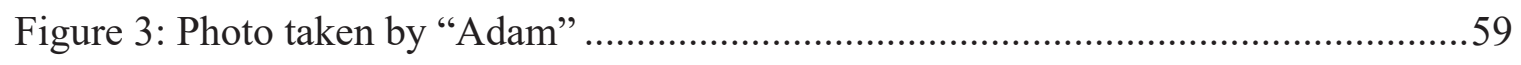

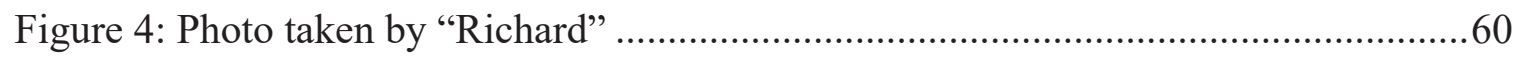

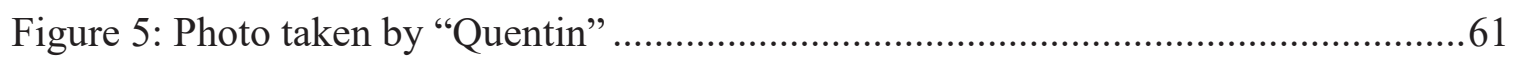

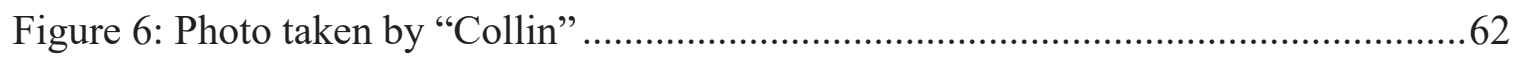

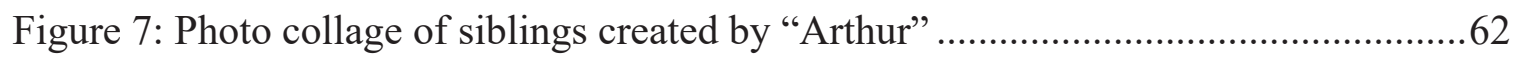

Figure 8: Photo of patches sewn on backpack taken by "Ethan" ..................................63

Figure 9: Photo collage of daughter and "chosen family" by participant "Thomas" .......64

Figure 10: Pre-transition photo of "Jared" with his father at his college graduation ........65

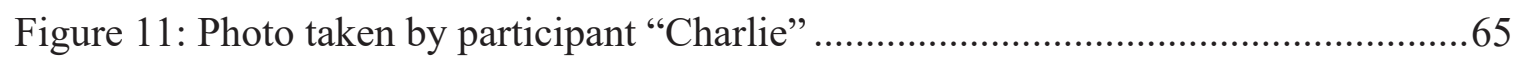

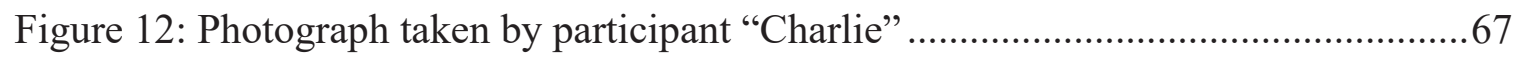

Figure 13: Photo by "Justin" symbolizing his struggle to stay connected to his identity .69

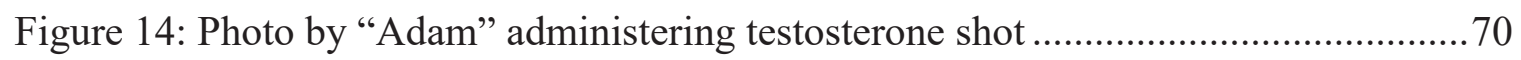

Figure 15: Photo of 'The Big Tree' taken by "Jared" .................................................... 72

Figure 16: Photo of impactful book taken by "Justin" .............................................. 74

Figure 17: Photo of impactful books as identified by participant "Collin"......................75

Figure 18: "Jared" Comparing Himself to Aydian Dowling...........................................77

Figure 19: Photo of Cicadas Shedding Their Shells by "Quentin" ................................79

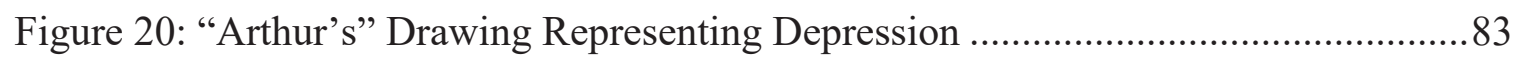

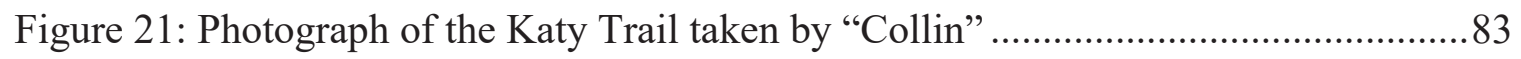

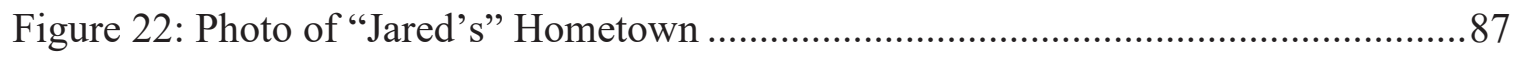




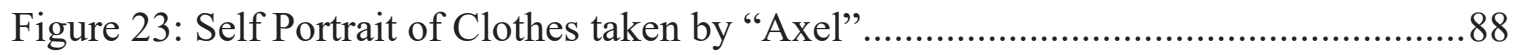

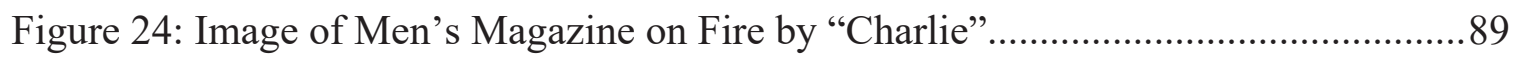

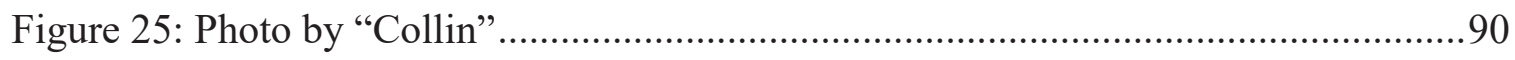

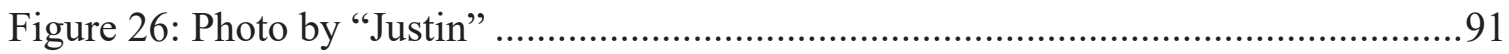

Figure 27: Image of Binding Taken by “Adam” ....................................................... 92

Figure 28: Photo taken by participant Thomas........................................................... 93 


\title{
THE INFLUENCE OF ROLE MODELS ON \\ TRANS MEN'S IDENTITY DEVELOPMENT
}

Jennah Strathausen

Dr. Francisco J. Sánchez, Dissertation Supervisor

\begin{abstract}
Transgender and gender nonconforming (TGNC) individuals face significant stigma and discrimination stemming from negative societal attitudes toward their experienced gender incongruence. Much of the LGBTQ literature on TGNC health disparities and gender minority stress focuses on the influence of overt acts of violence and oppression, often leaving more subtle and ubiquitous stressors, like invisibility, unexplored. In addition, there is a limited amount of literature on the experiences of transgender men, particularly those residing in the central U.S. Research suggests that the influence of positive role models can mitigate many of the stressors experienced by TGNC people. This study aimed to explore the influence of role models on trans men's identity development. Using Photovoice Methodology situated in Community-Based Participatory Research, this project collaboratively explored the needs, assets, and concerns of trans men living in Mid-Missouri. Twelve participants ( $M d n_{\mathrm{Age}}=31.5$ years-old) and the researchers separately grouped the participant-generated photographs and personal narratives into eight themes, including Authenticity, Acceptance, Inaccessibility, Isolation, and “Trans Enough?” Results supported the idea that access to positive role models serves as a protective factor for TGNC people. Results additionally highlight that trans men possess significant characteristics of resilience. Several implications for practice, public policy, and future research are provided.
\end{abstract}




\section{Chapter 1}

\section{INTRODUCTION}

Use a picture. It's worth a thousand words.

-Arthur Brisbane (1911, p. 18)

In October 2018, Gentry Middle School in Columbia, Missouri, USA, made local headlines: The principal decided to remove a photo display set up by the school's diversity committee in honor of "LGBT (Lesbian, Gay, Bisexual, and Transgender) History Month" because several area parents expressed "concern" that the display advocated a certain "lifestyle." The display included posters with images of famous individuals who were openly LGBT, including Mizzou football player Michael Sam, actresses Laverne Cox, and comedian Ellen DeGeneres. Administrators kept the display of the Jaguar PAWS Club (People Accepting Whole Selves, which is the school's Gay-Straight Alliance Club) logo, removing only the identifiable images of LGBT celebrities (Toomy, 2018). Although disappointing to many students at that middle school, the incident, nonetheless, highlighted the heightening awareness and attention being given to sexuality and gender issues by younger generational cohorts.

This increasing visibility and affirmation of Transgender and Gender Non-conforming (TGNC) youth in public institutions including schools has been seen as facilitating selfunderstanding and self-acceptance at earlier ages by TGNC youth (Austin, 2016). An increasing number of schools have been implementing affirmative practices such as enacting explicit antiharassment policies and protections based on sexual orientation, gender identity, and gender expression. Furthermore, many educators have begun incorporating positive representations of LGBTQ people, history, and events in the school curriculum (Kosciw et al., 2016). 
Independent of the larger LGBTQ community, TGNC people have long sought out visibility as a political goal to increase awareness of their experiences and advocate for civil rights (Sears \& Williams, 1997). While rates of violence and discrimination have been highlighted in both social and academic discourse, often more subtle and pervasive forms of transphobia, including invisibility and pathologization, go uncharted (Austin, 2016). This may be especially true for trans men (or those assigned female at birth but who later identify and transition to live as male) who are both fewer in numbers and less visible than trans women (or those assigned male at birth but who later identify and transition to live as female).

Like trans women, trans men have reported not being recognized for who they are, including being incorrectly labeled or mis-gendered by people in general because they do not fulfill societal stereotypes of what a male should look and behave like. Yet, even within the LGBTQ Community, TGNC people often report feeling ostracized by gay, lesbian, and bisexual people because they feel misunderstood or seen as irrelevant to civil rights based on sexual orientation (Klein, et al., 2015). Consequently, the TGNC community can be seen as fighting for their equal rights on two fronts: against the dominant cisgender and heterosexual culture; and against the cisgender yet non-heterosexual front. Trans men, then, have reported feeling forced to engage in a form of 'invisibility' in order to shield themselves from a societally hostile gaze, body policing, and exploitation (Holtby et al., 2015).

Despite the recent increase in research regarding LGBTQ individuals, the vast majority of scholarship on sexual orientation and gender diversity has been based on the idea that gender is strictly binary including traditional gender-based stereotypes, misconceptions, and biases (Frost, 2011; Meyer, 2013; Worthington et al., 2005). TGNC people in general—but trans men 
in particular - receive peripheral attention within the broader literature that claims to be inclusive of LGBTQ individuals (Beemyn \& Rankin, 2011; Currah \& Minter, 2000; Israel, 2005).

Statistical information on trans men's experiences is challenging to obtain in part due in part to a lack of data collection in population-based surveys (Flores et al., 2016; Nolan et al., 2019), as well as the broad range of terms used to describe transgender identities (Bornstein, 1995; Green, 2000; Halberstam, 2005; Meyerowitz, 2002; Wilchins, 2002, 2004). Furthermore, many trans men "live stealth" (or do not disclose that their birth sex was female) choosing to assimilate into their chosen communities without mention of their past experiences (Green, 2006). Due to these challenges, research on trans men's needs, health disparities, and lived experiences remain largely underrepresented in the literature.

One of the few studies on trans men's adoption of male norms was conducted by Abelson (2014) who interviewed 19 trans men in the San Francisco Bay Area. The participants reported performing defensive masculinity, including the expression of homophobic and antifeminine attitudes in order to "fit in" when they felt their physical safety threatened. These men described pressures they felt to meet normative standards expected of their male gender including posturing, acting aggressively, and joking about pornographic images (Abelson, 2014). Interestingly, these described pressures are similar to ones described by gay men who felt pressured to enact traditional notions of masculinity even among other gay men (Sánchez et al., 2009). In sum, trans men's authentic experiences have largely gone under the radar, because they are limited by the constraints of a heterosexist and cis-sexist society.

Like many of their LGBTQ counterparts, trans men report experiencing stigma and discrimination, which has been attributed to the negative societal attitudes toward their perceived gender incongruence (Bockting et al., 2013; Hendricks \& Testa, 2012; Lombardi et al., 2001). 
Transphobia may manifest as violence, harassment, bullying, and economic and employment discrimination (Mizock \& Mueser, 2014). Further violations of gender role norms often lead to societal condemnation and ultimately adverse psychological consequences for those that fall outside of a traditional gender binary (Schilt, 2010). According to the Gender Minority Stress Model (Testa et al., 2015), trans men's experiences of gender related rejection and victimization contributes to internalized transphobia, negative expectations, concealment and ultimately poor physical and mental health outcomes. Trans men experience significantly higher rates of depression, anxiety, substance abuse, and suicidality than cisgender men (Grant et al., 2010; Hendricks \& Testa, 2012). They are additionally more likely to participate in high-risk behaviors including substance abuse and indiscriminate sexual behaviors (Frost, 2011; Meyer 2013).

One protective factor against psychological distress is the presence of positive role models, who can help foster a sense of resilience and self-worth. The gender identity of a role model has been found to be a significant predictor of the role model's influence, particularly for adolescent boys (Bandura, 1977; Bussey \& Bandura, 1999; Bandura \& Walter, 1963). Role models can represent what is possible for a person to achieve; can motivate people to set and achieve ambitious goals, and can even "inoculate" people against internalized stigma by illustrating social belonging (Dasgupta, 2011). This is especially true among marginalized and underrepresented groups like trans men, who in dangerous situations may look to others like themselves for reassurance and inspiration (McIntyre et al., 2011). Being able to search the internet, watch films, read books or turn on the television, and see oneself positively reflected in the story is something that many people take for granted. According to theorists Gerbner and Gross (1976), "representation in the fictional world signifies social existence; absence means symbolic annihilation" (p.182). Both the attractiveness and effectiveness of role models is 
dependent on a salient shared group identity between the role model and aspirant (Bandura, 1976; Morgenroth et al., 2015).

While trans men's visibility in the media is currently at an all-time high, trans men remain significantly underrepresented. Films and television shows which have featured trans men tend to represent their experience as tragic and devastating (GLAAD, 2014). Often the roles of trans characters are given to cisgender actors who perpetuate the popular trope of a woman in disguise (Phillips, 2006). Albert Nobbs (García, 2011) is one such film in which the title character — played by cisgender actress Glenn Close — is portrayed as a woman who hides her "true" female identity under the cloak of maleness. "He walks stiffly and speaks in a low monotone, acting out a parody of masculinity that is charming, revealing and sad" (Scott, 2011, para. 2). Moreover, celebrities who identify as trans men are almost exclusively White (nonLatino), affluent, from urban areas, and constrained by traditional representations of femininity and masculinity (Lovelock, 2015). In a large-scale study on transgender identity, Beemyn and Rankin (2011) found "nearly half of the nearly 3,500 FTM sample reported initially lacking information about others like themselves — including knowledge that transitioning was even possible" (p. 120).

Given the importance of role models for people's general well-being, this dissertation study aims to address the gap in the scientific literature regarding role models in the lives of trans men. The key question studied was: What is the influence of role models on trans men's identity development in Missouri? To address this, I employed photovoice methodology (Wang, 1999; Wang \& Burris, 1997) — a methodology that is situated in Community-Based Participatory Research (Minkler \& Wallerstein, 2008). Key to this type of scientific approach is establishing and activating connections with the local trans community so that they actively co-investigate the 
community's concerns, strengths, and health barriers related to the theme of role models (Wang, 1997). The current study used documentary photography situated in grassroots social action to identify salient issues in the trans masculine community in Missouri.

In the next chapter, I will review the literature on role models while drawing on The Social Cognitive Theory of Gender (Bandura, 1976; Bussey \& Bandura, 1999), Group Identity Theory (Tajfel \& Turner, 1985) and of Gender Role Socialization Theory (Pleck, 1981; 1995). In particular, I will discuss gender as a psychosocial identity construct. This discussion includes how gendered behavior is learned through an interactive process of role modeling, as well, as how gender performance is regulated through societal rewards and sanctions. I then examine the degree to which gender is a salient aspect of social identity and how this social identity may either facilitate group cohesion and social belonging or contribute to ostracization and alienation. Next, drawing from Erikson's Theory of Psychosocial Development (Erikson, 1958, 1968) and Devor's (2004) foundational Model of Transsexual Identity Development, I explore how trans men come to form their trans identity, including how they resolve issues of role confusion and identity crisis. Before turning to the literature review, I offer some definitions as used in this dissertation.

\section{Key Terms}

- Ally: A person who is not LGBTQ but shows support for LGBTQ people and promotes equality in a variety of ways (PFLAG Glossary of Terms).

- Binding: The process of tightly wrapping one's chest in order to minimize the appearance of having breasts, often by using a binder (PFLAG Glossary of Terms).

- Cisgender/cis: term for someone who exclusively identifies as their sex assigned at birth. The term is not indicative of gender expression, sexual orientation, hormonal makeup, 
physical anatomy, or how one is perceived in daily life. (Trans Student Educational Resources, n.d.)

- Dead Name: The name that a transgender person was given at birth and no longer uses upon transitioning

- $\quad$ FTM F2M trans masculine- alternate identifies used by trans women. (Trans Student Educational Resources, n.d.)

- Gender: A set of cultural constructs describing characteristics that may historically be related to femininity, masculinity, women, men, non-binary people, or social norms. The term was coined in 1955 by sexologist John Money after noting the difference between gender and sex. (Trans Student Educational Resources, n.d.)

- The Gender Binary: A system of viewing gender as consisting solely of two, opposite categories, termed "male and female", in which no other possibilities for gender or anatomy are believed to exist. (Trans Student Educational Resources, n.d.)

- Gender Dysphoria: Anxiety and/or discomfort regarding one's sex assigned at birth. (Trans Student Educational Resources, n.d.)

- Gender Identity: One's internal sense of being male, female, neither of these, both, and other gender(s).

- $\quad$ MTF, M2F trans feminine- alternate identifiers used by trans men. (Trans Student Educational Resources, n.d.)

- Misgender: To refer to someone, especially a transgender or gender-expansive person, using a word, especially a pronoun or form of address, which does not correctly reflect the gender with which they identify (PFLAG Glossary of Terms). 
- Queer: an umbrella term that individuals may use to describe a sexual orientation, gender identity or gender expression that does not conform to dominant societal norms.

Historically, it has been considered a derogatory or pejorative term and the term may continue to be used by some individuals with negative intentions. Still, many LGBTQ individuals today embrace the label in a neutral or positive manner (Russell, Kosciw, Horn, \& Saewyc, 2010.

- Sex: A set of characteristics associated with reproduction and biology that generally assign individuals into categories of "male" and "female." (Trans Student Educational Resources, n.d.)

- $\quad$ T: Short for testosterone. (Trans Student Educational Resources, n.d.)

- $\quad$ TGNC: Transgender and gender nonconforming. A broad term referring to people who do not behave in a way that conforms to the traditional expectations of their gender, or whose gender expression does not fit neatly into a category (Human Rights Campaign Glossary of Terms).

- Transgender/Trans: encompassing term of many gender identities of those who do not identify or exclusively identify with their sex assigned at birth. The term is not indicative of gender expression, sexual orientation, hormonal makeup, physical anatomy, or how one is perceived in daily life (Trans Student Educational Resources, n.d.)

- Transition: A person's process of developing and assuming a gender expression to match their gender identity. Transition can include coming out to one's family, friends, and/or co-workers; changing one's name and/or sex on legal documents; hormone therapy; and possibly (though not always) some form of surgery. (Trans Student Educational Resources, n.d.) 
- $\quad$ Trans Woman / Trans Man: Trans woman generally describes someone assigned male at birth who identifies as a woman. This individual may or may not actively identify as trans. Many trans individuals prefer a space between trans and woman/man or prefer the use woman or man. (Trans Student Educational Resources, n.d.)

- Sexual Orientation: Emotional, romantic, or sexual feelings toward other people. While sexual behavior involves the choices one makes in acting on one's sexual orientation, sexual orientation is part of the human condition, one's sexual activity does not define one's sexual orientation; typically, it is the attraction that helps determine orientation (PFLAG Glossary of Terms). 


\section{Chapter 2}

\section{EXTENDED LITERATURE REVIEW}

This chapter will present literature on the two major parts of the research inquiry: gender identity and role models. I will first discuss trans visibility and media representation in the U.S. followed by information on the experiences of trans people in Missouri. The next part of the literature review will focus on gender identity research including Social Cognitive Theory of Gender, Group Identity Theory, and Gender Role Strain Paradigm. This will be followed by a closer look at gender identity development models, including Devor's (2004) Model of Transsexual Identity Formation. The second section on role model research will discuss role model research as it relates to the general population, as well as marginalized groups including gender minorities. The chapter will end with a discussion of the pilot study, "Masculinity and What it means to be a Trans Man in Missouri," and how the preliminary results of this study pilot informed the current research project.

\section{Transgender (In)Visibility}

According to the CDC's Behavioral Risk Factor Surveillance System (BRFSS) $0.6 \%$ or 1.4 million adults in the U.S. identify as transgender (Flores et al., 2016). This number is nearly double the estimates from 10 years ago and is comprised of a significantly greater number of people age 18-24 than in previous estimates (Flores et al., 2016). This increase in trans youth is likely reflective of a shift in how trans youth establish and express their gender identities. Access to information on the internet, visibility of images of trans people in popular media, and sociopolitical gains has likely relieved some of the isolation formerly experienced by trans youth (Beemyn et al., 2005, Savin-Williams, 2005). In effect, access to people like themselves has 
allowed trans youth to embrace their gender identities earlier in life, mediating their experience of shame and confusion.

The advent of the internet is frequently cited as one of the most significant developments in the trans community, because of its ability to spark communication and unite a diverse array of people under a unified political trans identity (Hill, 2004; Lev, 2007, Meyerowitz, 2002; Shapiro, 2004; Whittle, 1998). Whereas community was once defined by physical proximity, cyber-space has now allowed people to cross geospatial borders and to connect virtually. Online blogs, chats, live journals and news groups have disseminated information and facilitated intimate relationships, contributing to individual's ability to organize for civil rights and shaping an overall collective conscious (Lev, 2007; 2016).

The online world allows for a significant amount of anonymity that is far less possible in the real world. Users can choose to communicate and to disclose personal information as they see fit. Thus, users may choose to express aspects of their self — from personality traits to physical characteristics - that differ from what is expressed in their local communities and those with whom they interact with in their daily lives. TGNC people can thus freely express their gender identity online without being restricted by the body they inhabit or by concerns about “passing” (Lev, 2007; 2016). Furthermore, the anonymity of the internet allows people to develop relationships without the same risk of familial rejection, loss of employment, and other forms of discrimination that TGNC often experience in real life (Hegland \& Nelson, 2002; Jaffe et al., 1995; Matheson \& Zanna, 1992). The substantive invisibility of the online body in many ways enables trans people to present themselves more authentically (Hill, 2004).

In 2015, Laverne Cox became the first ever openly trans person to grace the cover of Time Magazine, next to a title which read, “Transgender Tipping Point: America’s Next Civil 
Rights Frontier." Cox went on to become the first trans person to be nominated for an Emmy award for her role of Sophia Burset in the Netflix series Orange is the New Black. In the series, Cox portrays a trans woman who is incarcerated after committing credit card fraud to fund her medical transition (Hill, 2016). Cox's role signals a promising shift in the visibility of trans issues as well as for trans actors, as trans acting roles have been traditionally given to cisgender performers.

In 2014 the Gay and Lesbian Alliance Against Defamation (GLADD), a national media monitoring organization, came out with a 10-year report (2002-2012) examining a decade of transgender representation on network television. This report concluded that the vast majority of depictions of TGNC people were portrayed as either victims or villains including serial murderers and perpetrators of sexual violence (GLAAD, 2014). GLAAD's most recent report for 2018 cited that the number of transgender, regularly appearing characters on broadcast primetime programming has increased to 26 from 17 who had appeared in 2017 (GLAAD, 2018). Recent representations of trans people have arguably become more dynamic. FX Network's Pose counts the largest number of transgender series regulars in a scripted U.S. series ever. Additionally, the CW Television Network's Super Girl recently introduced television's first ever transgender superhero (GLAAD, 2018). While these are generally favorable statistics for the trans community, only 5 of the 25 transgender character were trans men (GLAAD, 2018), thus signaling that trans men are not only underrepresented in research literature, but in popular media as well.

\section{Trans Men in Missouri}

Missouri's total state population in 2018 was $6,126,452$. The population of trans people in Missouri is estimated to be 25,050 (Movement Advancement Project, 2020), though this number 
is likely an underestimate as many people do not identify as "transgender," "live stealth," or do not disclose their gender identities for fear for their safety (Meerwijk \& Sevelius, 2017).

In July 2018, The Human Rights Campaign, the largest LGBT civil rights advocacy and political lobbying group in the U.S., released their fifth annual State Equality Index. This stateby-state report assessed how well states were protecting LGBT individuals from discrimination by detailing statewide laws and policies related to LGBT people (Warbelow et al., 2018). In 2018, Missouri was one of 28 states who received their lowest rating: "High Priority to Achieve Basic Equality.” The rating reflects a greater need for LGBT equality laws and nondiscrimination laws.

According to the Transgender Law Center, Missouri is one of 19 U.S. states with a negative gender identity policy tally (Transgender Law Center, 2019). Missouri’s nondiscrimination laws do not have specific protections for sexual orientation and gender identity discrimination (Transgender Law Center, 2019), nor are there explicit policies in Missouri ensuring equal coverage in private insurance or Medicaid. This absence of regulation has deleterious effects, especially for FTMs who desire to transition medically (Baker, 2017; Kahn, 2011; Padula et al., 2016).

In the state of Missouri, roughly $27 \%$ of the TGNC population lives in poverty with about 19\% of TGNC Missourians being unemployed (National Center for Transgender Equality, 2017). Of those employed, $27 \%$ reported mistreatment in the workplace, including verbal harassment and sexual assault (National Center for Transgender Equality, 2017). Additionally, mistreatment of trans boys in Missouri schools is significant with $74 \%$ of K-12 trans students reporting experiences of bullying. Of these students, $11 \%$ of $\mathrm{K}-12$ trans students left their schools due to mistreatment (National Center for Transgender Equality, 2017). These statistics 
are especially grim considering that most Americans spend about $15 \%$ of their lives in K-12 education and nearly $1 / 3$ of their lives working (National Center for Education Statistics, 2018).

Marginalization of the trans community manifests itself in many ways. Transgender youth are particularly vulnerable to victimization because of the additional internal and external pressures associated with identity development in late adolescence (Burgess, 2000; Goldblum et al., 2012; Toomy et al., 2013). Trans youth are often faced with developing their sense of self in communities, which not only invalidate their reality, but also reprimand them for violating traditional roles (Budge, 2013). Low body-esteem, identity confusion, and suicidality affect trans youth at disproportionate rates (Burgess, 2000). Families are often unreliable avenues of support either because they are ill equipped to empower their children or may even outright reject them (Burgess, 2000; Goldblum et al., 2012).

In spite of the need for Missouri to extend its LGBT protections, there have been several notable advancements in recent years. In the 2017 case, Lampley v. Missouri Commission on Human Rights, the court ruled that sex discrimination may be based on sex stereotyping (Aviles, 2019). The decision confirmed that an employee who is discriminated against because of how they are expected to behave has a legal right to file juridical action. In 2019, the Missouri Supreme Court ruled in favor of a trans student who sued his school district after not being permitted to use the boy's restrooms and locker rooms (Aviles, 2019). The court's decision to allow the student's lawsuit to move forward in the lower courts, thus recognizing that Missouri's prohibition on sex discrimination extends to gender minorities. The suit is still in process.

\section{Transgender Health Disparities}

Research consistently shows that trans individuals are at significantly greater risk for experiencing depression, anxiety, and suicidal ideation than their cisgender counterparts (Grant 
et al, 2010; Hendricks \& Testa, 2012; Meyer, 2013). Approximately 46\% of trans men will have attempted suicide in their lifetime (Haas, Rodgers \& Herman, 2014). This staggering number increases to 54\% among trans racial/ethnic minorities (Grant et al., 2010). Trans individuals are more likely to participate in risky health-related behaviors including smoking cigarettes, consuming excessive alcohol, using illicit substances, and engaging in unsafe sexual behaviors (Frost, 2011; Meyer 2013; Nuttbrock, Rosenblum \& Blumenstein, 2002). A 2010 national survey of transgender people revealed that HIV infection was four times the national average (Grant et al., 2010). Unfortunately, the same discrimination which contributes to transmen's health disparities is what prevents many trans individuals from pursuing healthcare. Stigma and discrimination are among the many barriers often resulting in the postponement of ameliorative care (Cruz, 2014; Heck et al., 2013).

\section{Gender Minority Stress Model}

According to the Minority Stress Model (Meyer, 2003), stigmatized minority groups repetitively experience high degrees of prejudice and discrimination. Over time, the accumulative stress resulting from these experiences contributes to poor physical and mental health outcomes (Meyer, 2003). Many of the aforementioned health disparities experienced by trans men have been found to be correlated to their experiences of marginalization; however, the Minority Stress Model does not account for the nuances specific to gender identity nor the protective coping factors trans people develop, including pride and resilience (Testa et al., 2015).

The Gender Minority Stress Model (Testa et al., 2015) was adapted to identify distal stress factors including gender-related discrimination, rejection, victimization, and nonaffirmation of gender identity. Mis-gendering is a common way in which trans men experience non-affirmation of their gender identity. Other people misgender trans individuals both 
deliberately and unintentionally through the use of incorrect pronouns or by government-issued identification cards that reflect the name and/or gender that the person was assigned at birth. Mis-gendering has been shown to increase internalized stigma and reduce a person's sense of strength and continuity in their identity (McLemore, 2013). Mis-gendering additionally runs the risk of "outing" someone as trans, thus potentially furthering their experience of harassment, violence, or ostracization (Herman et al., 2016).

Trans men's experiences of marginalization influence proximal stressors including expectations of rejection, concealment of one's identity, and internalized transphobia (Testa et al., 2015). In general, trans men are evaluated as "passing" more easily primarily due to the dramatic and mostly irreversible androgenic effects of exogenous testosterone - specifically related to secondary sexual- and other physical-characteristics (Bockting et al., 2013). While this ability to blend into one's chosen community may be desired, trans men may also feel pressure to conceal their gender variant identities in order to avoid the negative effects of stigma. This desire to pass may influence a person's level of self-consciousness and result in a preoccupation with blending in, which can in turn create greater stress (Bockting et al., 2013).

While discriminatory environments may adversely affect the physical and psychological well-being of trans men, pride in oneself and community-connectedness have been shown to be factors that promote resilience. Resilience has been shown to mediate the negative effects of adverse experiences through positive coping (Testa et al., 2015). A 2011 conducted on transgender resilience showed that a majority of the 21 participants endorsed "being a positive role model for others" as a component that influenced their pride in themselves and their overall resilience (Singh et al., 2011). Individuals who are prevented from transitioning are more likely to engage in non-suicidal self-injury (Dickey. 2012). Research has shown that trans men who 
received testosterone reported significantly higher quality of life and significantly lower levels of anxiety, depression, and social stress (Newfield et al., 2006).

\section{Social Learning Theory \& Gender Identity Development}

Numerous theories to date have been developed to explain human behavior. Yet until the 1970's, most popular psychological theories overlooked psycho-social influences, claiming that behavior originated from within and was compelled by the individual (Bandura, 1977). According to most of these theories, personality and behavior were viewed as inherent and consistent constructs, motivated by an individual's subconscious needs, drives, and impulses (Bandura, 1977). While previous psychodynamic theories had been adequate in explaining the consequences of past behavioral events, they fell short of predicting future outcomes and identifying causal factors (Mischel, 1968). Additionally, while new theories of behaviorism recognized the importance of environmental factors in influencing human practice, they were simplistic, overlooking the role of cognition and assuming individuals could be controlled by external factors in a one-way process of influence.

The Social Learning Theory of Gender Development integrated psychological and sociological determinants to explore how gender conceptions are constructed from specific experiences and operate alongside both motivational and self-regulating processes (Bussey \& Bandura, 1999). In this framework gender identity and gender roles result from a complex matrix of cultural influences and social systems. While biology likely plays an influencing role (Neibergall et al., 2019)—given the findings from neuroscience and genetics (e.g., Foreman et al., 2019; Luders et al., 2012)—gender roles are predominantly culturally designated (Bussey \& Bandura, 1999). Individuals are socialized, beginning in infancy, into stereotypically masculine 
and feminine roles that strongly influence the talents they cultivate, their self-conceptions, their opportunities and obstacles, and the career paths they choose (Bussey \& Bandura, 1999).

A person's behaviors, cognitions, and emotions are not only determined by direct experiences, but are influenced through a vicarious, symbolic, and self-regulatory process of observational learning (Bandura 1977; 1989; 1996). In essence, by attending to the behaviors of models, people are able to bypass a cumbersome trial and error process and predict the consequences of their actions based on the experiences of those who came before them. Bandura went on to suggest that the vast majority of behaviors that people perform are learned either intentionally or intuitively through the impact of example (Bandura, 1977; 1989; 1996).

\section{Observational Learning}

While previous stimulus-response theories required the influence of direct experience to inform behavior, Bandura introduced modeling as a learning mechanism in which individuals represent real outcomes symbolically (Bandura, 1977). Modeling provides an efficient avenue for learning complex behaviors without the risk of error, and potentially harmful consequences (Bandura, 1977). "Under most circumstances, a good example is therefore a much better teacher than the consequences of unguided actions" (Bandura, 1971, p. 5).

In Social Learning Theory, modeling is governed by a complex and interactive processes of attention, retention, reproduction and motivation (Bandura, 1967). In order for learning to take place, observers must attend or tune in to essential behavioral features. This is more likely to occur when there is an associational preference or interpersonal attraction between the model and observer. A large body of research shows that both children and adults learn a significant amount from film, tv, and other visual displays (Bandura, 1967). People develop attitudes, emotional responses and new patterns of behavior from viewing media. Given the significant amount of 
time people spend consuming visual media, these outlets play a significant role in shaping social attitudes and behavior (Bandura, 1969a; Flanders, 1968; Lumsdaine, 1961).

The second component required in observational learning is retention. In order to reproduce a specific behavior, the observer must remember the characteristics modeled. This retention is done through a process of image viewing and verbal coding where visual associations are prescribed, and verbal descriptions complete more complex sequences (Bandura, 1977). Studies have shown that viewers who code modeled activities into concise labels and vivid imagery lend themselves to the best outcomes for memory recall (citation).

The third component in observational learning is reproduction. The emulation or rehearsal of observed representation can be difficult. Even when a symbolic representation is observed and retained, an individual might have physical and social limitations which constrain the performance of the ideal. Furthermore, the process of reproduction relies heavily on selfadjustment, which often requires significant external feedback. Based on previous consequences, most people will seek to perform actions that have positive outcomes, while avoiding behaviors that illicit punitive ones. This social influence has a regulatory effect which motivates behavior based on symbolic conclusions

Finally, degree of motivation informs an individual's decision of whether or not to reproduce the observed behavior. This catalyst depends on the expectations of the observer, including experiences of both direct and vicarious reinforcement. This societal reinforcement might be positive or punitive and serves to regulate behavioral expression. This reinforcement has the power to not only manage behavior but shape the environment itself by controlling what people attend to and how effective they are in cataloguing and rehearsing what they've observed (Bandura, 1977). 


\section{Social Identity Theory}

A person's sense of who they are depends on the groups to which they identify with (Abrams and Hogg, 1990; Tajfel, \& Turner, 1979). There is no one selfhood; rather, there are multiple identities that influence the way we behave in different social contexts. When a person perceives themselves as belonging, they are part of the ingroup. The three processes that create ingroup/outgroup mentality are social categorization, social identification and social comparison. Humans categorize people in order to understand them and we define what is acceptable behavior based on the groups we belong to. Secondly, we adopt the identity of the group we belong to. Finally, once identified with a group, we compare our groups favorably against other groups in order to uphold self-esteem. During this process, individuals minimize within-group differences and maximize dissimilarity among members of the outgroup (Stets \& Burke, 2000) This includes selectively remembering positive and negative information about each group disproportionately. Often what stems from this act is prejudice and discrimination. Social behavior falls on a spectrum that ranges from interpersonal to intergroup behavior.

\section{Gender Role Socialization}

Historically, the majority of psychological research has focused on boys and men. Much of this past research has overlooked gender differences and assumed that the experiences of men were representative of society as a whole (Levant, 2011). Feminist scholars in the 1960's disputed this male-centric approach and suggested a gender specific framework (O’Neil, 1981a, 1981b; Pleck,1981). Male psychologists, sociologists and anthropologists have since followed suit, developing a psychology of men and masculinity. This framework rejects masculinity as a ubiquitous standard for human behavior and recognizes that "maleness" is achieved through a process of socialization that is both complex and at times problematic. Masculinity and 
femininity are psychosocial constructions that are both relational, interactive and subject to change over the lifespan.

\section{Gender Role Strain Paradigm}

Of the many theoretical approaches to gender identity development, the Gender Role Strain Paradigm (GRSP) is considered the leading psychological theory in the field of men and masculinity (Cochran, 2010; Wong, Steinfeldt, Speight, \& Hickman, 2010). Taking a social constructionist feminist perspective, GRSP views gender roles as socially constructed entities that originate from and serve to defend patriarchal, social and economic order (Levant, 2011). GRSP, a precursor to Social Constructionism, set the foundation for distinguishing differences between sex and gender, thus disputing essentialist views of masculinity. GRSP additionally questioned traditional masculine ideals of dominance, aggression, emotional restriction, relational distance and extreme self-reliance (Pleck, 1981).

The stereotypes of male dominance and aggression and female submission and nurturance serve to reinforce disparities in power. While either sex may "perform" various combinations of gender roles, there are rewards and sanctions which encourage individuals to practice traditional gendered enactments (Levant and Richmond, 2016). Often a violation of gender role norms can lead to societal condemnation and ultimately adverse psychological consequences. These consequences are typically more severe for males than females (Pleck, 1981).

\section{Masculine Ideology}

Whereas theories of masculine gender role identity assume actual trait differences between men and women, studies of masculine ideology view masculinity as comprising a set of socially constructed gender norms. While there exists certain biological difference between men 
and women (Parent \& Sánchez, 2020) that often become more pronounced at puberty (Chavarria et al., 2014), and gender expression varies across culture, men and woman are actually more psychologically alike than different in domains of ability, personality, social behavior and memory (Hyde, 2005). The traditional male ideology-normative approach asserts that men should have sex-specific characteristics not found in women including fulfilling such social roles as "father," "worker," and "soldier" (Gilmore, 1990). This dominant masculinity ideology upholds existing structures of power.

\section{Erikson's Identity Development}

Social psychologist Erik Erikson asserted that personality develops through eight stages of development from infancy to adulthood. He maintained that at each stage a person experiences a psychosocial crisis that will need to be successfully resolved in order to develop a healthy personality, as well as, to acquire tools to aid in future crises. Erikson's fifth stage; Identity vs. Role Confusion occurs in adolescence when an individual re-examines their identity, searches for a sense of self and begins to learn the roles they will occupy as an adult (Erikson, $1958,1968)$. The crisis during this stage is closely related to the discomfort experienced in relation to one's body, particularly the significant changes that take place during puberty. Erikson's model suggests that gender variant youth will continue to experience a state of crisis until they are able to resolve the disparities between their sex and gender (Pardo, 2008).

\section{Transgender Identity Development}

Most commonly, trans men report having always felt an incongruence and discomfort with their sex assigned at birth, even before they had the language to articulate this discord (Devor, 2014; Stieglitz, 2010). This incongruence becomes more pronounced during the period of puberty when feminizing hormones Trans adolescents are faced with the task of integrating 
their biological sex and gender identity into a unified self. This can be a daunting effort when both their bodies and the public perception betrays their sense of self. While the majority of people grow up being exposed to representations of their sex and gender experience, most trans individuals do not have access to models of trans experience, and generally lack the language to accurately describe their internal sense of gender identity (Levitt \& Ippolito, 2014). Often this process of developing a gender identity includes severe compromises to one's authentic self in order to secure relationships, economic security or physical safety (Levitt \& Ippolito, 2014).

Theories of transgender identity development are typically divided into categories of typologies and stage models. Typologies distinguish between trans people based on age of onset of gender dysphoria, sexual orientation, extent of cross-gender identification or childhood gender nonconformity. This project uses a stage model, characterized by a series of developmental phases that accounts for identity development as a process with distinct periods (Testa, Jimenez, Crystal, Rankin \& Susan, 2014).

\section{Devor's Model of Transsexual Identity Formation}

Devor's foundational model of transsexual identity formation was adapted from Cass's $(1979,1984,1990)$ homosexual identity formation model, as well as Ebaugh's (1988) work on role exit. Devor argues that humans are foremost social beings who desire to be seen by others as they see themselves. He notes that all people have a need to have their identity validated and confirmed and their sense of self mirrored in other's eyes (Devor, 2014). Witnesses from differing identity backgrounds have significant power to affirm or disaffirm one's gender identity, given their distance and relative objectivity. Devor's mirroring describes a vital need to see oneself in the eyes of others like oneself, as well as "For trans people to see their feelings and experiences reflected back at them through the lives of other trans folks" (Devor, 2014 pp.47). 
Devor's first three stages are marked by anxiety, confusion and attempts to understand one's gender through interpersonal comparisons between one's sex assigned at birth and that of others (Levitt \& Ippolito, 2014). Within these stages, individuals experience an ambiguous discomfort with their assigned sex and gender and may begin to experiment with alternate identities (Devor, 2014). The next three stages in Devor's model are defined by role confusion after a, typically "accidental” discovery of transgenderism. In these stages a person unexpectedly stumbles upon information about TGNC and begins deidentifying with originally assigned sex. The next four stages are marked by transsexual identity comparisons, testing trans identity and a gradual disidentification with one's natal sex and an identification with trans. The final four stages involve coming out to others, transitioning, integration and pride.

While trans people have descried experiencing a sense of relief when "discovering" their trans identity and even euphoria when they begin transitioning, ( $\mathrm{Wu}, 2016)$, individuals at this time are also at greater risk of stigma or violence due to their increased visibility (Holtby et al., 2015). Trans men who develop male secondary sex characteristics including beards and muscle mass might experiences a relative invisibility as they begin to pass. As trans people learn to live and engage with others in their new trans identity, they develop more coping strategies for managing stigma. They then begin to identify more openly as trans and become advocates (Devor, 2014).

\section{Role Models}

The term role model was coined by sociologist Robert Merton in 1957 to describe a person whose behavior or success can be emulated by others, particular younger people (Calhoun, 2010). Merton hypothesized that individuals compare themselves with reference groups of people who represent the social role that the individual aspires to (Doby, 1975). The 
concept of role model became popularized in the 1960's by career psychologists and workplace advocates who sought to identify the barriers to professional success face by marginalized groups (Laird, 2006).

The importance of role models has been further written about extensively in the field of motivation, namely how role models are instrumental in motivating both desirable and undesirable behaviors (Brustad \& Partridge, 2002; MacCallum \& Beltman, 2002). Research suggests that promotion-focused individuals who favor methods of pursuing favorable outcomes will be most attracted to positive role models, while individuals who are prevention-focused and who favor strategies to avoid undesirable outcomes will be most attracted too negative role models. (Lockwood \& Kunda, 2002).

Research into role models and their impact on the general population and cisgender individuals has shown the importance of influential others for self-development, especially among minorities. Having a person of significance to compare oneself to can provide guidance, empowerment, encouragement and relief. (Berkovich, 2015).

\section{Trans Role Models}

The influence of role models on identity development has been explored extensively from interpersonal, intrapsychic, systemic and sociological perspectives (Berkovich, 2015). From a Social Learning and developmental perspective, individual's identity development is influenced by what is modeled for them (Bussey \& Bandura, 1999). In these frameworks' individuals are able to forgo a cumbersome trial and error process themselves in favor of learning from the mistakes and successes of others who came before them. This is especially important for trans men, whose "mistakes" in gender performance may pose threats to their safety (Lombardi et al., 2001; Bockting et al., 2013). For cisgender individuals, a major task of adolescence is the 
establishment of an independent identity (Erikson, 1968). This task of identity formation is further complicated for adolescent FTMs who haven't experienced the years of socialization in their masculinity in the same ways as cisgender boys.

Trans role models act as behavioral models, who represent the possible and inspire individuals to achieve ambitious goals (Morgenroth et al., 2015). This is likely true for trans men whose path in life or "possible self" is actually limited by implicit societal signals about who is relevant (Asgari et al., 2010). Role modeling is an important factor in reducing risk and increasing protective factors. This is especially true for trans male youth who have less support and fewer resources (Burgess, 2000). Literature shows role models can foster resilience by modeling healthy and adaptive behavior, illustrating positive values, self-worth, and an orientation to the future. Positive role models correlate with increased health and wellbeing and decreased psychological distress, academic difficulties, deviant behavior, and risk taking. who is a natural fit or who belongs in certain environments (Asgari, et al., 2010).

Gender has been identified as a central component of one's self concept. Many societies designate social roles and power structures by gender (Pardo, 2019). However gender variant role models are not often accessible in familial or community contexts. Furthermore, trans issues remain largely invisible in the public media and existing outlets do not provide an adequate array of role models who represent the reality of trans experiences. While trans men might identify positive cisgender role models, these figures may lack an understanding and appreciation for the complexity of the trans experience, including how to negotiate their internal sense of gendered against their public identity labels (Pardo, 2019). This absence of identifiable role models may have deleterious effects for trans men's self-esteem and sense of belonging (Berkovich, 2015). 


\section{Pilot Study}

Within the psychological study of men and masculinities, trans men are one of the least studied subsets of men (Abelson, 2014; Green, 2005; Sánchez, 2016). Yet, this population is uniquely valuable in understanding the social construction of masculinity as trans men have had to learn how to navigate multiple gender roles (Schilt, 2010). Though there are several theoretical and conceptual frameworks for understanding the development and enactment of masculine norms (Connell, 2005; Levant \& Wong, 2017), these frameworks lack the unique perspective of those who have lived as both men and women.

In February 2018, I initiated a pilot study, "Masculinity and What it Means to Be a Trans Man in Missouri." The purpose of that study was to both explore the lived experiences of trans men in Missouri and to better understand how transmen conceptualized and enacted masculinity. In addition, the pilot study allowed me to develop further research questions that were salient for transmen. Fifteen participants ages 18-35 were recruited across Missouri through LGBT community outreach programs, Facebook postings, and snowball sampling. Participants engaged in 60- to 90-minute semi-structured interviews in-person or via Skype and answered questions regarding their attitudes toward masculinity, life experiences before and after the transition process, personal assessment of strengths, and basic demographics.

Using consensual qualitative research (CQR; Hill et al., 1997; 2005), participant interviews were coded into domains (i.e., topic areas), and core ideas were constructed for all the material within each domain. Preliminary results from this study yielded several themes, including that participants conceptualized masculinity positively and strongly associated with the development of secondary sex characteristics typical of males (e.g., facial hair) and stereotypical male roles (e.g., the ability to lead others). In contrast, participants reported negative aspects of 
the male role, including pressure to restrict emotions and to defend their masculine persona (i.e., responding to violence or the threat of violence from dominating masculinities by asserting one's own masculinity). Participants reported experiencing "gender identity journey," during which time they began questioning their gender identity, began coming out as gender non-binary to friends and family and taking social and medical steps to transition. Participants additionally reported difficulty locating role models during their "gender identity journey," negative depictions of trans people in the media and a general absence of accessible information related to being transgender.

While there were multiple interesting findings of this study which deserve further exploration, I was particularly drawn to theme of role models due to the zeitgeist of this moment in time. In spite of the increased representation of transgender role models in popular media, transmen are still inadequately represented. Additionally, public spaces, including schools in my own community have taken active steps to censor recognizable images of transgender role models. Having a better understanding of the scope and influence of trans men's role models could inform advocates, educators and individuals who wish to serve in these roles. 


\section{Chapter 3}

\section{METHOD}

This study used a constructivist paradigm to understand the influence of role models on trans men's identity development. Specifically, Photovoice—a unique methodology that has been rarely used in Counseling Psychology research—was used to allow participants to share their experiences and perceptions of the world through rich narratives that accompanied vivid photographs. This chapter will outline how this methodology was employed. Before detailing this approach, I will provide rationale for why this design was selected, I will describe the recruitment process, and I will disclose details on the researchers.

\section{Rationale for Qualitative Design}

Researchers have long argued the comparative value of qualitative and quantitative analysis (Patton, 1990). Each method represents essentially different paradigms with their own underlying assumptions (Bogdan and Biklen, 1982; Lincoln and Guba, 1985; Patton, 2002; Eisner, 1991). Given the scarcity of research on trans men's experiences (Beemyn \& Rankin, 2011; Currah \& Minter, 2000; Israel, 2005), the research question was best answered via phenological inquiry or qualitative study in which to explore the influence of role models on trans men's identity development, a phenomenon in which little is known (Strauss and Corbin, 1990). In the spirit of community-based participatory research participants were involved in defining the problem and data reports were descriptive, including rich detail and the voices of the participants in the text. The dearth of in-depth information gathered via focus group interviews, photographs and participant coding were best interpreted in narrative for, as results would have been statistically more difficult to represent (Hoepfl, 1997). Finally, recognizing the role of the 
researcher as a "human instrument" of data collection aligns with the researcher's theoretical orientation as a Constructivist.

\section{Researcher Background and Potential Bias}

Many types of bias can adversely affect the scientific process regardless of the type of methodology used. Within qualitative methodologies, the researcher plays the vital role of being both the instrument collecting the data and the instrument analyzing the data. Thus, it is important for qualitative researchers to disclose any background information that could influence their process to bolster the trustworthiness of the data. In this section, I will therefore provide personal background information relevant to this study, including my experience with the transgender community. I also offer some brief background information on my research assistant.

\section{Personal Life Experiences}

I hold multiple privileged identity backgrounds not limited to cisgender, White, heterosexual, and middle class. It was important for me to be aware of how my background informs both my values and my biases, and how they serve to influence my interactions with and perceptions of participants (Sue \& Sue, 2017). Growing up in a low SES, working class family has influenced my opinions on the unequal distribution of wealth in the U.S. and the resulting inequities. I additionally hold negative views of religiosity and social/political conservatism. Having previously conducted both research and clinical work with TGNC individuals, I had several expectations for this study. First, I assumed that most participants would identify their time of transition as adolescence. I expected that participants would hold multiple marginalized identities and that coming out would have improved their psycho emotional well-being. I suspected that participants would identify online vloggers as role models, but that in-person 
mentors would have a greater positive impact. Last of all, I anticipated resilience would be elucidated as a resulting theme.

The research assistant Felice described her most salient identity categories as Asian (Chinese), cisgender female, heterosexual, working class background and graduate student. Felice disclosed that her family holds conservative views about sex and gender, e.g. transitioning is "unnatural" and "why would people change their bodies?" Felice noted that she has a cisgender friend from Kuwait who has provided her some exposure to trans men and how TGNC individuals navigate the intersections of religion, culture, and gender identity.

\section{Social Constructivism Central to My Worldview}

When it comes to understanding human psychology, one of the key theories that I draw from is Social Constructivism (Piaget, 1950; Vygotsky, 1978). This theory posits that all cognitive functions are dependent on interactions with others. Learning is an inherently collaborative process in which reality is socially and culturally constructed through a complex and bi-directional process (Eggen and Kauchak, 1999; McInerney and McInerney, 2002; Schunk, 2012). People have many different ways of seeing and interpreting the world around them.

As a Constructivist I believe that reality has multiple dimensions, that knowledge is a human construction, and that understanding is a social construction this is co-created by the researcher and the participant (Hatch, 2002; McKinley, 2015). Lived experience is what defines a reality, and this "truth" is specific to every individual. My objectivity as a researcher is not only impossible; it would be disingenuous to deny my involvement in co-constructing the following narrative. The recognition of experiential reality plays particular importance when working with marginalized individuals, whose lived experiences have traditionally been negated or ignored altogether. 


\section{My Motivation for this Study}

I conducted this study first and foremost as an advocate, ally, and psychological trainee with the following goals in mind:

1. To facilitate greater access to resources, including role models that might positively influence trans men's psychosocial well-being.

2. To address the gap in literature on trans men's experiences while bringing awareness to the trans community's strengths and concerns (Wang \& Burris, 1997).

3. To empower trans men to be in greater control of how they are represented in research and to establish trusting relationships between community members, researchers, and practitioners.

My chosen form of advocacy is situated in Participatory action research (PAR), an interactive and collaborative process that engages community members in research to influence social change (Freire, 1982; Hall, 1992; Lewin, 1946). I became familiar with the trans community and its culture through my therapeutic work with gender non-conforming individuals at the University Counseling Center. Over the past 5 years I have attended numerous events sponsored by the local trans community in multiple roles as a counselor, a volunteer, and an LGBTQ ally. In 2016, I co-authored a book chapter reviewing current psychotherapy process literature related to gender diversity, sexual orientation, and intersectionality in the APA Handbook of Sexual Orientation \& Gender Diversity in Counseling Psychotherapy (Worthington \& Strathausen, 2016). Through both my scholarly work and my regular community participation, I observed first-hand the experiences of trans men while maintaining visibility in the community. I believe that through prolonged engagement I have become a more accepted participant in this 
community, while reducing my personal distortions and providing added depth and scope to the following findings (Lincoln, 1985).

I first became interested in documentary photography as a tool for social justice while studying photojournalism as an undergraduate. I was inspired by street photographers like Henri Cartier-Bresson and Diane Arbus who used photography to tell the stories of marginalized people, to archive important historical moments, to bring public awareness to social issues, and to highlight moments of unassuming beauty and humanity in their subjects. After graduation, I spent five years working as a freelance photographer before deciding to return to school to pursue a graduate degree in Counseling Psychology. I realize, in retrospect, that I've been attracted to each of these disciplines for what they share in common: Namely, I am interested in learning people's "stories" and empowering them to put their experiences to use towards a path of upward mobility.

Accessing information about the experiences of trans people has traditionally been difficult, partly due to the community's mistrust of research and researchers. Trans individuals have reported feeling exploited by researchers who appear to judge their experiences or who fail to share their results with the community. Trans individuals have questioned why they should participate in studies that do not directly benefit them in meaningful ways (Owen-Smith et al., 2016). As a cisgender researcher I have a special responsibility to ensure that I am accurately representing my participants' realities and that I am doing so in a way that doesn't serve to further exploit or marginalize this population.

\section{Srushya}

Srushya, a second-year Master's student in the Counseling psychology program, was recruited to assist with this project. She identified as South Asian American, heterosexual, and 
cisgender female. Her prior experiences with the TGNC community came from a friend who identified as a transman who she witnessed transition. Srushya aided in transcribing audio recorded meetings.

\section{Felice}

Felice, a second-year Master's student in the Counseling Psychology program, was recruited to assist with this project. She identified as an Asian American, heterosexual, and cisgender female. Her prior experience with the TGNC community came from a friend who identified as a transman and whom she witnessed go through the medical affirmation-process. Felice aided with data collection, transcribed audio recordings, and collaboratively analyzed the results in order to guard against bias, to help scrutinize research analysis, and to increase theoretical sensitivity ( Corbin \& Strauss, 1990; Strauss \& Corbin, 1994; 1997).

\section{Community-Based Participatory Research}

This dissertation study was informed by a Community-Based Participatory Research (CBPR) approach, aimed at empowering individuals from a historically marginalized group to represent their community and reflect upon the issues most important to them (Keller et al., 2008; Mitchell, 2011; Strack et al., 2004; Wang \& Burris, 1997). The research question was developed in response to participant interviews from the aforementioned pilot study and presented to participants who were recruited for the current study. The researcher then activated relationships with the local trans community in order to establish a partnership in which community members and researcher co-investigated the influence of role models in trans men's lives. The researcher sought to equitably involve participants in every stage of data collection and analysis to the degree participants wished to take on the responsibility. 
The researcher was guided by the basic principles of CBPR as outlined by Israel et al. (2000). This included recognizing the local community of trans men as a unit of identity, building on strengths and preexisting resources within the community, exchanging information and skills, balancing the generation of new knowledge with intervention, focusing on ecological perspectives, using a cyclical and iterative process of analysis, disseminating the results within the community, and maintaining prolonged exposure or a long-term commitment to the project. These efforts were made in the hopes of reducing the power differentials experienced by trans men. Using principles of co-learning, mutual benefit, and long-term engagement, the researcher conducted a systematic effort to include participants in the decision-making research processes along the way (Minkler \& Wallerstein, 2003).

\section{Photovoice}

As previously mentioned, I studied photojournalism as an undergraduate. I have always been impressed by the power of photography to capture what words cannot. Visual imagery has an ability to cross cultural and linguistic barriers and illicit compelling reactions from its audience (Latz, 2017). Photovoice was used as a form of Participatory Action Research in my methodology and design. The use of Photovoice in the health professions has expanded considerably in the past ten years (Teti et al., 2017); however, its application within Counseling Psychology is relatively unique. In Photovoice methodology, recruiting a focus group of 7-10 people has been identified as an ideal sample size (Wang, 1999).

Photovoice is a form of arts-based research, situated in constructivism, feminist theories, and critical consciousness (Wang \& Burris, 1997; Wang, 199). This method views participants as experts on their experiences and empowers them to document their lived realities and share these experiences with three main goals in mind: 
1. To enable people to record and reflect their communities'strengths and concerns.

2. To promote critical dialogue and knowledge about important community issues through large and small group discussions of photographs; and

3. To engage and inform policy makers regarding people's lived experiences (Wang \& Burris, 1997, p. 370).

Photovoice - a process which incorporates documentary photography and grassroots social action - has been viewed as an effective approach to promote dialogue between interviewees and researchers to develop thick descriptions in phenomenology (Van Mannen, 1990). A key aspect to this approach is that participants are seen as co-researchers versus merely subjects in a study. This co-researching process allows participants to develop research questions of interest, which produce powerful representations of their lived realities (Woodgate et al., 2014). For this study, the research question was developed in response to the concerns of the participants of the aforementioned pilot study. The resulting visual media has a unique way of facilitating access to participants' conscious and unconscious feelings about complex and difficult life situations (Woodgate et al., 2014).

Photovoice provides a novel approach with distinct advantages because it allows the participants familiar with their surroundings to represent their experiences first-hand (Wang \& Redwood-Jones, 2001). This approach is seen as providing data that is more accurate than that which would otherwise be filtered through the lens of the researcher. As part of this methodology, results should go beyond simply adding to the scientific body of knowledge; instead, they should be circulated among the local trans community who can then share this information with community stakeholders. The aim of this latter part is to raise critical 
consciousness in a way that enables individuals to take immediate action towards positive social change (Friere, 2005).

\section{Study Participants}

Participants (see Table 1, which includes pseudonyms that will be used in this report) were 12 self-identified trans men all of whom were Missouri residents. Age ranged from 18-45 $(M=30.25, S D=7.55 ; M d n=31.5$ years-old). Eleven participants identified as White (nonLatino) and one as biracial. Towns of residence included, Columbia, El Dorado Springs, Fayette, Fulton, Jefferson City, Kansas City, Moberly, St. Louis, and Springfield. All but 1 participant was currently undergoing hormone treatment, with the number of years being treated ranging from 2 to 7 years $(\mathrm{M}=3.46, S D=1.49 ; M d n=3$ years $)$. Participants self-reported sexual orientations included pansexual, Queer, predominantly gay, bisexual, predominantly heterosexual, exclusively heterosexual, and asexual. All participants had some level of college education. One participant discontinued participation after Meeting 2 for undisclosed reasons; he did not contribute photos or engage in the coding process.

Purposeful sampling techniques were used in an attempt to secure a relatively homogenous group of trans men from the local community to reach sample saturation. The researcher first recruited participants from the pilot study, before posting recruitment flyers (see Appendix A) at local LGBTQ agencies (e.g., the University LGBTQ Resource Center and University Queer Trans People of Color), and healthcare agencies/providers who work with the trans community (e.g., MedZou). Electronic advertisements were additionally posted on Facebook pages and in online newsletters of several trans affirmative groups (e.g., The Center Project). Eight of the twelve participants had previously engaged in the Pilot Study, "Masculinity 
and What it Means to be a Trans Man in Missouri." Four additional participants were recruited through word-of-mouth referrals.

Once an individual expressed interest in participating, they were screened in order to ensure that they meet the following criteria for inclusion:

- The participant was at least 18 years old

- The participant identified as a trans man (incl. FtM or transmasculine); and

- The participant was able/willing to commit to attend three in-person meetings, with each meeting lasting approximately 2 hours.

\section{Collaborative Meetings and Data Collection}

Over the course of six weeks during Summer 2019, I met with the participants at three separate points. Most of the participants were able to make the in-person meetings, which were held at The Mid-Missouri Center Project's (TCP) headquarters. This location was chosen because it was identified as a familiar, safe, and confidential space for LGBTQ individuals. Participants not familiar with the organization learned about its location and the events and resources offered by TCP. Three participants were unable to meet in-person due to work conflicts or because travel was too far; they convened separately in a virtual focus-group using Zoom (an internet-based videoconferencing service). Table 2 presents a layout of the summer timeline.

\section{Table 1: Focus Group Schedule}

\begin{tabular}{llll}
\hline & \multicolumn{1}{c}{ Meeting 1 } & \multicolumn{1}{c}{ Meeting 2 } & \multicolumn{1}{c}{ Meeting 3 } \\
\hline Topics & Welcome to study; & Photo aesthetics; & Process the experience; \\
Covered & Self-introductions; & Photo ethics; and & Method for the group \\
& Ground rules; & Study prompts & analysis; Analysis in \\
& Photovoice method; & & dyads; and \\
& Role models; & & Debrief of emotions \\
& Stakeholders; & &
\end{tabular}




\begin{tabular}{|c|c|c|c|}
\hline & $\begin{array}{l}\text { Verbal consent; and } \\
\text { First assignment }\end{array}$ & & \\
\hline \multicolumn{4}{|c|}{ In-person } \\
\hline Date & July 29, 2019 & August 12, 2019 & September 1, 2019 \\
\hline Time & 10:00AM-12:00PM & 10:00AM-12:00PM & 7:00-9:00PM \\
\hline \multicolumn{4}{|c|}{ Internet-based } \\
\hline Date & July 27, 2019 & August 3, 2019 & August 24, 2019 \\
\hline Time & 7:00-9:00PM & 7:00-9:00PM & 7:00-9:00PM \\
\hline
\end{tabular}

Note. Internet-based meetings, which were conducted using the Zoom platform, were for participants who could not make the in-person meeting. Times listed are in Central Time Zone.

In the next three sub-sections, I will detail what took place at each meeting, which lasted approximately two hours each. Participants received a total of $\$ 80.00$ in Visa gift-cards for participating in all parts of the Photovoice project: They received a $\$ 15.00$ gift-card for attending the first meeting; a $\$ 25.00$ gift-card for uploading their photos to a private account with an internet-based file hosting service (Dropbox, Inc.) and for attending a second meeting; and a $\$ 40.00$ gift-card for attending the final meeting. Given the length of each meeting, those who were able to make the in-person meeting were also offered food. Food for each meeting was donated by local restaurants. Childcare services were provided at TCP for one participant who would have otherwise been unable to participate.

\section{Meeting 1}

The first meeting at the TCP primarily focused on developing rapport with the group, sharing the study goals, describing the methodology that would be used, and acquiring consent 
for those who were interested in participating. Jared, a TCP representative, welcomed the participants to TCP. As not all were familiar with TCP, Jared provided an overview of the events and resources available at TCP.

I then introduced myself and my research assistant. I explained how I became interested in research with the TGNC community through my personal relationships and my experiences as a counseling trainee. I also disclosed how the results of the pilot study, "Masculinity and What it Means to be a Trans Man in Missouri," influenced the research question.

Next, the participants introduced themselves to the group: This included sharing their names, hometowns, and how they became interested in learning about this project. This was followed by an "icebreaker activity" that was aimed at helping group members get to know each other a little better. During the activity, participants drew a penny from a bowl and then were asked to go around the room and identify the year their penny was minted and share something significant they experienced in that year. After the activity, the group developed ground rules (e.g., what is said in group is not shared outside of study unless explicitly requested) for how to the conduct the remainder of this meeting and how to maintain confidentiality; this would also be used for subsequent meetings.

I then introduced the concept of CBPR and the Photovoice process. Highlighting the principles of CBPR, I shared examples of images from previous Photovoice projects (see Appendix H). Participants reported being impressed by the quality of the photos and how “simplistic images could say so much.” Participants additionally identified that photo captions were essential in order to understand the content within the photographs. Participants appeared enthusiastic about creating their own images. 
Participants then asked to define what the term "role model" meant to them. Most participants defined a role model as someone who a person can "see themselves in" and who acts as a guide or an advocate for others. Three participants noted that they preferred terms like "ally" to the term role model, noting that "ally" felt more egalitarian or "humble." These three participants noted that they associated the term "role model" with people who sought out positions of social influence and for personal gain. In general, nonetheless, participants noted that role models were pivotal in guiding their identity development, advising them through the transition process, helping them feel that their well-being would improve after transitioning, and illustrating how to express masculinity in a healthy way rather than a stereotypical way.

The facilitator transitioned to an open discussion/brainstorming session related to the research question and started with the question, "What is the influence of role models on trans men's identity development?" Follow up questions included

- Who are your role models?

- What are the qualities of a good role model?

- What lesson(s) would you share with your younger self?

This line of questioning was used to help establish the ultimate charge for the Photovoice data collection. This was not intended to be a part of the formal data analyses.

Participants reported that role models illustrated that coming-out and transitioning were possible. In particular, role modeling was seen as a "pay it forward" cycle in which role models provide support to young people who in turn developed the strength to become role models for others. Several participants talked about their personal role models being family members, drag kings, and trans male internet personalities. Many of the participants shared their difficulty locating role models, citing that drag kings and trans men are less publicly visible than drag 
queens and trans women. Participants noted that many trans men prefer to identify as men or "pass" as masculine women. Several participants expressed an ambivalent relationship with the internet and social media. These participants noted how they turned to the internet to locate role models because of the absence of information and resources in their physical lives. These participants noted that while YouTubers like Jamie Dodger were helpful, many internet celebrities “didn't seem real," were "too perfect," or unrelatable.

The facilitator then initiated a discussion about potential community stakeholders, including who might be a good audience for the work, and how this audience might contribute to positive social change. Participants suggested that the general public would benefit from understanding that being transgender isn't a "fad." Participants noted that the general public is not as unfamiliar with issues relating to trans men as they are with issues related to trans women. Participants additionally noted that younger trans people might benefit from locating potential role models, or at least seeing people like themselves.

The medical community as a whole (incl. doctors, mental health professionals, support staff, and third-party payers) was particularly noted as a stakeholder. Participants expressed that psychotherapists needed to have a better understanding of gender dysphoria, as well as the mental and physical challenges involved in transitioning. Participants additionally noted a need for additional surgeons who were skilled at performing top or bottom surgery. Participants noted that living in a rural location and the absence of health insurance coverage served as additional barriers to medically transition. Participants expressed their desire to keep the conversation going about potential stakeholders before deciding upon an audience.

At the end of Meeting 1, verbal consent (see Appendix C) to participate was collected along with a Personal Information Questionnaire (see Appendix B). This brief questionnaire 
asked about their household income, racial/ethnic identity, sexual orientation and gender identity, level of education, relationship status, and if/when they initiated hormone treatment. This was done at the end versus at the beginning so that participants were fully informed about what would be expected of them as participants in the study. Before ending Meeting 1, participants were instructed to email the facilitator a photograph of their shoes that they would discuss during an icebreaker activity in the following meeting; these instructions were intentionally vague/open ended to capture a variety of interpretations.

\section{Meeting 2}

The second meeting opened with the icebreaker activity. The photographs of shoes that were taken by the facilitator and the participants were projected onto a screen; and everyone was asked to describe the significance of the shoes that they had photographed. The remainder of the meeting was divided into two parts. In the first hour we discussed photography aesthetics and ethics and in the second hour we developed photography prompts related to the research question.

Photography Aesthetics and Ethics. A PowerPoint presentation (see Appendix I) was used to facilitate a discussion on photography aesthetics. The slides included photographs illustrating concepts of perception, symbolism, rule of thirds, perspective, negative space, and color (Latz, 2017). The facilitator showed images of her own shoes photographed in different ways and discussed how the meaning behind an image might change depending on how the subject within the image is photographed.

Next the facilitator discussed photography ethics including a subject's right to decide whether or not to be photographed, doing no harm as a photographer, using photographs for good, and representing people/places fairly and accurately. The facilitator explained when it was 
appropriate to ask the subject for permission to take their photo especially when a private figure is visibly identifiable. The facilitator additionally discussed the limitations and responsibilities of photographing minors, criminal behavior, and marginalized groups of people. Questions outlined by Wang (1999) were used to facilitate the discussion:

- What is an appropriate way to approach someone to take their picture?

- Should someone take pictures of another person without their knowledge?

- When would you not want to have your picture taken?

- To whom might you wish to give photos to? What might be the implications?

The researcher discussed how to address someone who might question the participant about why they are taking pictures. The researcher provided participants with subject consent forms, as well as Photovoice brochures summarizing the study, which they may distribute to interested parties (see Appendixes E, F, \& G). Participants were instructed to use a camera phone for taking photos. Each participant had access to a digital camera and did not require a loan device.

Photography Prompts. The second hour of the meeting focused on developing prompts that could be used for the project. The research question used in the first meeting was again put forth: What is the influence of role models on trans men's identity development?

Participants each suggested prompts to the group which were framed as open-ended questions and directive statements (Latz, 2017). These prompts included:

- How have role models influenced you in your life?

- What are some qualities of a Positive Role model?

- My experience being a role model for others has been... 
- If you could go back to your younger self-at a time in your life when you were struggling — what would you share with them that you have learned?

- What others (stakeholders) should know about trans men, individual and (trans) community strengths?

Through this prompt-development process, the facilitator asked participants to share both their individual perspectives, as well as to envision their responses on a collective level.

Participants asked if they could edit their photos using filters or Photoshop. In addition, participants requested including additional artistic mediums like paintings and drawings. The facilitator agreed, encouraging participants to take creative liberties. Several participants expressed concern that they were not "creative," noting they worried their images might not "be great." They were given assurances that what was most important was the content and/or message behind each image rather than in how inventive or visually pleasing the photo might be.

\section{Individual Photo Assignment}

The participants requested to have two weeks to complete their assignment. During that time, they were to go out in the community to individually photograph the themes of their prompt. They then needed to upload their images to a secure folder within the cloud-based storage-service, Google Photos. They were asked to identify 2-5 favorite images or 2-5 images that they felt best represented the research question to share and discuss in the final group meeting.

\section{Meeting 3}

In the final meeting participants discussed their experiences photographing the prompts, the facilitator introduced the SHOWED method of analysis, participants shared their images, and 
then they grouped into dyads to analyze themes (See Appendix J). Last of all, the group discussed their next steps in organizing a showing of their work to community stakeholders.

Processing the Experience. During this final meeting participants processed as a group what the experience of photographing the "assignment" was like for them. Participants reported several challenges that they had taking their photos, including technical difficulties, being short on time, difficulty visually representing the concepts the way they had envisioned them in their minds, difficulty locating subjects to photograph, and discomfort being photographed themselves.

Several participants reported that this was an unexpectedly emotional process. These participants stated that they revisited old photos of themselves pre-transition, noting that they were surprised at how difficult it was to look at these photos: "I don't like looking at pictures of myself pre-transition. It feels so surreal....like a stranger...." Another participant described how looking at photos of himself as a young child was easier than seeing photos of himself during adolescence: "Worst is when I'm on the verge (of transitioning) and I couldn't do anything about it....looking back it shows something wasn't right." One participant described how this project made them realize the lack of trans mentorship and community in their lives.

SHOWED Method. Prior to presenting their images on a digital projector, the researcher led participants through an exercise to aid in analyzing the images. Wang (1999) developed the SHOWED Method, which had previously been used in a photovoice projected based on trans men (Hussey's, 2016). The SHOWED acronym stands for

- What do you See?

- What is really Happening?

- How does this relate to Our lives? 
- Why does this situation, concern, or strength exist?

- What can we Do about it?

With the aid of a projector, each participant then shared 2-5 images that they captured while responding to these five questions (see Appendix J).

After each participant had an opportunity to share their images the group divided into dyads. The facilitator played a slide show of participant images in the background while the pairs discussed their general reactions to all the images. Afterward, they applied a variation of the SHOWED Method to discuss the body of work as a whole.

Debriefing Dyad Discussions. After thirty minutes the group then reconvened to report what they had discussed. Several dyads noted that it was nice for them to see that they shared similar experiences with other group members. Dyads also reported that they noticed a diverse array of different experiences among participants. These pairs noted experiencing an age divide within the focus group of older (over 30 years old) and younger participants. These members reported that due to their differences in age they experienced significantly different levels of social acceptance and access to resources. Jared stated,

I wish that I had what young trans people have now... they talk about, 'oh I got my first binder with all my friends. We tried it on, and we talked about how it works, and I got stuck and they helped me out of it, '... it was just like, so different from my experience.

One pair shared their discomfort viewing old photos of themselves, while another pair noted they enjoyed looking at old photos. "If you had asked me to share these photos 3 yrs. ago, I'd be uncomfortable. But since starting T, I'm fine. Shows how far I've come." 
Participant-Generated Themes. The group was next asked to split into smaller groups of three members. These members were given paper and asked to individually record 3-5 words or phrases that they perceived as strengths related to role models in their own life and in the lives of the other participants (as portrayed in the images). After ten minutes they were instructed to turn their paper over and individually record 3-5 words or phrases about the concerns related to role models as displayed in their images and those of the other members (Hill, 2016). The group then reconvened as a whole to share what was discussed and begin to identify emergent themes.

Stakeholders to Share Data With. In our final discussion about stakeholders several participants expressed concern about whether or not individuals outside the LGBTQ community would "care" about the body of work. Several participants expressed their belief that the images were more interesting than scientific data and helped illustrate that trans people are real and normal people. Potential stakeholders suggested included younger trans people, parents of trans kids, church groups, public schools, public libraries, medical/mental health professionals, and the LGBTQ community.

Participants expressed ambivalence about whether the presentation should be made available digitally and thus accessible to a wider audience of people and whether it should be in print and thereby more likely to be seen by individuals who are not necessarily seeking information about trans men. Some suggested having a showing in October as part of a LGBTQ history month; one person suggested November during Transgender Awareness Week; several participants were interested in shoring their work at the Summit to Improve Transgender Collaborative Healthcare (STITCH; a local transgender healthcare conference).

\section{Data Collection}


Data for this study consisted of three types of materials. First, audio recordings were made of all three meetings - both for those who attended in person and those who met virtually. Second, several types of written materials were collected, including the personal information questionnaire completed by the participants; field notes and analytic memos taken by both the researcher and research assistant during and immediately following each meeting (Corbin \& Strauss, 1990); participant notes taken during the photo analysis; and transcriptions of the audio recordings. Finally, visual materials consisted of the photographs taken by the participants.

\section{Participant and Data Security}

In June 2019, the University of Missouri Institutional Review Board approved this dissertation project as an amendment to the aforementioned study, "Masculinity and What it Means to be a Trans Man in Missouri." Given the nature of the study and its focus on a vulnerable population within Missouri, the study was reviewed and approved at the Exempt Level. Consequently, only verbal consent was required to participate in this study. To protect participant identity, pseudonyms are used throughout this report (see Table 1). 
Table 2: Participants

\begin{tabular}{lllll}
\hline \multicolumn{1}{c}{ Name } & Age & Hometown & Education & Sexual Orientation \\
\hline Jared & 30 & El Dorado Springs & Bachelor's & Queer \\
Quentin & 35 & Springfield & Some College & Excl. Heterosexual \\
Davis & 45 & Moberly & Some College & Excl. Heterosexual \\
Justin & 19 & St. Louis & Some College & Pansexual \\
Adam & 23 & Fulton & Assoc. Degree & Asexual \\
Axel & 19 & Fayette & Some College & Pred. Heterosexual \\
Ethan & 32 & Columbia & Some College & Pred. Gay \\
Arthur & 18 & St. Louis & Some College & Bisexual \\
Collin & 34 & Columbia & Bachelor's & Queer \\
Charlie & 39 & Columbia & Bachelor's. & Pansexual \\
Thomas & 32 & Jefferson City & Some College & Pred. Gay \\
Richard & 30 & Kansas City & Bachelor's & Pred. Heterosexual \\
\hline
\end{tabular}

Note. Names are pseudonyms; hometowns list where the participants were raised. Davis discontinued participation after Session 2. 
All data were stored on laptop computers that were stored in a locked drawer in a locked office on campus and in an encrypted internet-based data-storage service. These were all password protected. All data will be stored for 10 years before being destroyed after the completion of this project or after the submission of any potential publications (whichever is longer in time).

Participants provided verbal consent to use their photographs for the purposes of this dissertation report and for any future scholarly presentations and publications (see Appendix D). The faces of any individuals who are visually identifiable in the photographs have been obscured for the final deposit of this report. Images will not be used for any commercial purposes. Participants were informed that they may revoke their participation and consent for the researcher to use their images at any point.

\section{Data Analytic Strategy}

Data was analyzed in accordance with Constructivist Grounded Theory Methodology (Charmaz, 2006; Glasser \& Strauss, 1967; Strauss, 1994). Data included audio/video recordings, 165 pages of transcriptions from six focus groups, 66 photographic images, field notes, analytic memos, and participant-generated themes. Grounded Theory has been used frequently in Photovoice studies (Latz, 2017; López, Eng, Randall-David, \& Robinson, 2005) and lends itself to Participatory Action Research because of its flexible practices and its prioritization of the experiences voiced by participants (Teti et al., 2013). This project was modeled off of other studies that used both Grounded Theory and Photovoice analysis methods (Lopez et al., 2005;

Teti et al., 2013). Blending the Photovoice SHOWED Analysis with Grounded Theory Analysis empowered participants to take the lead in interpreting the meaning of their experiences, while Grounded Theory provided a conceptual framework for taking action to address these needs. 
Data analysis began at the onset of the study through a process of note taking, analytic memos, and constant comparison (Corbin \& Strauss, 1990). The ongoing analysis was used to test categories and their relationships, as well as to guide the direction of focus group meetings. In an effort to reduce bias and increase theoretical sensitivity, the aforementioned Master's level student who assisted in the focus groups was invited to independently code data, discuss categories, and collaboratively generate theory (Corbin \& Strauss, 1990). Other strategies to reduce bias included prolonged engagement and having the participants review results.

Constructivist Grounded Theory differs from Strauss and Corbin's initial approach in that it asserts that neither data nor theories are discovered, rather they are co-constructed through interactions between researcher and participant (Charmaz, 2006). In order to demonstrate reflexivity, it was important to acknowledge that the data analyses are influenced by the values, biases, and expectations of the researchers. Therefore, a document was created at the onset of the study (see Appendix K), outlining both researcher's identity backgrounds, biases and outcome expectations for the study. This document was continually referred to in an effort to guard against forced data ( Mills, Bonner, \& Francis, 2006).

Prior to coding, two aforementioned Master's level students transcribed the audio recordings verbatim from each of the six in-person and virtual focus group meetings. These students were added to the IRB, bound by confidentiality and not otherwise engaged in the research process. Transcripts were edited for clarity only. Data was then analyzed according to Creswell $(1998,2012)$ in three separate steps. In the first step the two researchers each read the transcripts and independently used open coding, employing line by line analysis to identify categories within the conversations relevant to the phenomenon being studied. This resulted in a smaller set of themes that describe the phenomena being investigated. The coding schemes were 
then triangulated (Lincoln \& Guba, 1985). The researchers convened to discuss their individual coding schemes, resolved any incongruencies and combined themes into a master coding scheme.

All data was uploaded into Atlas.ti (Scientific Software Development, 2011), a qualitative data analysis software package. This program served as a supplementary tool to organize and methodically analyze the large volume of unstructured data, while examining/visualizing relationships. The word cruncher tool was used identify the frequency of language used, enabling researchers to highlight themes from the actual spoken words of the participants (Manning, 2017).

The second step outlined by Creswell $(1998,2012)$ is known as axial coding. During this stage the researchers independently identified interrelationship of categories. This included causal conditions that influence the phenomenon, strategies that resolve the studied phenomenon and environmental components that influenced the strategies approval and outcomes. During this stage, hypothetical relationships between major categories and their subcategories were constructed (Babchuk, 1997). The researchers reconvened to discuss these relationships before reaching an agreement of terms.

In the third step the researchers worked together using selective coding to generate theory by interpreting the interrelationships that emerged among categories assembled during axial coding (Creswell, 2012). Throughout these steps the researchers employed a process of constant comparison whereby each finding was compared to previous findings as they emerged from the data analysis (Glasser \& Strauss, 1967). Once additional themes were identified, a member check was conducted. Participants were contacted via email with descriptions of the additional 
grounded theory themes asked for amendments or additional input. None of the participants responded with feedback. 


\section{Chapter 4}

\section{RESULTS}

This chapter presents the results of all study analyses. First, a description of the content of the third focus group is provided. Second, an outline of results of a preliminary SHOWED analysis of the data (Wang \& Burris, 1990) conducted by the participants themselves, followed by the results of a Grounded Theory analysis conducted by the researcher and a Master's-level student assistant. Included in this chapter are participant's original images and direct quotes. The chapter ends with a discussion of Trustworthiness (Lincoln \& Guba, 1985). The researchers were able to confirm the six participant-generated themes of Bravery, Acceptance, Advocacy, (In)Visibility, (In)Accessibility, and 'Trans Enough?' The researchers additionally found 2 additional themes of Isolation and Constructing Masculinity.

\section{Participant Analysis}

During Meeting 3, the image-viewing process began with a total of 50 discrete pieces of visual data from the in-person focus group: 5 original drawings, 1 screenshot of a Twitter page, 1 internet-based social media meme, 1 photo retrieved from the internet (El Dorado Springs Chamber of Commerce) and 42 original photographic images taken by the participants. The Zoom group shared 11 original photographic images. The exploratory coding completed with the participants highlighted both participant's concerns and strengths of 6 discreet but overlapping categories related to trans men and role models. Concerns included (In)Visibility, Inaccessibility, and 'Trans Enough?' Role model strengths identified by participants included (Family) Acceptance, Advocacy, and Bravery. 


\section{Bravery}

Participants identified bravery as an emergent theme among images, noting that coming out, transitioning, and advocating for others takes considerable courage. To express one's gender identity means confronting many real fears including family disappointment and rejection, societal judgement and invalidation, and discrimination and outright violence. Participants discussed how bravery for a trans person might look different than it does for a cisgender person. As shown in Figure 1, participant "Arthur" (age 19) described how, as a child, he identified as a swimmer, and then gave up

Figure 1: Image taken by "Arthur"

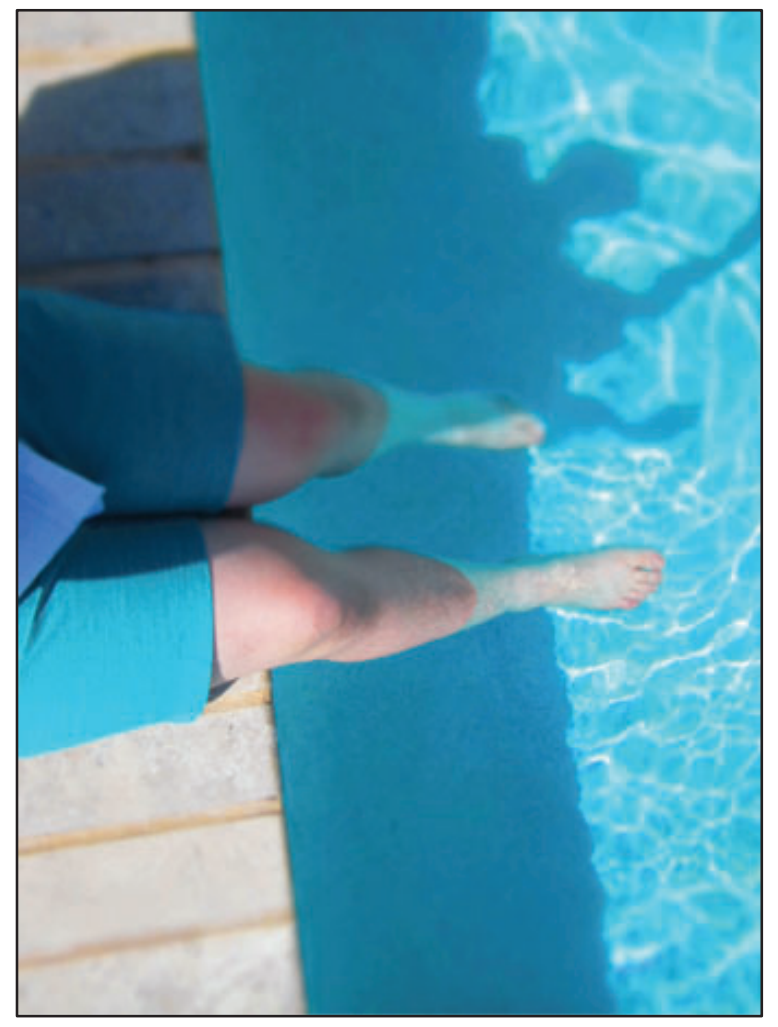

Note. Arthur stated, "Those are my legs. It kind of just shows the hesitance for swimming. Most of the time I just sit on the side-line, mostly just getting my feet wet, which is hard for me because when I was younger, I was kind of the 'swimmer.' I swam for about five years in my life... and I just stopped because I don't feel comfortable". 
swimming in adolescence due to feeling uncomfortable with his body. He referenced how the "simple" act of entering a pool for a trans man requires overcoming considerable fears related to showing his body.

\section{Authenticity}

Several participants identified authenticity as a subcategory of bravery. Authenticity was defined as living as one's true self through honesty and vulnerability. Participant "Adam” (age 23) described how he preferred his idols to be "messy, complicated and fully human," rather than a "false ideal" of themselves. "Arthur" agreed that role models should give people permission to occasionally have bad days or make mistakes. He noted that authentic trans men's experiences are difficult to locate on the internet, stating that often people on social media are not relatable and do not seem real.

The people you see online, these trans role models, you never know when they make mistakes...I think it's hard, especially if you are someone who is either in the closet for personal reasons or family or just not ready. If you see this idolization and you see this perfect being, it's kind of puts you down, 'cause you're like, I'll never be that perfect person. It's better to have someone who's real and makes mistakes and they fuck up every now and then.

“Unapologetically myself" was a frequently used term to describe subjects in photos exhibiting authenticity. As shown in Figure 2, "Charlie" (age 39) spoke about how he embraces his authentic self-expression, in spite of sometimes being treated by others like as if he were a spectacle.

Figure 2: Photo taken by "Charlie" 


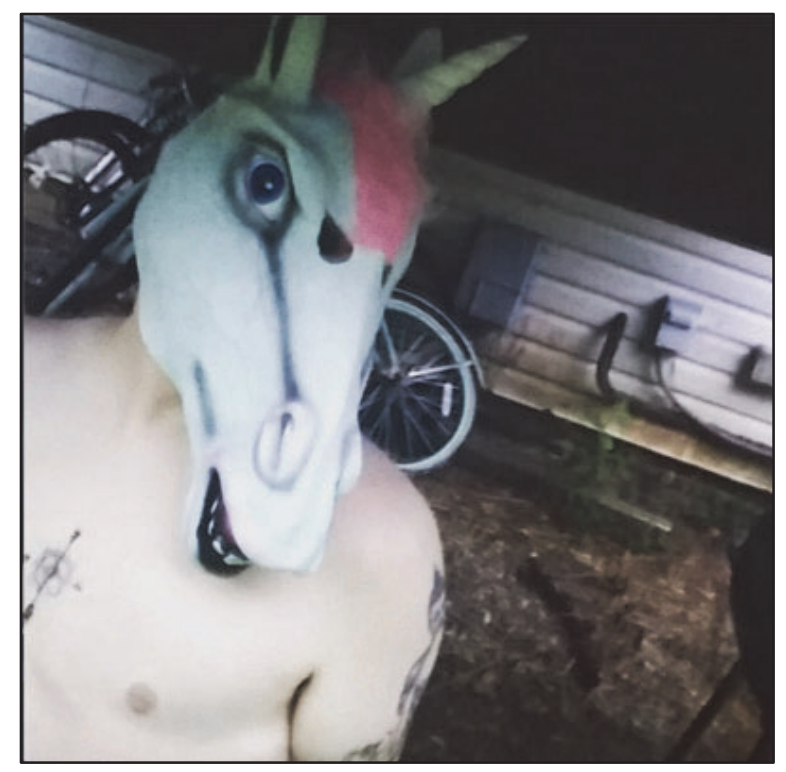

Note. Charlie noted, "Being openly trans often feels like being some kind of mystical creature... Sometimes I have to just remind myself that being whatever I am has to be enough, even if it's strange or shocking, because it's better than being inauthentic or jamming myself into an ill-fitting box."

Participants noted that they admired authentic people and that seeing these subjects living out as their true selves inspired the participants to want to be strong for others. While participants reported that they appreciated the courage to express one's gender identity, they also reported that they recognized that issues such as personal safety often precluded one's ability to live as their true self. Authenticity was additionally viewed as a balancing act. "Charlie" noted the "calculated risks" he took in efforts to be true to himself, while maintaining personal safety:

There's always that tension of, you know, I can be denied work or housing and, if

I end up in any sort of institutional system, like nobody has to treat me like a person...I take a lot of risks, but they're always so deeply calculated.

\section{(Family) Acceptance}

One of the most salient themes that emerged in both participant exploratory coding and later in grounded theory generation was the category of acceptance-particularly acceptance 
shown by family members. Participants defined acceptance as a quality of being seen, recognized, and supported. Acceptance was displayed by family who used the correct name or pronouns, attended pride events and medical appointments, or through symbolic gestures. Those participants who reported accepting and supportive family members were more likely to identify those family members as personal role models. Several members who described feeling less accepted by their family, identified family members who had passed away as lost sources of support who could have fulfilled the position of role model.

Six participants reported having at least one accepting family member and among those, each described varying degrees of support. "Adam" (age 23) reported that he delayed coming out to his grandmother for years because of fears he would disappoint her, He described his feeling relieved and moved to tears when, after coming out to her she "showed her support" by giving him his late grandfather's shaving kit (see Figure 3).

"Richard" (age 30) shared that he has many supportive people in his life, noting that he looks up to his father, seen in Figure 4, who was also the most accepting person of his coming out and transitioning. "Richard" described how his family ascribed to non-traditional gender roles, noting that his mother was "strong" and "independent", and his father did most of the cooking and laundry.

"Quentin" (age 35) additionally identified his father as his role model, noting that his dad is the most supportive person in his life. "Quentin" described how his dad is Figure 3: Photo taken by "Adam" 


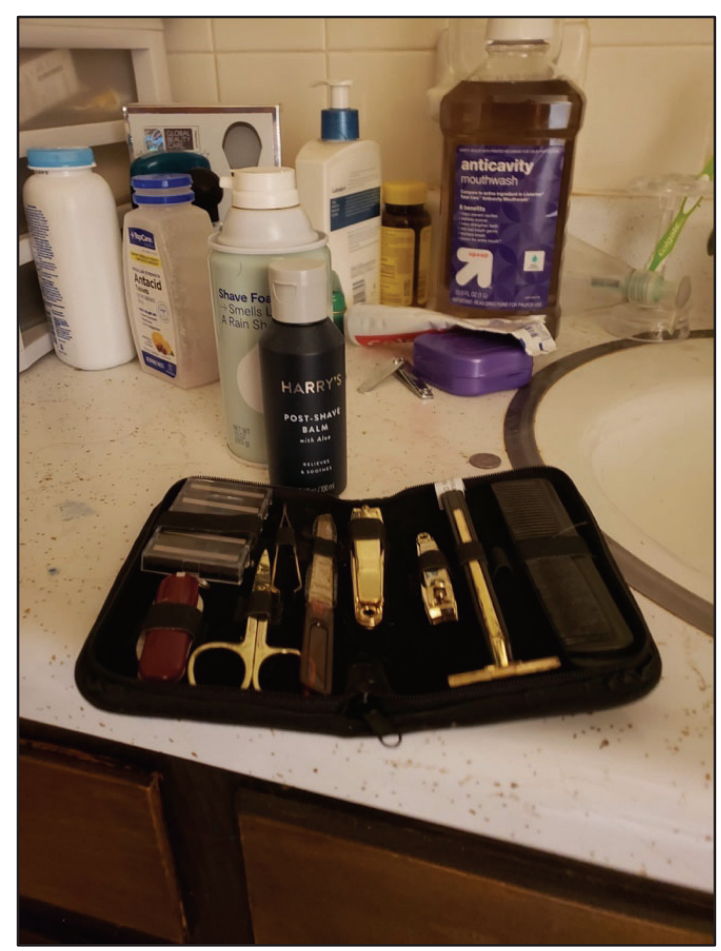

Note. Adam shared, "This is one of the things she gave me... so he passed away about five years ago, and we are getting ready pack up and leave, and she gave it to me before I left. She looked at me and she was like "grandpa says that you need this more". I am not going to use it, but it's a symbolic thing. This was 9:00 in the morning on a Sunday, and she was making me cry."

Figure 4: Photo taken by "Richard"

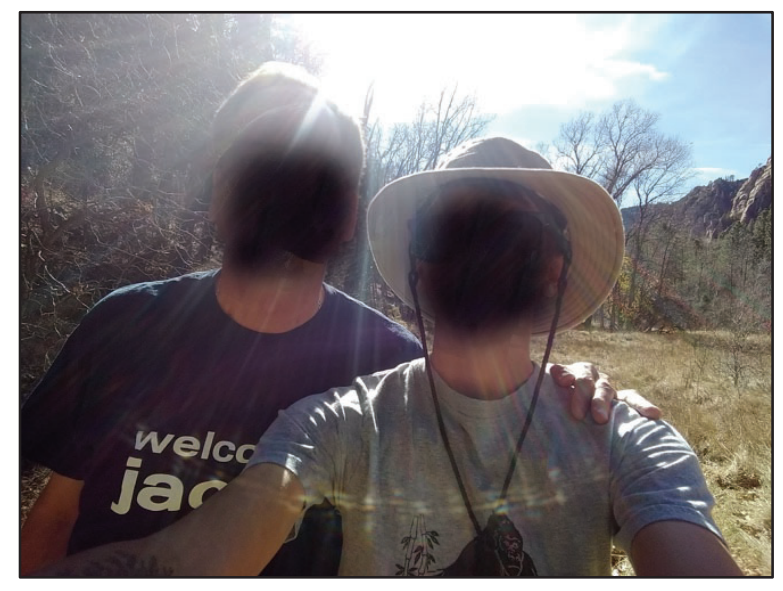

Note. Richard stated, "That's my dad. We were at the Grand Canyon, and we spent a lot of time walking on the trails together...I hiked those trails with him when I was young. I don't know, something about hiking that makes me feel like a guy, you know, in my dad's shadow. That's really all there is. He's a very kind and sensitive man, which I think is what I aim to be as well." 
someone who he can go to with questions and who first taught him how to shave. "Quentin" described how his dad, a Methodist minister seen in Figure 5, served as the officiant at “Quentin's” wedding.

Figure 5: Photo taken by "Quentin"

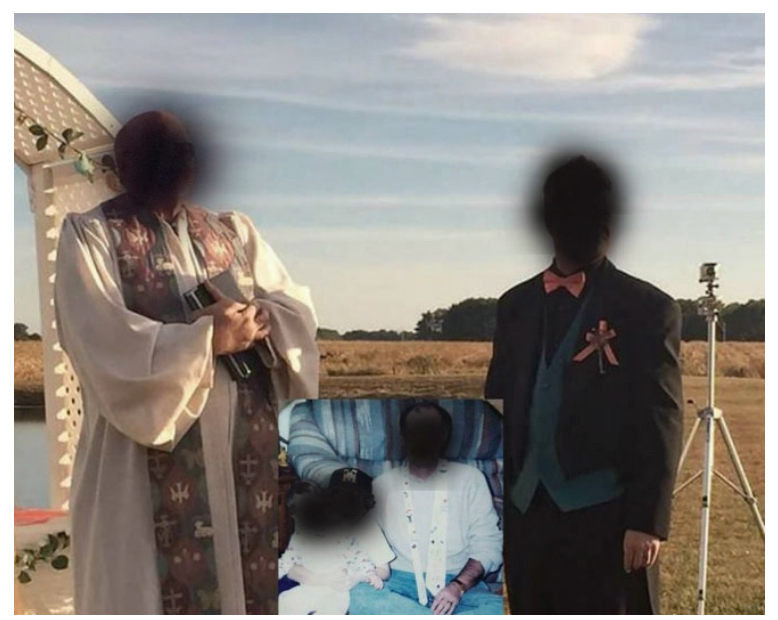

Note. Quentin shared, "My dad is a Methodist minister, retired now. He actually married my wife and I.... and to be so supportive like that, I kind of look up to my dad. He's definitely my role model. I didn't really have a lot of extra trans people to teach me different things."

"Collin" (age 34) shared that while he has many "unsupportive" family members, his preschool-aged daughter has no problems understanding and accepting his gender identity. "Collin" shared that his daughter calls him "Baba," which recognizes his unique parenting identity, and described how she makes him feel accepted through her artwork, pictured in Figure 6.

Other participants reported more mixed reactions among family, including how acceptance was a gradual or ongoing process. Several participants described how their parents "are coming to terms with" their gender identity or how their family experienced grief reactions to the loss of their daughters. "Arthur" shared a series of three family 
Figure 6: Photo taken by "Collin"

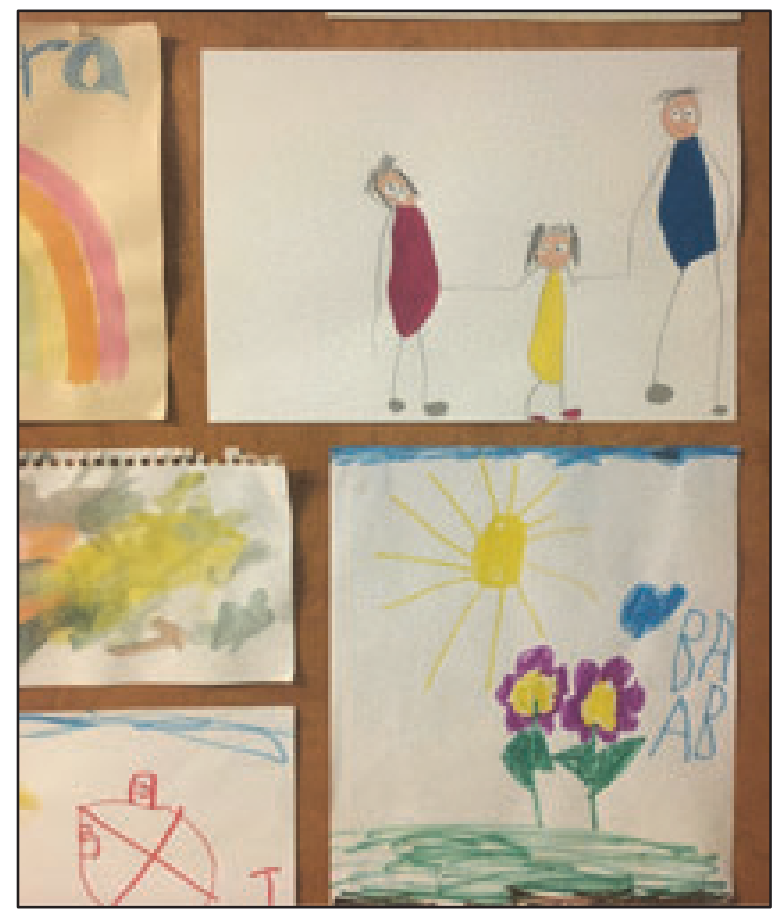

Note. Collin shared, "I feel so loved by this art she creates and again wanted to demonstrate... just this normal thing that a kid drawing picture for you is accessible to everybody even if you are trans. It's really important for me to be somebody. It's really important to me to have my queerness represented which sometimes vanishes as a mostly passing trans guy in a relationship with a woman."

portraits taken of himself with his three sisters each a year apart. The photos in Figure 7 illustrate his transition and represent the change in his family composition. "Arthur" described how difficult his transition has been for his mother identified strongly as the mother of four daughters.

"Ethan" (age 32) described how his mother, who is now his advocate, has progressed in her acceptance of him, noting that she initially struggled with having a transgender kid. He shared an image he had taken of his backpack covered in patches seen in Figure 8, which illustrates the ways in which she shows her support.

Six participants reported experiencing little to no family acceptance. These participants described feeling pressure to remain in the closet or hide their gender identity Figure 7: Photo collage of siblings created by "Arthur" 


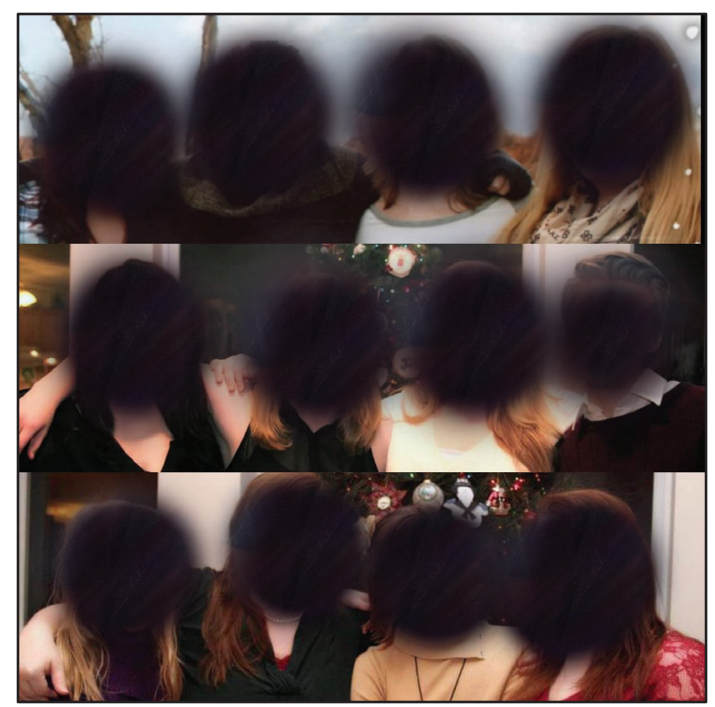

Note. Arthur shared, “These are me with all my sisters. My mom's whole identity was having four girl's and so each picture is a year apart. They are all Christmas photos, so I feel like I'm the one that changed the most, between my haircuts and my style, and just like feeling way more comfortable So, it's been hard for her to accept me not matching what she basically gave me at first because she still feels maybe there's something wrong."

Figure 8: Photo of patches sewn on backpack taken by "Ethan"

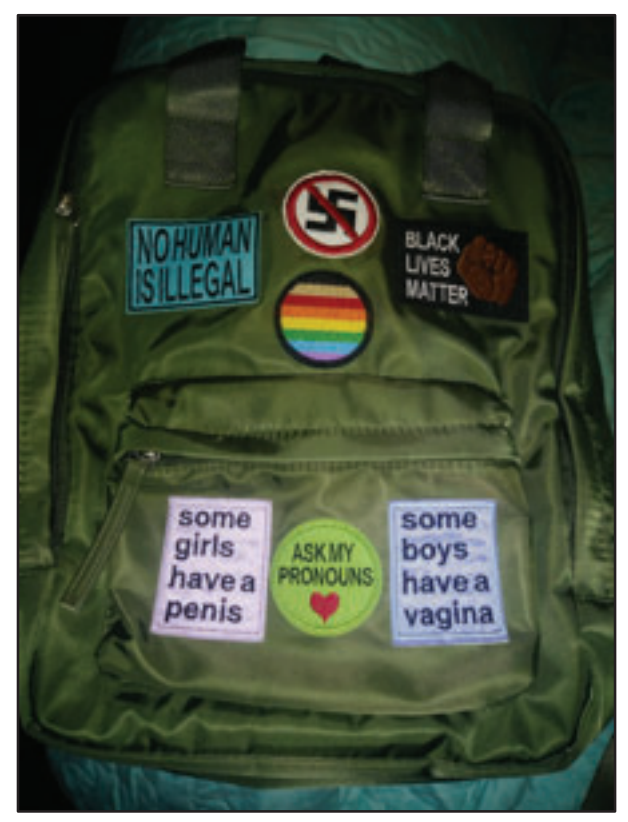

Note. Ethan shared, "My mom put them (patches) all on this pack back for me, and it shows how far she's come. She's always been gay ally, but it was hard for her to have a trans kid. It was pretty hard. But going from that, to going to PRIDE with me, going with me to trans appointments and putting that on a backpack for me, it was pretty far away for her." 
from certain family members. They reported their parent's intentional misgendering, use of dead names, and outright family rejection. "Thomas" (age 33) reported that after coming out his family disowned him. During this time, he also lost his home and began sleeping in his car. Thomas described the importance of his "chosen family", or those friends who became his family and who mentored him during a difficult time in his life. He represented this family in a photo collage seen in Figure 9.

After coming out at age 29 , I lost the vast majority of family and friends overnight. It took a few years to rebuild, but I am proud to have my chosen family. They scooped me up and showed me true love and acceptance while living authentically.

Figure 9: Photo collage of daughter and "chosen family" by participant "Thomas"

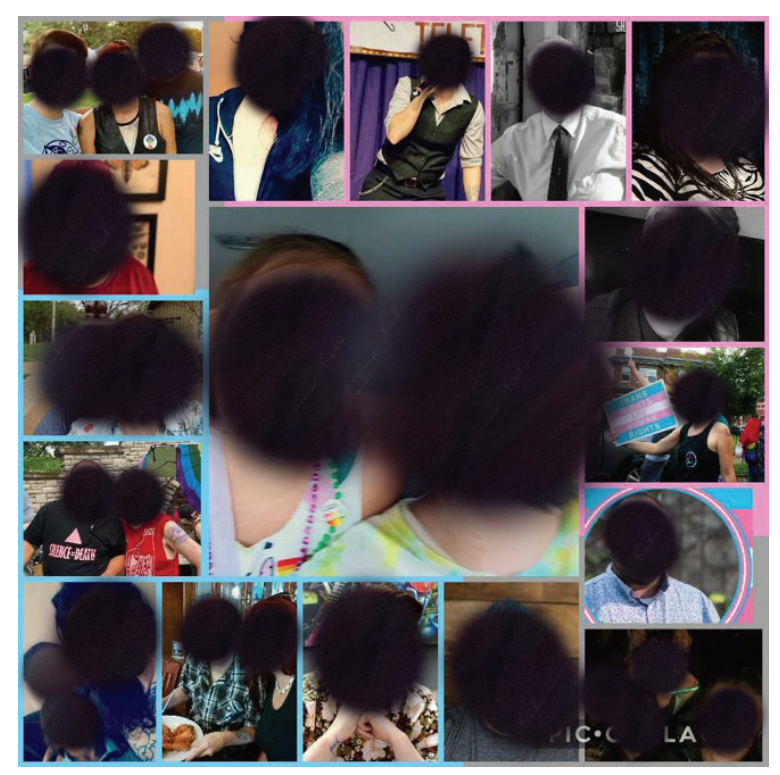

Note. Titled: "Transgender People are Human Too.” 
"Jared" (age 30) reported that his father was his role model, noting that his dad was a good father and husband and "generally really good person." "Jared" reported that his father passed away shortly before "Jared" came out, noting that at that time he lost his biggest source of support. Jared noted that he doesn't usually share pre-transition pictures of himself, citing that he deleted most. "Jared" described the photo shown in Figure 10 of he and his father at his college graduation as one of the few photos of this time in his life that he has saved.

Figure 10: Pre-transition photo of "Jared" with his father at his college graduation

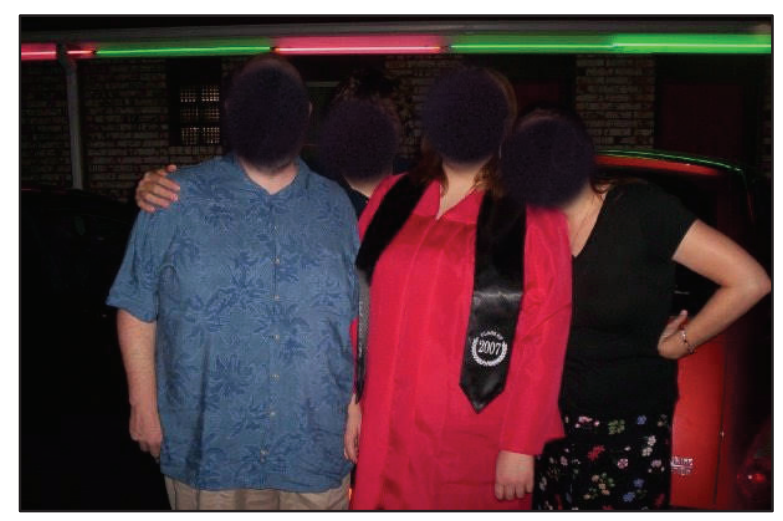

Note. Jared shared, "This is one of the very last pictures I had with my dad before he started getting really sick...I came out in June and he passed away in April, so he never actually got to meet the real me. Among all my family, he would be the most accepting."

Many participants described fears about coming out in relation to disappointing their family and agreed that they would have come out and transitioned sooner, had they been assured of their family's acceptance of their gender identity. "Charlie" described how his grandparents died before he had gotten his "gender shift together," noting that they were hardworking people who could have been described as role models. He shared how his grandmother was a significant part of his upbringing, and how he sometimes

Figure 11: Photo taken by participant "Charlie" 


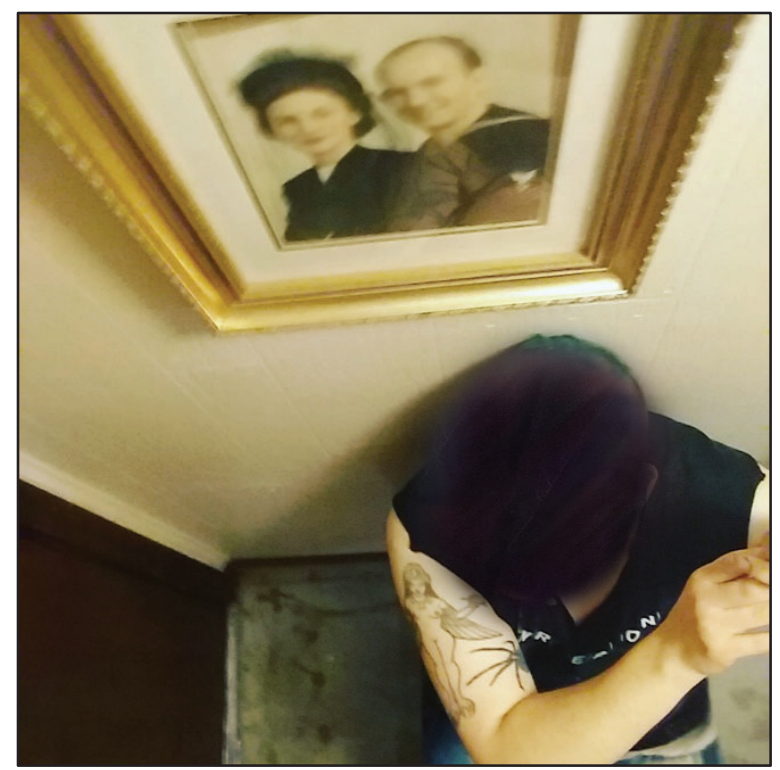

Note. Charlie shared, "That's a picture of my maternal grandparents, my grandfather died before I was born, and my grandmother died before I had really got my gender shift together, but I was already out as a queer. I was never allowed to come out to her at all... my grandmother is a big part of me growing up and I wonder, what would they make of me? Would they be proud of me?"

wonders what they would think had he come out to them. Figure 11 shows a photo of Charlie sitting under a portrait of his grandparent's and considering their response to his gender expression.

\section{Advocacy}

A third emergent theme related to strengths was identified as advocacy. Advocacy was expressed through activism, the sharing of resources, displaying symbols of solidarity, and modeling a healthy masculinity. Advocates were described as approachable, caring, supportive, allies, and people who you could talk to. Throughout the focus group meetings participants displayed a form of advocacy, by sharing memes from social-networking services such as Twitter, Facebook, and Reddit that served to validate, normalize and provide information to one another. 
Many of the participants were involved in some form of activism or public education.

"Richard" talked about advocating for trans rights through his presentation of "Trans 101" talks at local libraries. "Justin" (age 18) shared how his decision to pursue medical school was inspired by a desire to advocate for the medical needs of trans patients. "Charlie" shared a validating experience where he was thanked by another trans person for displaying a trans affirmative button on his shirt seen in Figure 12

While we were going into to the venue and getting our seats, I actually ran into a real young trans kid, who also had the button, and he was like "thank you so much for wearing that”. It kinda kicked my ass. I am just really intensely protective of other people in my community and want to be that person for other people, help them survive and also give them strengths that they need to be that person for other people later.

Figure 12: Photograph taken by participant "Charlie"

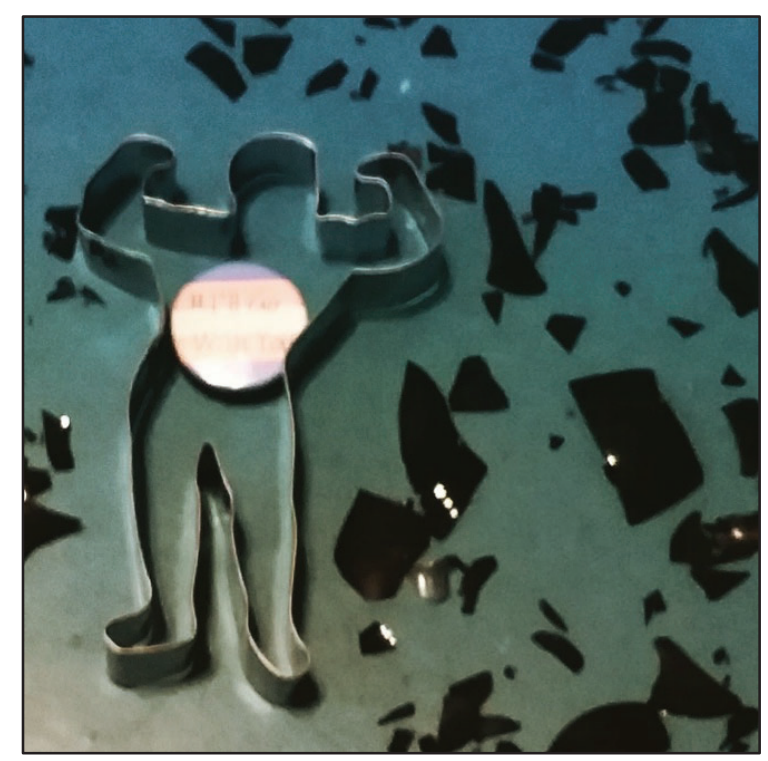

Note. Charlie described his Trans Rights button: "I wore that button, because I feel like it's important to be visible, and also, there is a lyric of this song, that is literally 'I will go with you'... because you can be that person for someone else...give them the strength to survive and to be that person for other people." 


\section{Visibility}

Participants agreed that increased visibility of transgender people and transgender issues is an overarching goal and noted their concern about misinformation and misunderstanding that takes place around trans issues in both cisgender and LGBT communities. "Arthur" and "Adam" discussed common misinformation that transitioning and undergoing hormone treatment will result in a change in sexual orientation. "Adam" stated, "They thought I would go from liking girls to liking guys.”

"Justin" noted a common misperception is "they're just women wanting to be men" and that they might "change their minds" after transitioning. He noted that cisgender people often misunderstand gender dysphoria and tend to downplay the distress trans people experience. "Justin" described a period of time in his life after he realized he was trans, but hadn't yet transitioned, noting how difficult it was not to have his gender identity recognized by others. He discussed the "unrelenting" messages he received from society misgendering him and his daily struggle to remind himself who he is. "Justin" portrayed this struggle in Figure 13.

In the period when I knew I was trans, I hadn't told anyone else, you are constantly, everyday bombarded with your birth name, with your pronouns, and you know that it's wrong, but don't want to correct anyone. Then you go home, you are going to remind yourself that I was right in this. I wasn't wrong, this is who I am.

Multiple participants highlighted the fears and misperceptions related to initiating hormone therapy, particularly Testosterone (often referred to as just "T" within the 
Figure 13: Photo by "Justin" symbolizing his struggle to stay connected to his identity

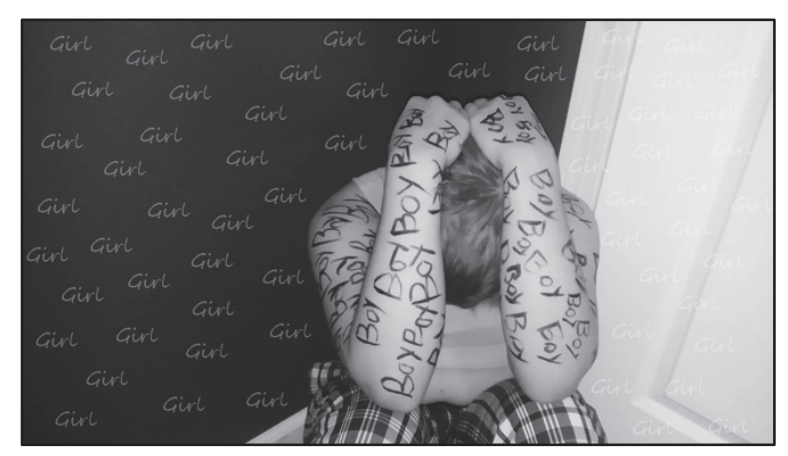

Note. Justin described his desperation to be seen as a boy, "I was suffering... hadn't come out yet. My depression got really bad, and I started self-harming, and it was on my arms. One of the things I did once to try and get over selfharming, was just take eyeliner, just mark instead of cutting, and remember looking at my arms just being covered, and that's kind of where I got this idea for this."

community). "Justin" shared that his mother was worried that his initiating testosterone shots would instigate a change in his personality, causing him to experience "rage" or to "go crazy." "Collin" described that his partner did not want him to start testosterone therapy because of concerns that it would "change him." "Ethan" shared how people associate "testosterone rage" with cisgender men who use testosterone to "bulk up."

Other concerns regarding testosterone therapy included experiencing a loss of emotions, becoming less affectionate, and exhibiting anger outbursts or violent behavior. "Adam" suggested that because testosterone reduces dysphoria and increases confidence, people might misperceive someone's new-found self-assuredness as aggressive or opinionated. He went on to describe how starting hormone therapy has been a positive experience for him, which is represented in Figure 14.

You're getting to come out and live the way you want to live. You're excited and people see your personality change. A lot is that you've finally started $\mathrm{T}$ and people finally know. There will be people who like you better when you were 
quiet/didn't speak your mind. They may say you're more aggressive because you stand up for yourself.

Figure 14: Photo by "Adam” administering testosterone shot

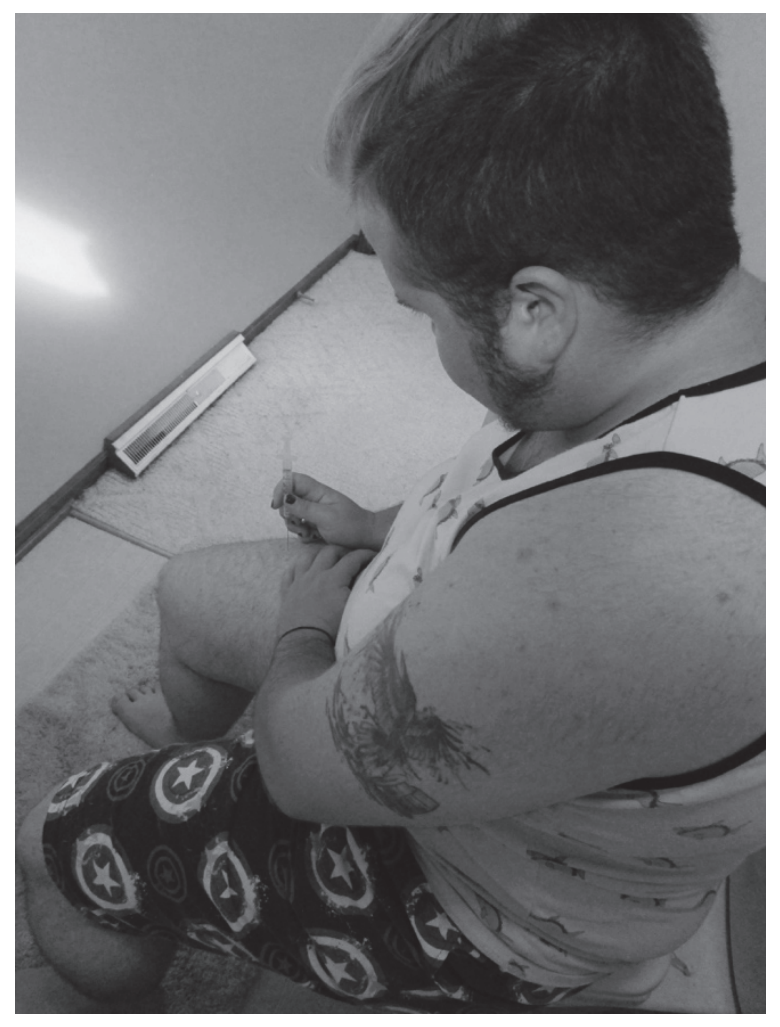

Note. Adam shared, "I went to the mall the other day, and I saw myself in the doorway, and I was like "who is that guy come out of the mall", and I'm like "oh shit that's me". It was a good feeling though. So, testosterone was one of the things that I was not $100 \%$ sure about, but the more I am doing it the more I feel better. It's helping a lot."

\section{(In) Visibility}

Participants highlighted that some individuals who transition simply identify as men and do not wish to share their histories or be seen as transgender. Others, like Collin, spoke about how his passing as a White cisgender man has led others to make assumptions about his level of privilege. He noted feeling a lost connection to the trans community, noting he often feels like "an outsider" in LGBT spaces. 
Participants agreed that they desired greater visibility of trans male role models, and many endorsed that they enjoyed being advocates and role models themselves. While group members agreed that there should be more clear, accurate, and visible information about trans issues, they also discussed the risks associated with bringing attention to a historically marginalized group. Participants noted several concerns related to increased visibility. These concerns included fears for their physical safety, loss of privacy, feeling ill-equipped to be "idols," or feeling too self-conscious to have others look up to them.

Several participants shared that it is difficult to be a role model for others when they themselves are struggling. Participants described how they sometimes feel pressure to put on a "fake face." Thus, they try to present themselves as stronger and more self-assured than they actually feel.

Group members overwhelmingly reported experiencing ongoing feelings of selfconsciousness and insecurity that impacted their comfort with public attention. Participants described how they are "constantly" checking in with themselves about how they walk and talk and continually wondering how they are being perceived by others. Participants also described varying degrees of gender dysphoria, noting that their chest, height, voice, and hands were physical features which they felt most discomfort with. While participants noted this dysphoria improving as they progressed in their transition, they also noted that the transition process itself is continuous and never ending. "Adam" described the ongoing and exhausting process of selfevaluation he experiences on a daily basis:

I don't know...I feel somewhat comfortable, but also self-conscious. I'm always thinking about how people are reading me, are they wondering, you know, "is that a girl, or a boy"? I guess I don't think about it a lot, but I am very self-conscious 
about how people receive me, and in my past even thinking about it all the time.

You know, I feel really dysphoric about my chest. I am always trying to hide it

when I work through my day. Yeah, pretty body conscious. I'm happy with where

I am, but I feel like I have a long way to go.

Several participants described how increased visibility can feel burdensome in that they are pushed into roles of public educator or diplomat. "Justin" shared that while he welcomes opportunities to be an advocate, he feels uncomfortable being called a role model. "Jared" talked about how "small" he feels when compared to the many important people who have come before him (see Figure 15).

Figure 15: Photo of 'The Big Tree' taken by "Jared"

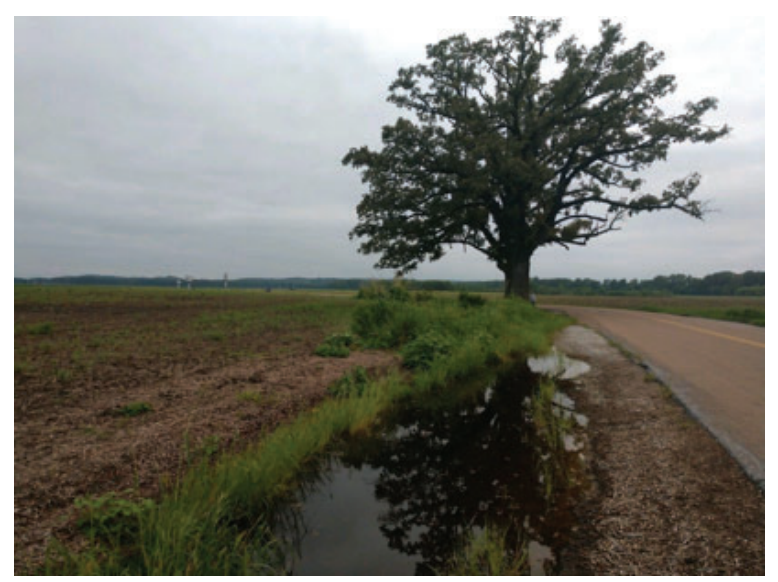

Note. Jared stated, "This is a picture I took of the big tree. If you look really closely, I'm in this picture very, very small. I was trying to represent how it feels when someone says you are like a role model and they look up to you. It makes me feel like, kind of uncomfortable. I'm just a tiny person, and the tree represents the amount of people that should be looked up to that are not me... I just feel small, and young, and uncomfortable."

"Thomas" shared that he sometimes feels like the "token trans person" at his work,

noting that as the only trans person in a small and rural community he feels added pressure to be a positive representation of a trans man. He went on to describe his desire to be known by his neighbors for his carpentry skills or for being a dad or for something other than his gender 
identity: "Yeah, I mean, I'm kind of coming to grips with where I'm like, starting to be known as 'that guy,' you know, like there's something different about him.”

Several participants lamented their loss of privacy since coming out. They shared how when friends or acquaintances learn that they are trans, these people feel emboldened to ask invasive personal questions, and how these people often become offended when the participant attempts to establish boundaries. "Adam" expressed his frustration at how many people treat him like a novelty or ask about his "dead name"(birth name he has since changed). He described how some people even ask him about whether he has pursued gender affirming surgical interventions, noting that he often turns the question back to them by asking, "What's in your pants?"

Finally, participants spoke about feeling forced into roles as delegates and stewards of information before they were prepared for such leadership roles. "Justin" described how difficult it can be to maintain one's dignity as a trans man while confessing that they don't have all of the answers:

Sometimes you are kind of forced into being the role model whether you are fully prepared for it. Like you might not know all of the information, but people would ask you about all these questions, and some people don't want to say, 'I don't know,' because they might be seen as 'not really being trans' or something, so you have to try to keep up the face.

\section{Inaccessibility}

In addition to challenges locating trans affirmative information and role models, group members described added barriers to engaging with these resources. Participants identified multiple obstacles they faced in accessing everything from healthcare and medical interventions to sourcing accurate information related to legal and medical transitioning. Participants described 
how this absence of accessible positive role models resulted in increased feelings of isolation, a burdensome process of experimentation, a delay in transitioning, and a prolonged dysphoria.

Participants agreed that there is not only a scarcity of trans masculine role models, but a representation which lacks diversity. Four participants spoke about the important role that books played as sources of accurate information, as representations they could identify with, and depictions of people they could look up to. Participants described reading about the experiences of people who had "been there" and how this helped them to figure out what their own transition might look like. This included learning about other's experiences with gender and "working with masculinity."

"Justin" described how when he first started questioning his gender he began to read “every single book about trans people I could get my hands on." He noted that he continued to doubt that he was transgender even after having top surgery, because he hadn't yet come across a narrative that mirrored his own experience. "Justin" went on to describe how excited he was to read about someone, who like him, experienced greater ambivalence. "Justin" represented his “oh shit!” moment discovering Nina Here Nor There, which is depicted in Figure 16.

Figure 16: Photo of impactful book taken by "Justin"

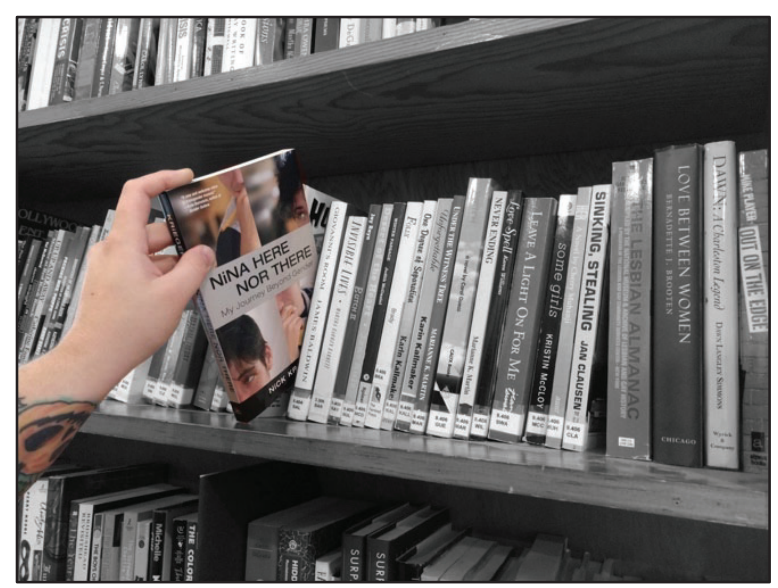


Note. Justin shared, "Nina Here Nor There...It's a really good book and was one of the first stories I've read that was not, 'I popped out of the womb and was like, 'I am trans!' So, it really resonated with me... After I read that book, I was like 'oh, maybe I am a trans.' I feel like it's easier to find book role models than it is to find real life role models."

Participants additionally described how when they were growing up, books provided characters with whom they could identify and a queer community that was otherwise missing in their own towns and neighborhoods. "Collin" described how growing up he read many books with gender diverse protagonists, noting that he "should have known" the reason he was attracted to this form of literature. He photographed a number of books that were influential in his gender identity development in Figure 17.

A second sub-theme identified was the significance of internet access and ambivalent feelings about whether representations of trans men on the internet positively influenced other TGNC individual's identity development. Participants had divergent views about whether this influence has had a mostly positive or negative impact. Several

Figure 17: Photo of impactful books as identified by participant "Collin" 


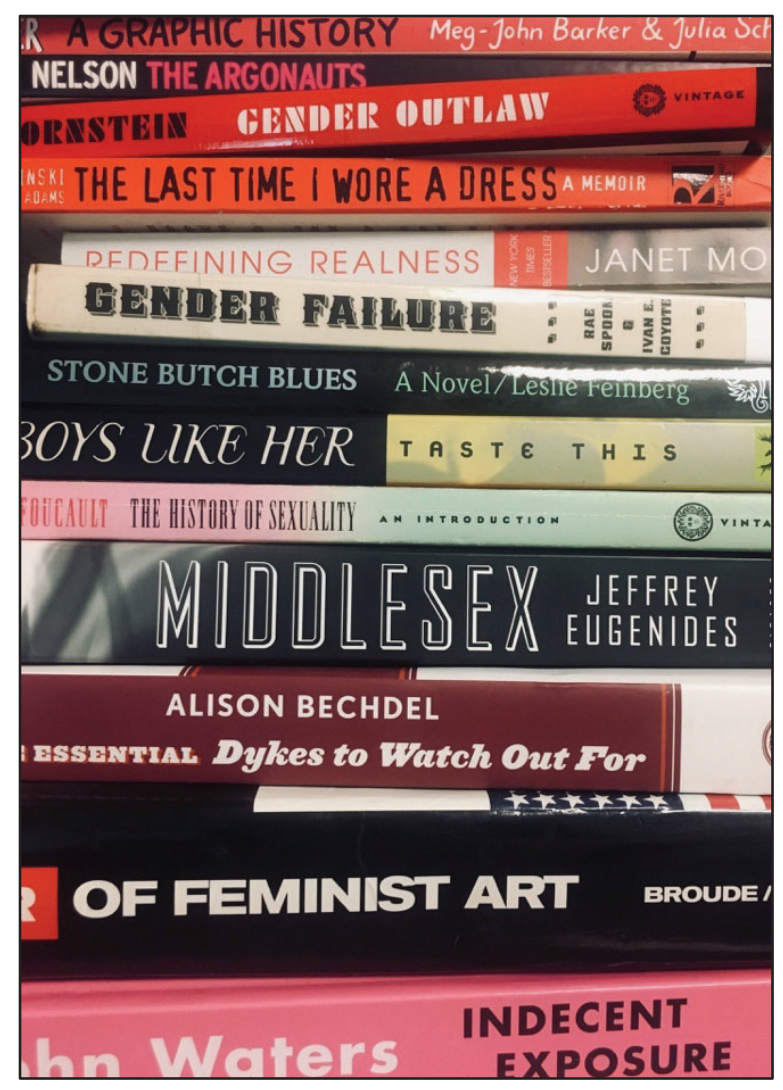

Note. Collin reported, "I think that from a really young age I was reading Queer literature and finding people in books that I could relate to, rather than people in my real life...I was reading A Boy Like Her, which was full of genderqueer people, with top surgeries scars, tattoos, and just feeling like, God I relate to these people!"

participants identified how the internet was a primary resource for them in learning about hormones, surgery, or legally changing their name. "Axel" shared how after going online he was able to see that being trans did not have to look just one way and that there was a spectrum of masculine presentations. Other participants identified trans celebrities that they admired, including Jamie Raines (who goes by Jammie Dodger on YouTube) and Buck Angel (a transman adult-film actor). These trans celebrities have garnered a considerable virtual fan base and have been able to reach a larger audience through online videos, webcasts, and cyber posts: 
Role models in the trans community for me represent a lot since when I was fairly young. Seeing trans role models especially on the internet in their 30 s even in their 20s gave me hope. O.K. this is possible, there are other people out there.

For other group members, online role models were simply not relatable. That is, many had difficulty identifying with transmen on the internet because most of these people presented themselves in an entirely positive light and seemed "unreal." For instance, "Jared" shared how many trans male celebrities look flawless and portray a physically unattainable masculine ideal. Figure 18 shows "Jared" comparing himself to trans activist Aydian Dowling, who was on the cover of November 2015 issues of Men's Health magazine. He described how he is unable to see himself in these positions of influence, noting that the temptation for self-comparison leaves him feeling discouraged.

Figure 18: "Jared” Comparing Himself to Aydian Dowling

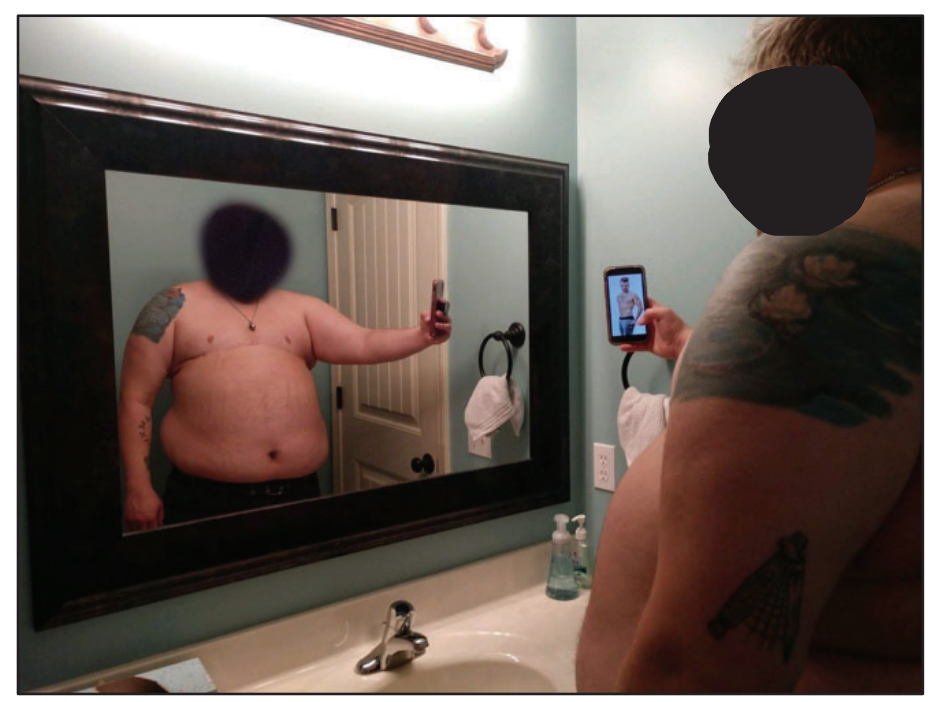

Note. Jared shared, "I had top surgery like a year-and-a-half ago, and I'm very happy with that... But those famous trans people, they are like super buff, and really in shape, and super good-looking, and like on the cover of Men's Fitness and all the stuff, and I'm like that's not something that I can see myself in... and I still try to compare myself with those people sometimes." 
Participants shared how people on social media appear perfect, happy, and in control.

They noted that these figures were lacking vulnerability, and that this of personal hardship.

“Arthur" identified how YouTube celebrities never talk about the hardships they face.

People who are wanting to be role models on the internet. They're just putting out

all the good. You know, they're not putting out the drawbacks of, "well my

hormones levels were too high, or my dysphoria was so bad after this call that my

insurance wasn't going to cover my top surgery, and so I had a complete mental

breakdown. Instead. It's a 'you know I'm back from a leave of absence and

everything's going good, blah blah blah...

Finally, participants identified how the online community lacks the face to face contact

they desire. They noted that the best types of role models are those who can listen and provide an interactive form of mentorship. Most participants shared that they lacked this type of mentorship and noted that this absence resulted in feelings of greater confusion and isolation. Participants additionally identified that role models are particularly inaccessible for trans men over 30 yearsold, living in rural areas, and with fewer financial resources. These group members who came of age in the 1980's or earlier, reported not having the same access to the internet and noted that less access to information about TGNC influenced societal stigma and misinformation.

"Davis" (age 41), who described growing up in a small town in the 1970s, shared that he had never heard of the term LGBT, let alone had access to gender affirming resources until well into adulthood. He shared his frustration at having spent nearly $\$ 1,000.00$ experimenting with ineffective packers and erectile devices before realizing they only increased his dysphoria.

"Quentin" (age 36) described getting married in Missouri in 2002 and the complicated and time-consuming legal process he went through to be wed to his long-time partner as "man 
and wife." He recounted how alone he felt and how much he wished he had someone who could have prepared him for the process. "Quentin" additionally discussed the scarcity of information about gender affirming surgery at the time of his phalloplasty in 2010, citing the multiple complications he experienced and regrets over the surgeon he chose. "Quentin" described how the inaccessibility of role models meant that he lacked important information that could have aided in his identity development. Figure 15 represents how both he and many other trans men make decisions about their gender identity "transformation" on their own.

Figure 19: Photo of Cicadas Shedding Their Shells by "Quentin"

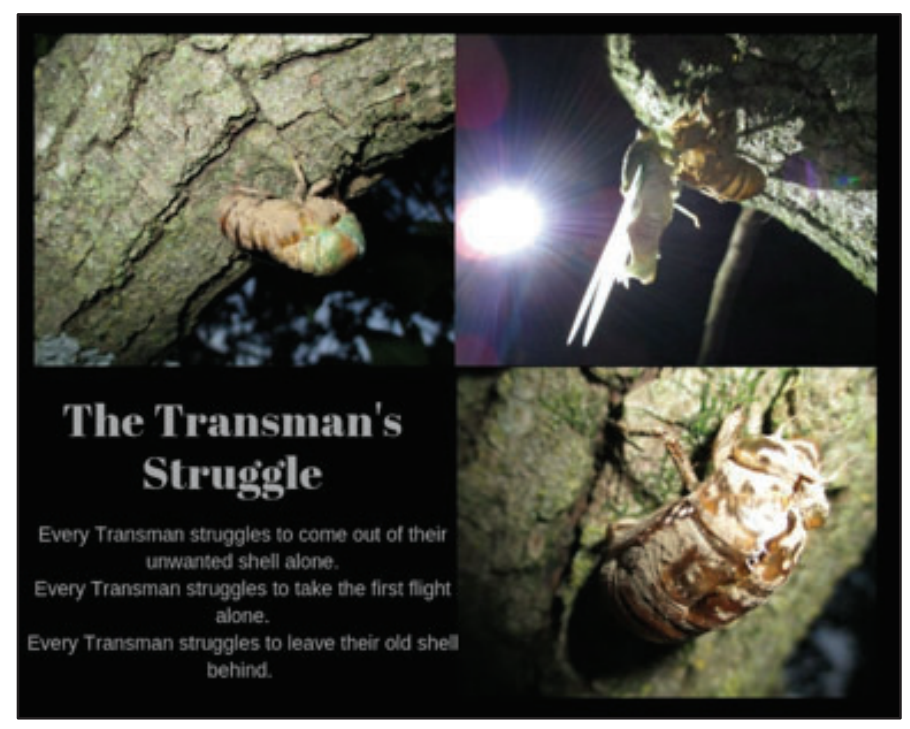

Note. Quentin stated, "To me it was kind of like the journey that all trans men go through, you know, and a lot of us go through it alone, so it was kind of like this cicada, they're going to have to learn how to shed themselves by instinct and you kinda have to rely on your instincts to do stuff."

\section{Trans Enough?}

The sixth and final participant-generated theme described both the self-doubt they experienced and the ongoing pressure they encountered to prove themselves as transgender within both cisgender and LGBTQ communities. Participants reported having to convince others of their seriousness/commitment to being TGNC, to adopt a universal narrative, and to live up to 
high standards of a transmasculine embodiment. Group members described being compelled to meet these criteria in order to access medical interventions and to avoid social exclusion and rejection. Participants shared how this type of gatekeeping has served to confine them in their gender expression and reinforced feelings of confusion and inadequacy.

The medicalization of the term "transgender" had forced individuals to pursue a narrative that relied on the "wrong body discourse." This discourse was established in a sex/gender binary whose very language limitation cannot accurately portray the trans experience (Catalano, 2015). "Jared" described how, in spite of the years of confusion and ambivalence he experienced surrounding his gender identity, he was compelled to recount a story in which he had always identified as a boy. He reported adopting this compulsory storyline in order to receive a diagnosis of Gender Identity Disorder and gain access to biomedical options for his transition. "Jared" went on to explain how it took him longer to discover he was trans, thus transitioning later in life, because his personal experience did not align with this sanctioned narrative.

Several other participants described the high standards ascribed to trans men including pressures to be fit, good looking, and well informed. "Adam" described how he realized that he frequently compares himself to trans masculine ideals on Instagram, YouTube, and other social media outlets. He shared how this constant comparison often leaves him feeling flawed and doubting if he is "trans enough." Several other participants discussed the difficulty they have had in constructing a balanced trans masculinity that is neither "too feminine" nor "normatively masculine." These participants spoke about their desires to pass and the challenges and conflicts they faced fraternizing with cisgender guys while simultaneously challenging a "toxic masculinity" of "entitlement", "misogyny", and "homophobia." 


\section{Grounded Theory Analysis}

Data was additionally analyzed in accordance with Constructivist Grounded Theory Methodology (Charmaz, 2006; Glasser \& Strauss, 1967; Strauss, 1994). Grounded Theory has been used frequently in Photovoice studies (Latz, 2017; López et al., 2005) and lends itself to Participatory Action Research because of its flexible practices and its prioritization of the experiences voiced by participants (Teti et al., 2013). Data analysis began at the onset of the study through a process of note taking, analytic memos and constant comparison (Corbin \& Strauss, 1990), and it consisted of 691 minutes of audio/video recordings from six focus groups (equaling 165 pages of transcripts), 66 photographic images, field notes, analytic memos, and participant-generated themes. Ongoing analysis and constant comparison were used to test the validity of categories and their relationship with one another, as well as guide the direction of focus group sessions.

Constructivist Grounded Theory differs from Strauss and Corbin's initial approach in that it asserts that neither data nor theories are discovered; rather they are co-constructed through interactions between researcher and participant (Charmaz, 2006). In

Table 3: Example of the Coding Process

\begin{tabular}{|c|c|c|}
\hline Open Coding & Selective Coding & $\begin{array}{c}\text { Core } \\
\text { Category }\end{array}$ \\
\hline \multicolumn{3}{|c|}{ Axial Coding: Transitioning } \\
\hline $\begin{array}{l}\text { "Proud of myself when I do my shots" } \\
\text { "Finally taking control of my health" } \\
\text { "I dropped T awhile back for some health reasons" } \\
\text { "Men are conditioned to not access healthcare" } \\
\text { "Top surgery, it was awesome... a little more expensive" } \\
\text { "Didn't know anybody in Mo that had bottom surgery" }\end{array}$ & $\begin{array}{l}\text { Medical Sphere: } \\
\text { Biomedical interventions }\end{array}$ & Authenticity \\
\hline \multicolumn{3}{|c|}{ Axial Coding: Challenges } \\
\hline $\begin{array}{l}\text { "Inherited masculinity of our society" } \\
\text { "Constant balance to be me or dial it back" } \\
\text { "Conservative hometown detrimental to figuring who I } \\
\text { am" } \\
\text { "Constantly reminded that you're not the correct height" }\end{array}$ & $\begin{array}{l}\text { Social Sphere: } \\
\text { Management of } \\
\text { information, social } \\
\text { pressure, and } \\
\text { interpersonal } \\
\text { relationships }\end{array}$ & Authenticity \\
\hline
\end{tabular}




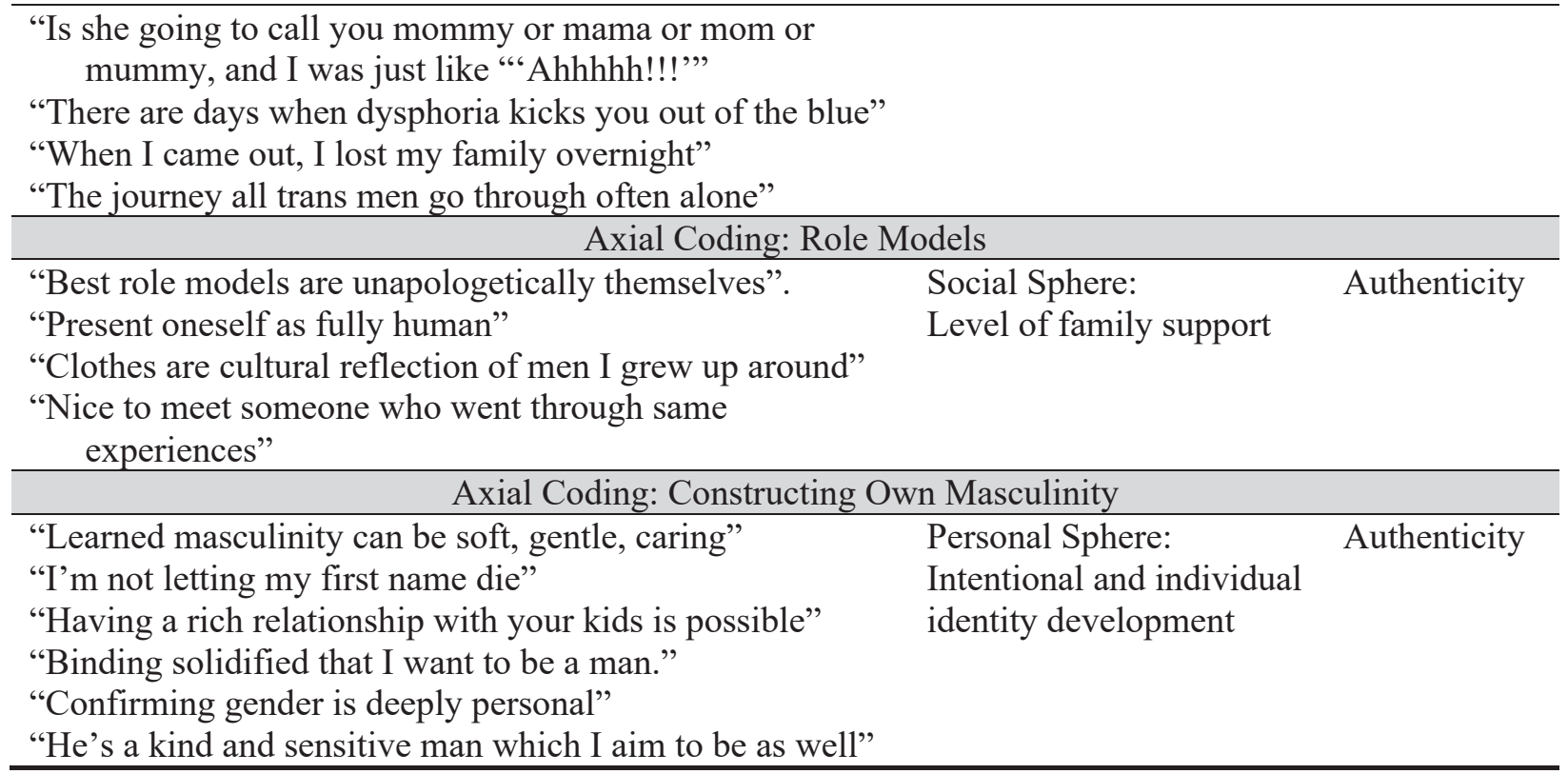

Note. Coding from left to right across the table indicates increasingly abstracted stages of analysis. The substantive finding is that trans men value authenticity. While complete authenticity was described as never fully actualized, it was identified as a goal and a primary way in which role models influence trans men's identity development. order to demonstrate reflexivity, it was important to acknowledge that the data analyses are

influenced by the values, biases, and expectations of the researchers. Therefore, a document was created at the onset of the study, outlining both researcher's identity backgrounds, biases and outcome expectations for the study (see Appendix 10). This document was continually referred to in an effort to guard against forced data (Mills, Bonner, \& Francis, 2006).

\section{Isolation}

Participants frequently referenced their gender identity as a "journey" that was filled with many ups and downs. For most participants this journey was described as a "deeply personal" process that they navigated on their own. Each of the twelve original participants endorsed having experienced feelings of considerable isolation. This sense of loneliness was frequently manifested alongside other mental health concerns including depression, anxiety, gender dysphoria, self-harm, and suicidality. "Arthur" shared a drawing he made shortly after he came out. The illustration in Figure 20 represents his struggle with depression and his attempts to hide his feelings from others. 
Participants described how they experienced isolation as a form of suffering; and they noted that this isolation increased during adolescence and through the time that they "came out" and began their first steps towards transitioning. Participants reported that this isolation was both a form of self-protection via withdrawal, as well as an unwanted consequence of their lacking resources and support. "Collin" (see Figure 21) described how his anxiety has kept him from connecting to others, noting that he now realizes that his attempts to protect himself through selfisolation have actually prevented him accessing much needed support.

Figure 20: “Arthur's” Drawing Representing Depression

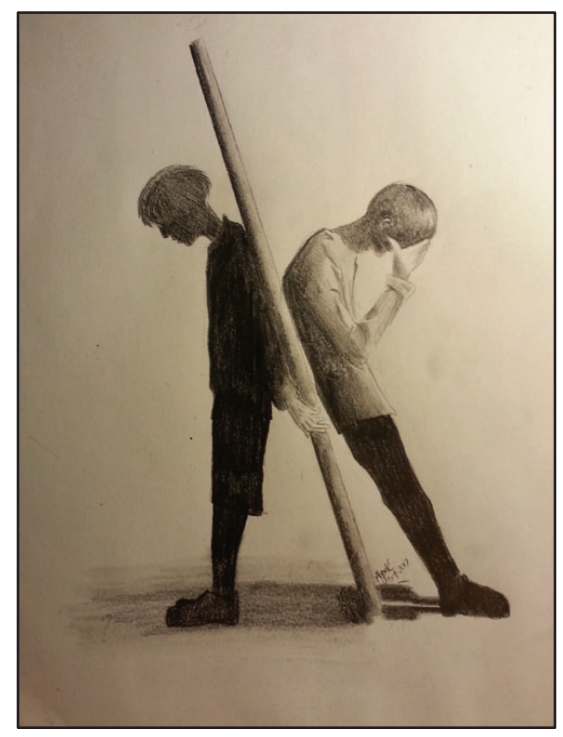

Note. Arthur shared, "This is a drawing I made shortly after I came out... after my first short haircut. It's kind of like an internal battle with yourself, with mental health...depression. I still have it, but it was worse back then. The guy on the right is just trying to be you in your normal everyday life, and kind of trying to hide the guy on the left, who is depression, who is trying to come out, seek help. It's just not a fun time."

Figure 21: Photograph of the Katy Trail taken by "Collin" 


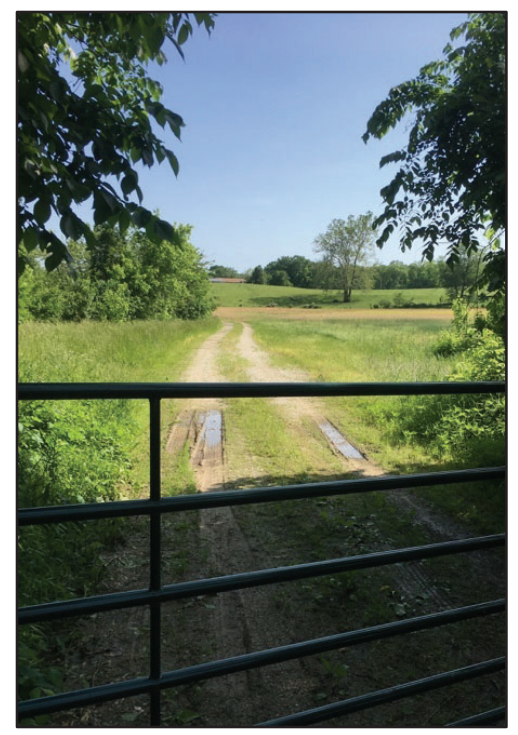

Note. Collin stated, "This is just from the Katy Trail- I found a lot of symbolism in it. I guess the way I was thinking about the image was knowing other people have walked there but not seeing anybody on it, not really being able to access it totally, not seeing where it goes. Especially the gate for myself. I've done a lot of isolation in my life and to be totally honest, I have a lot of anxiety around other trans people, and that has really kept me from connecting. I'm sure it has robbed some richness in my life because of that, so it's kind of like self-imposed gatekeeping."

Multiple participants referenced a "dark time" in their lives that was marked by confusion, depression, dysphoria, and fears that there was "something wrong" with them. Participants described how they "hid in the closet" or were "shut down" by others when they attempted to share that they were either questioning their gender identity or struggling with mental health concerns. "Justin" described how experimenting with different gender identity terms like "demi boy" and "bi gender" allowed him to avoid coming out as trans and "freaking out" his family. Other participants described their anxiety about how disclosing their identity would lead to disappointing family members, damaging relationships, or simply "wrecking everything." For participants under the age of 30, they described a limited acceptance of their identity and experiences, where being LGBT or depressed was agreeable as long as they did not talk about it.

"Axel" (age 19) shared that while he knew people who had transitioned, he was unable find anyone willing to meet with him to learn about the legal process of changing his name. 
"Justin" (age 19) described how being gay was more acceptable in his community than being depressed:

I grew up in the suburbs and there is this like mentality. Especially where I grew up, of pleasing your parents as much as possible. So, you had to like, have the best grades, and you had to focus. So, you could be gay, but you had to be happy, you couldn't have suffered at all. You had to be a really happy gay.

Similarly, "Arthur" (age 19) described his regrets that he and his TGNC friends didn't share more about their personal experiences and hardships:

In my high school, I think it was you were allowed to be gay, but you weren't allowed to talk about it, and you could hang out with your boyfriend, if you're a boy, in the hallway or whatever...you wouldn't talk about the bad stuff ...you wouldn't talk about your transitions or anything like that. So, I think everyone sort of just suffered in silence and then once they were through the suffering phase, then they would start talking so I wish we had communicated more when we were actually going through like, the hard part.

Participant's degree of isolation was largely impacted by additional factors including age, socioeconomic status, regional location, and their hometown's religious/political affiliation. While coming out and transitioning were identified as significant steps in improving this isolation, fears regarding personal safety and family disappointment were noted as the most compelling barriers to pursuing these steps.

Participants in the focus group identified a generational divide between older (over 30) and younger ( 25 and under) participants. The five 'older' participants reported that they pursued transitioning later than they would have liked (in their late 20 's-40's) because they lacked 
information, support, and resources. These participants described how because they came of age in a time where being trans was less understood and accepted, they experienced prolonged feelings of isolation, alienation, and other "detrimental" outcomes. "Collin" described how he realized the complete lack of trans mentorship he has had in his life, particularly as a young person. "Collin" described how he sometimes envies the resources that he sees available to younger trans men:

I wish that I had what young trans people have sometimes now...they would talk about "oh I got my first binder, I was with all my friends, and we, like tried it on, and we talked about how it works, and I got stuck and they helped me out of it," and whatever, and it was just like, so different from my experience, but I feel like there is such power in that community that young people are being able to build, of like showing each other the way, helping each other through it.

"Jared" went on to describe how it was not only the decade he grew up in, but the nature of where he grew up that contributed to his experiences of adversity. He described how in his "conservative," Christian hometown" of 3,000 people the local church leaders publicly lobbied against LGBT inclusion. "Jared" noted that he found an image of his hometown via a search on Google (see Figure 22) because he hasn't wanted to return for "a long time."

When I was growing up, I didn't have internet. I lived in a town of three thousand people which was Christian, conservative and white and no LGBTQ people. I didn't know these things to find those role models to help figure myself out. Quentin (age 36) shared that at the time he lived in Springfield there were only 2 openly trans men and that these men were only visible once a year at the local PRIDE festival. Davis (age 45) shared how in the 1970's, the rural area he grew up in was simply unaware that gay or 
transgender people existed. He went on to describe how this absence of information and knowledge contributed to his confusion and fears related to his body:

Figure 22: Photo of "Jared's" Hometown

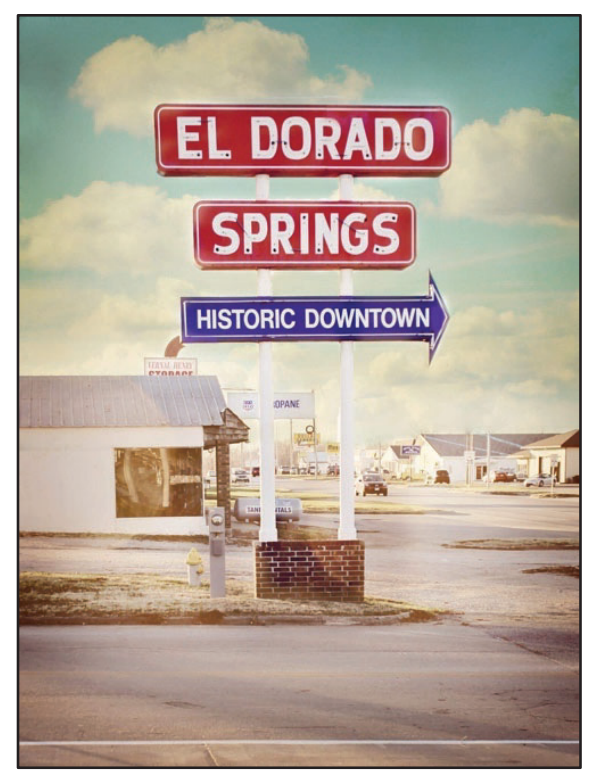

Note. Jared retrieved this picture from the El Dorado Springs Chamber of Commerce website. He noted, "This is like where I grew up. It's like, a shithole. It's like a town in Southwest Missouri with 3,000 people. it's very, very conservative, and I feel like it was detrimental to my figuring out who I was for a long, long time growing up there."

I grew up in a small town...there wasn't a drop of alcohol for a hundred miles, let alone someone who did not fit to the 'male-female' box. There was no LGBTQ. Didn't know those letters even existed until I got into college...I thought I was dying when I got my menstrual, literally. It's kind of funny cuz I just watched the movie about hemorrhaging and my menstrual started. And I wasn't a girl, so it wasn't going to happen to me, and I'm like oh my God I'm going to die I'm going to bleed to death right here...having those young emotions towards the girls and wanting to be one of the guys. And not having anyone being there to support you, not even your parents. 


\section{Constructing Masculinity}

During the preliminary participant coding, group members identified Authenticity as a subtheme of Bravery and a strength within the trans male community. Upon further analysis the researchers found that Constructing Masculinity was a significant theme relating to authenticity, but with distinct features that deserved further discussion. For trans men, identity development is a more intentional process and has unique features compared to most identity development models. Participants described a complex and highly individualized process of constructing their physical, psychological, and social identities while simultaneously re-defining the norms and ideals of masculine expression. Re-constructing one's physical presentation included making decisions regarding style of dress, binding, hormone therapy, and top and/or bottom surgery. Social and psychological changes included stages of coming out, changing one's name, and titles, adjusting to change and personal loss.

Several participants discussed the societal expectations of masculinity that they "inherited" and the sometimes-ambivalent process of determining which values they shared and which they rejected. "Axel" spoke about mirroring the emotional restriction he witnessed while growing up, only to realize later on that he preferred to be more "caring and affectionate." "Axel" noted that he still prefers the "traditional" male style of dress he grew up with (see Figure 23).

Some participants including "Davis," "Richard," and "Axel" spoke of embracing "traditional" masculine qualities like physical strength and emotional stoicism while some such as "Adam" and "Collin" embraced a more "fluid queer identity" that privileged "communication" and "caretaking”. Participants universally identified "toxic Figure 23: Self Portrait of Clothes taken by "Axel" 


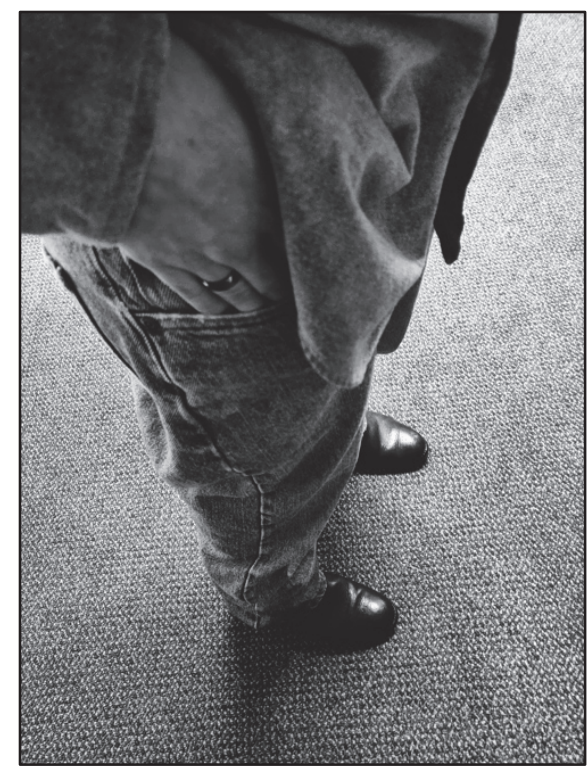

Note. Axel stated, "This is pretty typically for me, what I wear all the time. ... jeans, and a buttoned-up shirt and boots... I mean this is the cultural reflection of the men that I grew up around. This one for me, it was about struggling to find my soft side. Because I inherited the masculinity of our society, and I feel I had always had this strong front... I don't know, an emotional kind of brick wall. I felt like it would make me more of a man in society I guess and realizing that... that's just stupid. It will make me more like other guys you see, but it certainly doesn't make you a better person. I learned you can be soft and gentle, and it doesn't change your masculinity at all. You know, you can have masculinity that is soft and gentle, and caring and loving."

masculinity" as an expression they wished to avoid. Toxic masculinity was defined by such qualities as entitlement, homophobia and misogyny. "Charlie" described his distaste for the "violently binary" media messages that promote "unhealthy" masculine ideals. He expressed the importance of challenging those messages and showing others that masculinity doesn't have to look like what ones read about in men's magazines. He represented his confronting these messages in Figure 24.

Multiple participants identified how they have learned that men can be "soft", "gentle," or "caring". Three participants identified parenthood as a salient identity category. These participants discussed how their dysphoria had increased after receiving Figure 24: Image of Men's Magazine on Fire by "Charlie" 


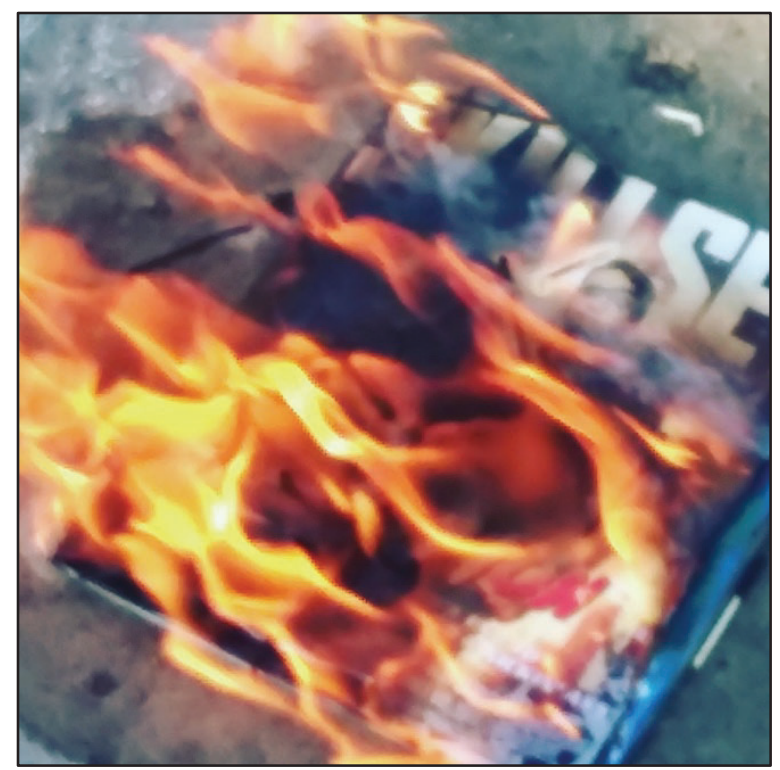

Note. Charlie stated, "I walked into a Barnes \& Noble and found the absolutely douchiest masculine magazine that I could find...the whole article was about Harley Woods becoming masculine, and the whole thing was like, gun ads urban... the worst. Um...like part is deciding what to accept and what to reject, and part of role modeling is being vocal and visible, and you know, it's like this is nonsense I want to burn it down, especially when we are not interrogating, thinking about them and looking at how they affect us and people around us."

messages from their community that misgenders them as mothers. These participants also described their process of re-defining caretaking as a paternal quality. "Collin" shared how his nickname from his daughter, "Baba," served as an important title that recognized his unique identity as a parent. He described the close relationship he has with his daughter, as well as his desire to show other trans people that having children is attainable (see Figure 25).

"Justin" described himself as a "cat dad" (see Figure 26) and spoke about how he realized that he identified with parenthood:

I became their main caretaker, people would be like, "oh, go see mommy" when they let the cat go, and that felt really wrong. I remember telling Figure 25: Photo by "Collin” 


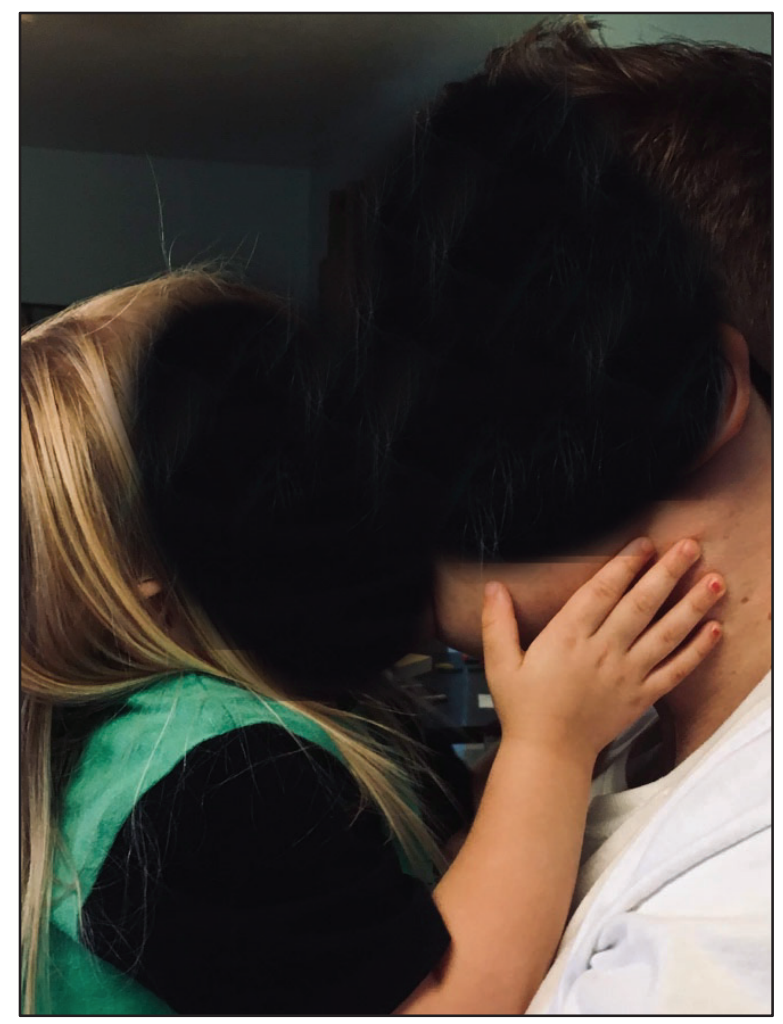

Note. Participant Collin shared, "...Some of the things that I've learned about myself in kind of walking my own path, I think one of the biggest things, my most important role for sure is my role as a parent, and I just have my daughter to thank for it. I just wanted to show a normal scene of my life. Having kids is possible, and having a rich relationship with your kids is possible even if you are trans. I had no struggles with my daughter understanding my identity."

them, I never wanted to have kids, I don’t wanna have kids, I don’t wanna

be a mom. But after I came out, I would talk to my cats, "come to dad, come

here," and then I was like, that fits, I like that. I want to be a dad, and that was a

big thing for me.

While most participants agreed that physical qualities such as height, muscularity, and physical strength are not prerequisites of manhood, they often desired these qualities or felt "less than" when comparing themselves to others who possessed these features. Participants described how they constructed a physical presentation that was congruent

Figure 26: Photo by "Justin" 


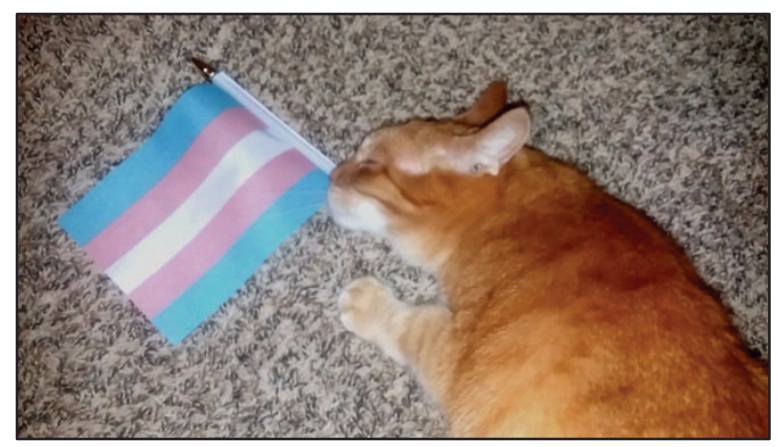

Note. Justin's cat playing with a miniature trans flag.

with their internal view of themselves. Participants unanimously agreed that taking these steps toward transitioning significantly improved the quality of their lives. Transitioning itself looked very different among participants. The two most widely discussed affirmative interventions were binding and hormone therapy or testosterone shots.

\section{Binding}

Participants each described how they each practiced binding at some point in their transition. For some this was an intermediary step before top surgery, while for others a current practice. Participants described a positive, albeit ambivalent relationship with binding that on one hand reduced dysphoria, made them feel powerful, and provided an alternative to self-harm, but on the other hand was often painful or came with unintended side effects. "Adam" described how binding was one of the firs things he did that solidified his identity as a trans man, noting that the first time he tried it he realized he "wanted it all the time." "Adam" represented the power he feels in binding in Figure 27.

Participants described how early on they would bind with Ace bandages or wear their binders for 16 or more hours a day. This continuous confinement led to increased body acne and damage to their ribcage. For some participants, binding was described as

Figure 27: Image of Binding Taken by "Adam" 


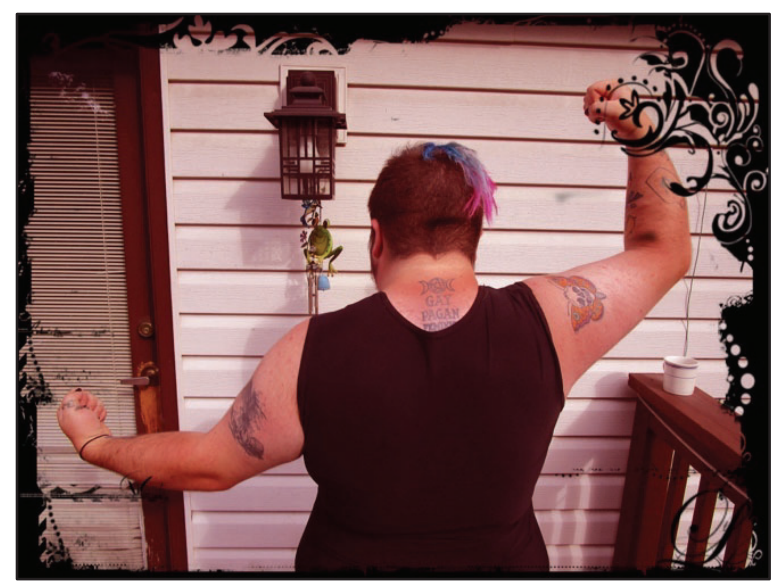

Note. Adam stated, "So binding is something that I've always been in with a love and hate relationship. I love it in the sense that I feel more myself and just more power, but it's also painful, difficult, and I can't do it all the time. So top surgery is one of the biggest things I want right now. It's been really hard to do it, but it does help a little bit every time I do it."

an act of desperation, a necessary action to reduce their dysphoria. "Charlie" spoke about how he "had no alternative" that binding was, "keeping me alive."

\section{Testosterone}

All twelve of the original participants had pursued hormone therapy in the form of testosterone shots (see Figure 28). One participant had discontinued hormone therapy for undisclosed health reasons. Participants spoke at length about both the positive and negative effects of initiating testosterone, noting they experienced a "second puberty" with considerable changes that equalized after approximately two years. Effects were mainly positive and included both increased confidence, pride, and a greater sense of control. Participants described physiological changes they desired including increased facial and body hair, squaring of the jawline, a deepening of the voice, and increased libido. "Collin" described how initiating testosterone therapy was a form of empowerment:

Figure 28: Photo taken by participant Thomas 


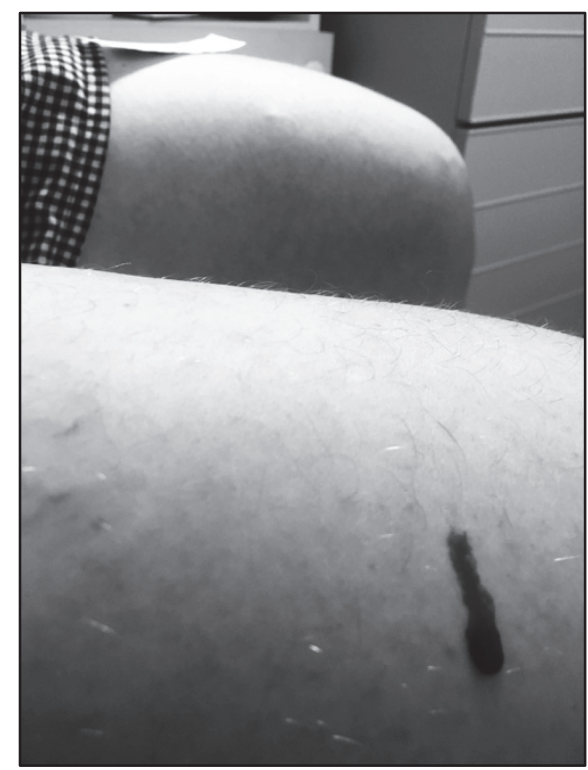

Note. Adam shared, "... doing the shot like every two weeks, I am like, taking action to show that I am in control of this."

I've read online about stories about people being like, being psyched out about their shots, where they have to have somebody else do it for them, which is honestly totally fine, but I don't see a lot of people being like yeah it hurts but also this is part of what it is. I am totally proud of myself when I do my shots and it feels like I've spent a lot of my life not taking control of my health and body and choices. Transitioning was like a big decision for me, to be like, actually I have to start to take control of my life.

Participants additionally described fewer desirable changes included male pattern baldness, sore throat, increased premenstrual symptoms during the first year, excessive perspiration, and intense body odor. Several participants spoke at length about struggling with acne breakouts that were worse than what they experienced during their "first adolescence." Participants described that they largely learned about testosterone from the internet, noting that there is a lot of misinformation being circulated. Participants used the focus group time to share 
information with one another about how testosterone can be administered trans dermally, the availability of free hormone therapy at the local Planned Parenthood, and "African black soap" is the best treatment for acne. Participants identified that they had wished they had someone who could have prepared them for all of the changes they would experience when they initiated testosterone treatment.

\section{Trustworthiness of the Data Analysis}

Credibility was attempted through prolonged engagement, member checks, and triangulation. Triangulation was achieved through the use of multiple data sources including focus group interviews, transcripts, participant photographs, participant's initial data analysis, field notes, and researcher memos. Data analysis was additionally triangulated by having a second researcher code transcripts individually.

The focus group meetings took place over the course of five weeks, and email communication was maintained over the next six months in order to plan multiple venues for sharing the work with community stakeholders. Through these interactions the researcher attempted to build rapport and foster a relationship of mutual trust and respect (Creswell, 2008; Glesne, 1999; Shenton, 2004). Member checks were conducted both during and after the Photovoice meetings. Participants were given the opportunity to review their captions in order to confirm the accuracy of their statements.

At the time of this dissertation defense, the plan was to share these findings with attendees at the Summit to Improve Transgender Healthcare (STITCH) in Columbia, MO, which had been scheduled for April 2020. Given the COVID-19 pandemic, however, that event was postponed until next year. The plan will be to present it at that time. 
The robust and detailed account of the researcher's experiences during data collection includes specific connections to social and cultural contexts, thorough description of recruitment, data collection procedures, participant photographs, participant captions and other contextual information. This information should assist the reader in determining the transferability of research findings to their own scholarly or environmental contexts (Glesne, 1999; Shenton, 2004).

\section{Chapter 5}

\section{DISCUSSION}

The purpose of this study was to explore the influence of role models in the identity development of trans men. Through the use of Photovoice - a methodology based on a 
constructivist paradigm - I was able to identify key themes related to the experience of trans men in Mid-Missouri. Images and personal narratives collected by eleven transgender men reveal areas of perceived strengths and challenges relating to role models.

Specifically, based on these analyses grounded in Community-Based Participatory Research, I identified eight dominant themes from the interviews that I conducted. Themes included Bravery, Acceptance, Advocacy, Invisibility, Inaccessibility, Trans Enough?, Isolation, and Constructing Masculinity. Transgender and gender non-conforming people face significant health disparities, resulting from stigma, discrimination and violence. Given that positive role models might mitigate gender minority stress experienced by trans men, it is important to improve our understanding of the nature of role model influence.

\section{Bravery in the Face of Adversity}

First, the participants identified the bravery that is required - whether or not one wants to be brave- to disclose their transgender identity and to take the steps necessary to confirm their identity. Coming-out, transitioning, and advocating for others takes considerable courage.

Pursuing authenticity as a trans man means confronting many real fears including family disappointment and rejection, societal judgement and invalidation, discrimination and outright violence (Bocking et al., 2013; Hendricks \& Testa, 2012; Lick et al., 2013). Everyday activities like using a public restroom, entering a swimming pool, or interacting with one's children are situations that invite public scrutiny and personal dysphoria.

Participants recognized that their increased level of risk made them vulnerable and that this vulnerability can be used as a strength. By sharing one's experiences of adversity, including their feelings and mistakes, participants perform daily acts of psychological bravery. Modeling this vulnerability gives others trans individuals permission to be confused and to struggle, and it 
reassures others that they can overcome these challenges. While participants value bravery and authenticity witnessed in their community, they also acknowledge that not all trans men have the resources and privilege to live out and as their "true selves". Participants additionally identified that there is a shortage of identifiable role models in media representation, noting that they would like to see trans male role models who are more like them and who are willing to show vulnerability.

\section{Acceptance}

Second, the participants described the role that self-acceptance places in their "gender identity journey." Participants described this journey as a process of self-understanding and selfacceptance. Participants described having to cultivate significant self-insight in order to accept who they are. They described how acceptance is also a form of recognition and support they can provide to others in their community. Participants who identified accepting family members were additionally more likely to identify these family members as their personal role models and to view these role models as possessing qualities they wished to emulate. Those participants who endorsed less family acceptance, also identified family members who were no longer living as role models who would have shown acceptance .

Much like transitioning was identified as an ongoing process, family acceptance was viewed as a process in which family members came to terms with participant's coming out and even grieved the loss of the participant's former identity. Several participants identified fears surrounding family rejection as a primary reason they delayed coming out and/or transitioning.

\section{Invisibility}

Third, Participants identified how the absence of clear and accurate information made publicly available and visible broadcasted has led to considerable misinformation and 
misunderstanding about the trans masculine community. They noted that this misunderstanding perpetuates fear in both trans cisgender communities. Misinformation included conflating sexual orientation with gender identity, concluding that gender dysphoria is a phase, and that testosterone is responsible for increased anger or violence. Participants additionally endorsed experiencing prolonged dysphoria and gender identity ambivalence due to the absence of visible and affirmative role models.

These reports confirm that increasing visibility and affirmation of TGNC youth in public institutions like schools may facilitate self-understanding and acceptance at an earlier age (Austin, 2016). While participants agreed that they desired increased visibility of trans masculine role models, these concerns included fears for their physical safety, loss of privacy, feeling illequipped to be idols, or feeling too self-conscious to have others look up to them. This experience describes another form of invisibility or identity invalidation that interferes with human's basic social desire to have their sense of self mirrored in other's eyes (Devor, 2004)

\section{Inaccessibility}

Fourth, the participants described the barriers to accessing resources necessary to assist with their transition. Barriers to accessing resources was a considerable theme throughout focus group discussions. Inaccessible resources included information, healthcare, and role models themselves. Participants talked about how their personal role models were often found in fictional book characters or transmasculine internet celebrities. These role models were insufficient because they lacked interactional mentorship, lacked vulnerability and because they put pressure on other transmen to strive for an unattainable physical ideal. Inaccessibility was an even greater challenge for participants who were lower SES, over 30 years-old, or who came-ofage in rural/religiously conservative regions. 


\section{Trans Enough?}

Fifth the participants disclosed the continued sense that they were failing to fulfill some nebulous understanding of what it means to be "masculine enough." Participants identified how they struggled with feelings of inadequacy and insecurities about whether or not they were "Trans Enough.” Reported challenges included having to convince others of their seriousness and commitment to being TGNC, adopting a universal "wrong body" narrative, and attempting to live up to unattainable standards of a transmasculine embodiment.

Participants reported experiencing stress from implicit expectations to prove their "transness". Members described feeling invalidated when their personal experiences did not align with the dominant identity development narrative and "less than" when they were not as physically fit, knowledgeable, or well-adjusted as other trans role models appeared. While the influence of positive role models has the potential to foster resilience and self-worth (Dasgupta, 2011; Morgenroth, 2010), it seems having too few role models or role models that are flawless in their example may actually serve to impair trans men's feelings of social belonging.

\section{Isolation \& Advocacy}

Sixth, the participants shared the degree to which they felt isolated in their genderidentity journey and the need for them to advocate for themselves, and for future generations. Participants described their gender identity journeys as ongoing lonely expeditions. Isolation was often experienced in tandem with anxiety, depression, self-harm, and suicidality. Isolation related adversity was more pronounced among participants who were older, lower SES, and came-of-age in towns with conservative political and religious ideologies. Isolation was related to fears surrounding coming out, family disappointment or rejection, societal condemnation and physical safety. Isolation was additionally experienced due to an absence of identifiable 
transmasculine role models and mentors. Having either negative self-comparisons or an absence of social identification influenced participants feelings alienation and ostracization (Tajfel, 1979).

Each participant identified how their personal experiences of hardship, influenced their desire to advocate for other trans men. This advocacy looked like public activism, sharing information, displaying symbols of solidarity, and modeling a healthy masculinity. Participants preferred the term advocate to the term role model, citing how it was a "humbler" term. In their advocacy participants sought to be approachable, caring, supportive, allies, and people who were accessible listeners and conversation partners.

\section{Constructing Masculinity}

Finally, the participants identified the difficulties in understanding and then fulfilling what the norms are for masculine men to fulfill in the U.S. Participants described a complex and highly individualized process of constructing their physical, psychological, and social identities while simultaneously re-defining the norms and ideals of masculine expression. Transgender identity development is a complex intrapersonal and interpersonal process of constructing one's self-concept (Devor, 2004). Establishing a positive masculine identity requires identifying role models to emulate, practicing a gendered enactment, and responding to societal feedback via rewards and sanctions (Bussey \& Bandura, 1999). Without visible, accessible, and identifiable role models, trans men have a harder time establishing their identities, navigating hardships, and are more likely internalize experiences of gender related rejection and victimization (Testa et al., 2015). 


\section{Limitations}

While this project contains rich and valuable data on the experiences of transgender men in Missouri, some important limitations of this study should be noted. First, the study sample presents limitations to generalizability of findings. This sample is highly specific: transgender men living in Missouri. In addition to being highly specific, the size of the current sample $(N=$ 11 ) is small and not sufficient to make claims about the larger transgender community as a whole. Focusing solely on transmasculine experiences provides a glimpse into the lived experiences of a very specific group of gender non-conforming individuals. Future research with larger samples of TGNC individuals across the U.S. would add to the findings of this study. The sample was also contingent upon people whom the researcher had access to. Ideally, the participant group would have been more homogenous, in particular in relation to age.

Opening a second focus group via Zoom allowed three additional participants to take part in the study who would have been otherwise unable to participate. While this virtual group made the project more accessible to additional voices, the group discussions may have been more robust if there were at least seven members in each group (Wang \& Burris, 1997). Additionally, the remote group did not appear to build as much rapport as the in-person group. This may be due to the remote nature of web conferencing, as well as some technical issues related to participant bandwidth which caused interruptions in conversation.

The final limitation was an unforeseen pandemic (COVID-19) which has thus far limited participants' ability to showcase their work publicly. The group had a confirmed a showcase of participant photos at both the Summit to Improve Transgender Healthcare (STITCH) and via Hickman High School's newspaper. The closure of Columbia Public Schools and postponement of the conference has put a hold on participant's reaching a wider public audience. 
Notwithstanding these limitations, there are some important implications for future research, clinical practice, and for advancing the public interest. I now turn to these implications.

\section{Implications for Future Research}

Much of the literature on transgender individuals is conducted with clinical populations and focuses on phenomenon related to victimization, minority stress, and resulting health disparities (Austin, 2016; Holtby et al., 2015)). Transgender men are a resilient population that has shown courage in the face of adversity. Future research studies informed by positive psychology could explore the unique strengths that serve as protective factors for TGNC individuals. The role of advocacy might be particularly relevant, given that participants have identified the empowerment they experience when advocating for others. Advocacy might also be conceptualized as a form of philanthropy that contributes to a meaningful life (Konrath, 2014).

Additional quantitative studies on TGNC role models might assess more specific information on how many role models are real people, how many are fictional characters, and how many are celebrities. A quantification of general traits may help to develop a deeper understanding about who are and who are not the people that participants look up to. This information could be used by practitioners or those wishing to fulfill roles as advocates. Finally, identifying how role models and their functions change at different stages in TGNC people's lives may better illustrate what role model responsibilities are most valued.

Psychologists should continue to research transgender issues, and in particular bridge the gap in research on trans men's issues. Future researcher should explore other factors which contribute to positive identity development among trans men such as the role of family acceptance across family members. 


\section{Implications for Practice and Policy}

Transgender and gender non-conforming TGNC individuals are an increasing demographic with unique healthcare needs. (Nolan, 2019) As more transgender individuals present to psychotherapy (APA, 2009), psychologists need to be equipped in providing culturally competent and trans affirmative services. First, psychologists are encouraged to consider indications by this and other studies that family acceptance is a considerable protective factor for LGBT youth, predictive of greater self-esteem, social support and mental and physical health outcomes(Klein \& Golub, 2016; Pflum et al., 2015). As such, psychologists should be equipped to provide family therapy and early interventions to promote parental and caregiver acceptance (Pariseau, 2019; Ryan et al., 2010; Toomey et al., 2010). Given that positive role models have the potential to mitigate some of the minority stress experienced by TGNC individuals, therapists should assist in activating trans men's social supports, including mentors in their local LGBT community.

Psychologists should additionally be aware of how pervasive experiences of isolation are for TGNC individuals and assess for other comorbid mental health concerns including anxiety. depression, self-harm and suicidal ideation. Interventions should include affirmation, activation of social supports and partnering with resources, and partnering with resources

Results of this study should also be applied to public policy. Psychologists are encouraged to act as social justice advocates outside their counseling offices and press for equitable legislative policies (Fouad, Gerstein, \& Toporek, 2016). School policies should not only incorporate explicit protections for transgender students against harassment, bullying and discrimination, they should provide education about gender expression to LGBT issues to students, staff, administrators, and teachers. In addition, schools should be equipped with gender- 
neutral bathroom options for students, teachers, and staff, and should refrain from gendered segregation in practices such as school uniforms, school dances, and extracurricular activities (Kosciw, 2018). Schools additionally might provide opportunities for support or social groups. such as a Gay-Straight-Alliance.

\section{Conclusion}

Despite limitations, study results provide valuable information for psychologists working with trans men/TGNC. First, results underscore the deleterious effects of family rejection, isolation, invisibility and inaccessibility of resources on trans men. These effects include significant rates of depression, anxiety, substance abuse, suicidal ideation, and self-harm. Thus, psychologists working with TGNC individuals should assess the impact of this psychological distress, particularly suicidal ideation. Trans affirmative psychologists should also be able to activate social supports and have a working knowledge of local gender affirming resources, including services related to social, legal, and medical transitioning.

Results confirm that positive role models can mitigate gender minority stress and its associated health disparities (Testa, 2015). Isolation was cited as a universal experience and one that could be alleviated by increased visibility of role models, particularly those that are physically accessible. Given that family members who show acceptance are frequently cited as role models, increased attention should be paid to interventions that facilitate family support, particularly in early adolescence. Additionally, psychologists should consider the important role of authenticity and the pressures faced by trans men to prove themselves in both LGBT and cisgender communities.

Psychologists should be encouraged to think creatively in research and practice with TGNC individuals, including how visual or other creative art interventions might assist 
participants in accessing and articulating complex and sometimes painful experiences. This study additionally highlights the important role that both families and schools have in supporting TCNC youth. Finally, this study highlights resiliency factors including bravery, authenticity and advocacy as a means of empowerment and should reminds psychologists of the importance of using strengths-based approaches. 


\section{References}

Abrams, D., \& Hogg, M. A. (1990). Social identity theory: Constructive and critical advances. Springer-Verlag Publishing.

Aitken, M., Steensma, T.D., Blanchard, R., VanderLaan, D.P., Wood, H., Fuentes, A., Zucker, K.J. (2015). Evidence for an altered sex ratio in clinic-referred adolescents with gender dysphoria. J. Sex. Med. 12 (3), 756-763, http://dx.doi. org/10.1111/jsm.12817.

Abelson, Miriam. (2014). Dangerous privilege: Trans men, masculinities, and changing perceptions of safety. Sociological Forum 29 (3): 549-70

Alessi, Edward J. (2013). Acknowledging the impact of social forces on sexual minority clients: introduction to the special issue. Clinical Social Work Journal, 41,223227. doi:10.1007/s10615-013-0458-X

American Psychological Association. (2012). Guidelines for Psychological Practice with Lesbian, Gay, and Bisexual Clients. American Psychologist, 67(1), 10-42. doi: $10.1037 / \mathrm{a} 0024659$

American Psychological Association. (2009, January 1). Report of the APA Task Force on Gender Identity and Gender Variance. http://www.apa.org/pubs/info/reports/genderidentity

Arcelus, J., Bouman, W. P., Van Den Noortgate, W., Claes, L., Witcomb, G., \& Fernandez-Aranda, F. (2015). Systematic review and meta-analysis of prevalence studies in transsexualism. European psychiatry : the journal of the Association of European Psychiatrists, 30(6), 807-815. https://doi.org/10.1016/j.eurpsy.2015.04.005

Asgari, S. , Dasgupta, N. , Cote, N. G. (2010). When does contact with successful ingroup members change self-stereotypes?: A longitudinal study comparing the effect of quantity 
vs. quality of contact with successful individuals. Social Psychology, 41, 203-211. https://doi.org/10.1027/1864-9335/a000028

Austin, A. (2016). "There I am": A grounded theory study of young adults navigating a transgender or gender nonconforming identity within a context of oppression and invisibility. Sex Roles, 75, 215-230. http://dx.doi.org/10.1007/s11199-016-06007

Austin, A., \& Craig, S. L. (2015). Transgender affirmative cognitive behavioral therapy: clinical considerations and applications, Professional Psychology: Research and Practice. 46 (1), 21-29 doi.org/10.1037/a0038642

Aviles, G. (2019, February 27). Missouri supreme court extends LGBTQ protections in rulings. Retrieved from https://www.nbcnews.com/feature/nbc-out/missouri-supremecourt-extends-lgbtq-protections-rulings-n977361

Baker K. E. (2017). The Future of Transgender Coverage. The New England journal of medicine, 376(19), 1801-1804. https://doi.org/10.1056/NEJMp1702427.

Bandura A. (1971), Social Learning Theory, New York: General Learning Press.

Bandura, A. (1989). Human agency in social cognitive theory. Amer- ican Psychologist, 44, 1175-1184.

Bandura, A., and R. H. Walters. 1963. social learning and personality development. New York: Holt, Rinehart and Winston.

Bandura, A. (1996). Self-efficacy: The exercise of control. New York: Freeman.

Baum, F., MacDougall, C., \& Smith, D. (2006). Participatory action research. Journal of epidemiology and community health, 60(10), 854-857. https://doi.org/10.1136/jech.2004.028662

Beemyn, G., \& Rankin, S. (2011). The lives of transgender people. Columbia University Press. 
Bussey, K., \& Bandura, A. (1999). Social cognitive theory of gender development and differentiation. Psychological Review, 106, 676-713.

Budge, S. L., Adelson, J. L., \& Howard, K. A. S. (2013). Anxiety and depression in transgender individuals: The roles of transition status, loss, social support, and coping. Journal of Consulting and Clinical Psychology, 81, 545-557.

Beauchamp, T. (2009). Artful concealment and strategic visibility: Transgender bodies and US state surveillance after 9/11. Surveillance \& Society, 6(4), 356-366.

Beemyn, B., Curtis, B., Davis, M., \& Tubbs, N. J. (2005). Transgender issues on college campuses. In R. L. Sanlo (Ed.), Gender identity and sexual orientation: Research, policy, and personal perspectives (New Directions for Student Services, No. 111; pp. 49-60). San Francisco: Jossey-Bass

Beemyn, Genny and Susan Rankin. 2011. The Lives of Transgender People. New York, NY: Columbia University Press.

Bess, J. A., \& Stabb, S. D. (2009). The experiences of transgender persons in psychotherapy: Voices and recommendations. Journal of Mental Health Counseling, 31, 264-282.

Billings, A. G. \& Moos R. H. (1980). The role of coping responses and social resources in attenuating the stress of life events. Journal of Behavioral Medicine, 4(2), 139-157. doi:// 10.1007/BF00844267

Bockting, W. O., Miner, M. H., Swinburne Romine, R. E., Hamilton, A., \& Coleman, E. (2013). Stigma, mental health, and resilience in an online sample of the US transgender population. American Journal of Public Health, 103, 943-951. http://dx.doi.org/10.2105/AJPH.2013.301241 
Bogdan, R. C., \& Biklen, S. K. (1982). Qualitative research for education: An introduction to theory and methods. Boston: Allyn and Bacon, Inc.

Bornstein, K. (1995). Gender outlaw: On men, women, and the rest of us. New York: Vintage Books.

Borrelli, B., Sepinwall, D., Ernst, D., Bellg, A. J., Czajkowski, S., Breger, R., DeFrancesco, C., Levesque, C., Sharp, D. L., Ogedegbe, G., Resnick, B., \& Orwig, D. (2005). A new tool to assess treatment fidelity and evaluation of treatment fidelity across 10 years of health behavior research. Journal of consulting and clinical psychology, 73(5), 852-860. https://doi.org/10.1037/0022-006X.73.5.852

Brisbane, A. (1911, March 28). Speakers give sound advice. Syracuse Post Standard, page 18 .

Brown, R. D., Clarke, B., Gortmaker, V., \& Robinson-Keilig, R. (2004). Assessing the campus climate for gay, lesbian, bisexual, and transgender (GLBT) students using a multiple perspectives approach. Journal of College Student Development, 45, 8-26.

Brustad, R. J., \& Partridge, J. A. (2002). Parental and peer influences on children's psychosocial development through sport. New York: Wiley.

Budge, S. L., Adelson, J. L., \& Howard, K. A. S. (2013). Anxiety and depression in transgender individuals: The roles of transition status, loss, social support, and coping. Journal of Consulting and Clinical Psychology, 81, 545-557.

Burnes, T.R, Singh, A. A., Harper, A. J., Harper, B., Maxon-Kann, W., Pickering, D. L., Moundas, S., Scofield, T. R., Roan, A., \& Hosea, J. (2010). American Counseling Association: competencies for counseling with transgender clients. Journal of LGBT Issues in Counseling, 4(3-4), 135-159. 
Burgess, C. (2000). Internal and external stress factors associated with the identity development of transgendered youth. Journal of Gay \& Lesbian Social Services, 10(3-4), $35-47$.

Calhoun, C. J. (2010). Robert K. Merton: Sociology of Science and Sociology as Science. Columbia University Press. Retrieved from http://cup.columbia.edu/book/978-0-231-

\section{$\underline{15112-2 / \text { robert-k-merton }}$}

Carroll, L., Gilroy, P.J., Ryan, J. (2002). Counseling Transgendered, Transsexual, and Gender-Variant Clients. Journal of Counseling \& Development, 80 (2), 131-139. doi://10.1002/j.1556-6678.2002.tb00175.x

Catalani, C., \& Minkler, M. (2010). Photovoice: a review of the literature in health and public health. Health Education \& Behavior, 37 (3), 424-451.

Catalano, D. C. J. (2014). "Welcome to Guyland: Experiences of Trans* Men in College" Doctoral Dissertation. Retrieved from https://scholarworks.umass.edu/dissertations_2/60

Catalano, D. C. J. (2015). “Trans enough?” The pressures trans men negotiate in higher education. TSQ: Transgender Studies Quarterly, 2, 411-430

Charmaz, K. (2006). Constructing grounded theory: A practical guide through qualitative analysis. Thousand Oaks, CA: Sage.

Chavarria, M. C., Sánchez, F. J., Chou, Y-Y., Thompson, P. M., \& Luders, E. (2014). Puberty in the corpus callosum. Neuroscience, 265, 1-8. doi: 10.1016/j.neuroscience.2014.01.030

Connell, R. W. (2005). Masculinities (2nd ed.). Polity Press.

Corbin, J. M., \& Strauss, A. (1990). Grounded theory research: Procedures, canons, and evaluative criteria. Qualitative sociology, 13(1), 3-21.

Cruz T. M. (2014). Assessing access to care for transgender and gender nonconforming 
people: a consideration of diversity in combating discrimination. Social science \& medicine (1982), 110, 65-73. https://doi.org/10.1016/j.socscimed.2014.03.032

Currah, P., \& Minter, S. (2003). Transgender equality: A handbook for activists and policy makers. Washington, DC: National Gay and Lesbian Task Force Policy Institute/ National Center for Lesbian Rights.

Dasgupta, N. (2011). Ingroup experts and peers as social vaccines who inoculate the selfconcept: The stereotype inoculation model. Psychological Inquiry, 22(4), 231-246. https://doi.org/10.1080/1047840X.2011.607313

De Cuypere, G., Knudson, G., \& Bockting, W. (2010). Response of the World Professional Association for Transgender Health to the proposed DSM 5 criteria $\backslash$ for gender incongruence. International Journal of Transgenderism, 12(2), 119-123.

Devor, A. H. (2004). Witnessing and mirroring: A fourteen stage model of transsexual identity formation. Journal of Gay \& Lesbian Psychotherapy, 8(1-2), 41-67. https://doi.org/10.1300/J236v08n01_05

Devor, H. (1997b), More than manly women: How female-to-male transsexuals reject lesbian identities. In Gender Blending, eds. B. Bullough, V. Bullough \& J. Elias. Amherst, NY: Prometheus, pp. 87-102

Dickey, L. M. (2012). Non-suicidal self-injury in the transgender community. Dissertation Abstracts International: Section B: The Sciences and Engineering, 73(6-B), 3976.

Doby, J. T. (1975). ROBERT K. MERTON: THE SOCIOLOGY OF SCIENCE (Book). Social Forces, 54(1), 281-282. https://doiorg.proxy.mul.missouri.edu/10.2307/2576098 Dugan, J. P., Kusel, M. L., \& Simounet, D. M. (2012). Transgender college students: An 
exploratory study of perceptions, engagement, and educational outcomes. Journal of College Student Development, 53(5), 719-736. doi:10.1353/csd.2012.0067

Eisner, E. W. (1991). The enlightened eye: Qualitative inquiry and the enhancement of educational practice. New York, NY: Macmillan Publishing Company.

Eggen, P. and Kauchak, D. (1999). Educational Psychology: Windows on Classrooms ( $4^{\text {th }}$ ed.). Prentice Hall.

Erikson, E.H. (1958). Young Man Luther. New York: Norton.

Erikson, E.H. (1968). Identity: Youth and Crisis. New York: Norton.

Faugier, J., \& Sargeant, M. (1997). Sampling hard to reach populations. Journal of Advanced Nursing, 26, 790-797.

Festinger, L. (1954). A theory of social comparison processes. Human Relations, 7, 117 140.

Flores, A.R., Herman, J.L., Gates, G.J., \& Brown, T.N.T. (2016). How Many Adults Identify as Transgender in the United States? Los Angeles, CA: The Williams Institute.

Foreman, M., Hare, L., York, K., Balakrishnan, K., Sánchez, F. J., Harte, F., ... Harley, V. (2019). A genetic link between gender dysphoria and sex hormone signaling. Journal of Clinical Endocrinology \& Metabolism, 104, 390-396. doi: 10.1210/jc.2018-01105

Fouad, N. A., Gerstein, L. H., \& Toporek, R. L. (2006). Social justice and counseling psychology in context. In R. L. Toporek, L. H. Gerstein, N. A. Fouad, G. Roysircar, \& T. Israel (Eds.), Handbook for social justice in counseling psychology: Leadership, vision, and action (pp. 1-16). Thousand Oaks, CA: Sage.

Freire, P. (1982). Creating alternative research methods: Learning to do it by doing it. Creating knowledge: A monopoly, 29-37. 
Freire, P. (1973). Education for critical consciousness. New York: Seabury Press.

Frost, D. M. (2011). Stigma and intimacy in same-sex relationships: a narrative approach. Journal of Family Psychology, 25 (1), 1-10. doi: 0.1037/a0022374

García, R. (Director). (2011). Albert Nobbs [Film]. Mockingbird Pictures.

Gerbner, G., \& Gross, L. (1976). Living with television: The violence profile. Journal of Communication, 26(2), 172-199. https://doi.org/10.1111/j.1460-2466.1976.tb01397.x

Gerbner, G., Gross. L., Morgan, M., \& Signorielli, N. (1982). Charting the mainstream: Tele• vision's contributions to political" orientations. Journal of Communication, 32(2), 100 127.

GLAAD. (2014). Victims or villains: examining ten years of transgender images on television. Retrieved from https://www.glaad.org/publications/victims-or-villains-examining-tenyears-transgender-images-television

GLAAD. (2018). Where we are on tv: GLAAD's annual report on LGBTQ inclusion. Retrieved from http://glaad.org/files/WWAT/WWAT_GLAAD_2017-2018.pdf

Glesne, C. (1999). Becoming Qualitative Researchers: An Introduction. New York, NY: Longman.

Goldblum, P., Testa, R. J., Pflum, S., Hendricks, M. L., Bradford, J., \& Bongar, B. (2012). The relationship between gender-based victimization and suicide attempts in transgender people. Professional Psychology: Research and Practice, 43(5), 468475. https://doi.org/10.1037/a0029605

Grant, J. M., Mottet, L. A., Tanis, J., Herman, J. L., Harrison, J., \& Keisling, M. (2010). 
National Transgender Discrimination Survey Report on health and health care. National Center for Transgender Equality and National Gay and Lesbian Task Force. Washington, DC, 123.

Green, J. (2000). Introduction to transgender issues. In P. Currah \& S. Minter (Eds.), Transgender equality: A handbook for activists and policy makers (pp. 1-12). Washington, DC: The Policy Institute of the National Gay and Lesbian Task Force.

Green, J. (2004). Becoming a visible man. Nashville, TN: Vanderbilt University Press. Green, J. (2005). Part of the package: Ideas of masculinity among male-identified trans people. Men and Masculinities, 7(3), 291-299.

Green, J. (2006). Look! No, don’t! The visibility dilemma for transsexual men. In S. Stryker \& S. Whittle (Eds.), The transgender studies reader (pp. 499-508). New York: Routledge. Haas, Ann P., Philip L. Rodgers \& Jody L. Herman. 2014. Suicide Attempts among Transgender and Gender Non-Conforming Adults. Los Angeles, CA: The Williams Institute and American Foundation for Suicide Prevention. Retrieved from https://williamsinstitute.law.ucla.edu/wp-content/uploads/AFSP-Williams-Suicide$\underline{\text { Report-Final.pdf }}$

Hall BL: From margins to center: The development and purpose of participatory action research. Am Sociologist 23:15-28, 1992

Halberstam, J. (2005). In a queer time and place: Transgender bodies, subcultural lives. New York: New York University Press.

Heck, N. C., Croot, L. C., \& Robohm, J. S. (2013). Piloting a Psychotherapy Group for Transgender Clients: Description and Clinical Considerations for Practitioners. Professional Psychology: Research \& Practice, 46 (1), 30 36.doi://org/10.1037/a0033134 
Hegland, J. E. \& Nelson, N. J. (2002). Cross-dressers in cyberspace. Exploring the Internet as a tool for expressing gender identity. International Journal of Sexuality \& Gender Studies.7 $(2 / 3), 139-161$.

Hendricks, M. L., \& Testa, R. J. (2012). A conceptual framework for clinical work with transgender and gender nonconforming clients: An adaptation of the Minority Stress Model. Professional Psychology: Research and Practice, 43(5), 460-467.

\section{http://dx.doi.org/10.1037/a0029597}

Hill, C. E., Knox, S., Thompson, B. J., Williams, E. N., Hess, S. A., \& Ladany, N. (2005). Consensual qualitative research: An update. Journal of Counseling Psychology, $52,196-205$.

Hill, C. E., Thompson, B. J., \& Williams, E. N. (1997). A guide to conducting consensual qualitative research. The Counseling Psychologist, 25, 517-572.

Hill, D.B. (2004, July). Coming to terms: Using technology to know identity. Paper presented at the $112^{\text {th }}$ Annual Convention of the American Psychological Association, Honolulu, HI.

Hoepfl, M. C. (1997). Choosing qualitative research: A primer for technology education researchers. Journal of Technology Education, 9(1), Article 4. Retrieved 12 January 2009, from http://scholar.lib.vt.edu/ejournals/JTE/v9n1/hoepfl.html

Holtby, A., Klein, K., Cook, K., \& Travers, R. (2015). To be seen or not to be seen: Photovoice, queer and trans youth, and the dilemma of representation. Action Research, 13(4), 317335.

Israel, B. A., Parker, E. A., Rowe, Z., Salvatore, A., Minkler, M., López, J., Butz, A., Mosley, A., Coates, L., Lambert, G., Potito, P. A., Brenner, B., Rivera, M., Romero, H., Thompson, B., Coronado, G., \& Halstead, S. (2005). Community-based participatory 
research: lessons learned from the Centers for Children's Environmental Health and Disease Prevention Research. Environmental health perspectives, 113(10), 1463-1471. https://doi.org/10.1289/ehp.7675

Israel, T. (2005). ... and sometimes T: Transgender issues in LGBT psychology. Newsletter of the Society for the Psychological Study of Lesbian, Gay, and Bisexual Issues, $21(3), 16-18$.

Jaffe, J. M., Lee Y-E Huang, L., \& Oshagan, H. (1995). Gender, Pseudonyms, and CMC: Masking identities and baring souls. Paper submitted for presentation at the $45^{\text {th }}$ Annual Conference of the International Communication Association, Albuquerque, NM. Retrieved March 25, 2005, from http://members.iworld.net/yesunny/genderps.html James, S. E., Herman, J. L., Rankin, S., Keisling, M., Mottet, L., \& Anafi, M. (2016). The Report of the 2015 U.S. Transgender Survey. Washington, DC: National Center for Transgender Equality.

Keller, Colleen; Fleury, Julie; Perez, Adrianna; Ainsworth, Barbara \& Vaughan, Linda (2008). Using visual methods to uncover context. Qualitative Health Research, 18(3), 428-436.

Kemmis, S., \& McTaggart, R. (2005). Participatory action research: Communicative action and the public sphere. Sage Publications Ltd.

Kemmis, S., McTaggart, R., \& Nixon, R. (2013). The action research planner: Doing Critical participatory action research. Springer Science \& Business Media.

Khan L. (2011). Transgender health at the crossroads: legal norms, insurance markets, and the threat of healthcare reform. Yale journal of health policy, law, and ethics, 11(2), $375-418$. 
Klein, K., Holtby, A., Cook K., \& Travers, R. (2015) Complicating the Coming Out Narrative: Becoming Oneself in a Heterosexist and Cissexist World, Journal of Homosexuality, 62:3, 297-326, DOI: 10.1080/00918369.2014.970829

Klein, A., \& Golub, S. A. (2016). Family rejection as a predictor of suicide attempts and substance misuse among transgender and gender nonconforming adults. LGBT Health, 3, 193-199.

Konrath, S. (2014). The power of philanthropy and volunteering. In F. Huppert \& C. Cooper (Eds.), Wellbeing: A complete reference guide. Volume VI, Interventions and policies to enhance wellbeing. (pp. 387-426). Chichester: Wiley Press

Kosciw, J. G., Greytak, E. A., Giga, N. M., Villenas, C., \& Danischewski, D. J. (2016). The 2015 national school climate survey: The experiences of lesbian, gay, bisexual, transgender, and queer youth in our nation's schools. New York, NY: GLSEN. Retrieved from https://www. glsen.org/article/2015-national-school-climate-surve

Kozee H. B., Tylka, T. L., \& L. Andrew, B. (2015). Measuring transgender individuals comfort with gender identity and appearance: development and validation of the transgender congruence scale. Psychology of Women Quarterly, 36 (2), 179-196. doi:// $10.1177 / 0361684312442161$.

Laird, Pamela Walker (2006). Pull: Networking and Success since Benjamin Franklin. Cambridge: Harvard University Press. ISBN $\underline{9780674025530 .}$

Latz, A. O. (2017). Photovoice research in education and beyond: A practical guide from theory to exhibition. New York: Routledge.

Lev, A. I. (2007). Transgender communities: Developing identity through connection. In K. J. Bieschke, R. M. Perez, \& K. A. DeBord (Eds.), Handbook of counseling and 
psychotherapy with lesbian, gay, bisexual, and transgender clients (pp. 147-175).

Washington, DC: American Psychological Association.

Levant, R. F., \& Richmond, K. (2016). The gender role strain paradigm and masculinity ideologies. In Y. J. Wong \& S. R. Wester (Eds.), APA handbooks in psychology series. APA handbook of men and masculinities (pp. 23-49). Washington, DC, US: American Psychological Association. http://dx.doi.org/10.1037/14594-002

Levant, R. F., \& Wong, Y. J. (Eds.). (2017). The psychology of men and masculinities. American Psychological Association.

Levitt, H. M., \& Ippolito, M. R. (2014). Being transgender: The experience of transgender identity development. Journal of Homosexuality.

Lewin, K. (1946) Action research and minority problems. Journal of Social Issues, 2 (4), $34-46$.

Lim, M. (2012). If I can be myself, I can do anything: A Photovoice exploration of the experiences of transgender college students. Retrieved from: WorldCat.org database.

Lincoln, Y., Guba, EG. (2005). Paradigmatic controversies, contradictions, and emerging confluences. In N. K. Denzin \& Y. S. Lincoln (Eds.), The SAGE handbook of qualitative research (3rd ed., pp. 163 - 188). Thousand Oaks, CA: Sage Publications.

Lockwood, P., Jordan, C. H., \& Kunda, Z. (2002). Motivation by positive or negative role models: Regulatory focus determines who will best inspire us. Journal of Personality and Social Psychology, 83(4), $854-864$. 
Lombardi, E. L., Wilchins, R. A., Priesing, D., \& Malouf, D (2001). Gender violence: Transgender Experiences with Violence and Discrimination. Journal of Homosexuality, 42(1), 89-101.

López, E. D. S., Eng, E., Randall-David, E., \& Robinson, N. (2005). Quality-of-Life Concerns of African American Breast Cancer Survivors Within Rural North Carolina: Blending the Techniques of Photovoice and Grounded Theory. Qualitative Health Research, 15(1), 99 115. https://doi.org/10.1177/1049732304270766

Lovelock, M. (2017). Acceptance, humanity and emotional excess: The politics of queer suffering in Big Brother UK. European Journal of Cultural Studies, 20(4), 449-463. https://doi.org/10.1177/1367549415603377

Luders, E., Sánchez, F. J., Tosun, D., Shattuck, D. W., Gaser, C., Vilain, E., \& Toga, A. (2012). Increased cortical thickness in male-to-female transsexualism. Journal of Behavioral \& Brain Science, 2(3), 357-362. https://doi.org/10.4236/jbbs.2012.23040

MacCallum, J., \& Beltman, S. (2002). Role models for young people: What makes an effective role model program? Tasmania: National Youth Affairs Research Scheme, 19-108.

Mamary, E., McCright, J., \& Roe, K. (2007). Our lives: An examination of sexual health issues using Photovoice by non-gay identified African-American men who have sex with men. Culture, Health \& Sexuality, 9(4), 359-370.

Manning, J. (2017). In vivo coding. In Matthes, J. (Ed.), The international encyclopedia of communication research methods. New York, NY: Wiley-Blackwell. Retrieved from https://doi.org/10.1002/9781118901731.iecrm0270 
Matheson, K., \& Zanna, M.P. (1992). Computer-mediated communications: The focus is on me. Social Science Computer Review, 8, 1-12.

McInerney, D. M. and McInerney, V. (2002). Educational Psychology: Constructing Learning (3rd ed.). Prentice Hall.

McKinley, J. (2015). Critical argument and writer identity: Social constructivism as a theoretical framework for EFL academic writing. Critical Inquiry in Language Studies, 12, 184-207

Mckinley, C. J., Luo, Y., Wright, P.J., \& Ashley, K. (2015). Reexamining lgbt resources on college counseling center websites: an over-time and cross-country analysis, Journal of Applied Communication Research, 43 (1), 112-129. doi:// 10.108000909882 .2014 .982681

McIntyre, R. B., Paulson, R. M., Taylor, C. A., Morin, A. L., \& Lord, C. G. (2011). Effects of role model deservingness on overcoming performance deficits induced by stereotype threat. European Journal of Social Psychology, 41(3). 301-311. https://doi.org/10.1002/ejsp.774

McLemore, K. A. (2015). Experiences with misgendering: Identity misclassification of transgender spectrum individuals. Self and Identity, 14, 51-74. doi:10.1080/15298868.2014.950691

Meerwijk, E. L., \& Sevelius, J. M. (2017). Transgender population size in the United States: A meta-regression of population-based probability samples. American Journal of Public Health, 107, e1-e8.

Meyer I. H. (2003). Prejudice, social stress, and mental health in lesbian, gay, and bisexual populations: conceptual issues and research evidence. Psychological bulletin, 129(5), 674-697. https://doi.org/10.1037/0033-2909.129.5.674 
Meyer, I. H. (2013). Prejudice, social stress, and mental health in lesbian, gay, and bisexual populations: conceptual issues and research evidence. Psychology of Sexual Orientation and Gender Diversity, 1 (S) 3-26. doi: 0.1037/2329-0382.1.S.3

Meyerowitz, J. (2002). How sex changed: A history of transsexuality in the United States. Cambridge, MA: Harvard University Press.

Miller, P. H. (2011). Theories of developmental psychology. New York: Worth Publishers.

Miller, S. J., \& Binder, J. L. (2002). The effects of manual-based training on treatment fidelity and outcome: A review of the literature on adult individual psychotherapy. Psychotherapy: Theory, Research, Practice, Training, 39(2), 184.

Mills, J., Bonner, A., \& Francis, K. (2006). The development of constructivist grounded theory. International journal of qualitative methods, 5(1), 25-35.

Minkler and Wallerstein, ed. (2008). Community-Based Participatory Research for Health: From Process to Outcomes. ISBN 978-0-470-26043-2.

Mitchell, Claudia (2011). Doing visual research. Thousand Oaks, CA: Sage.

Mizock, L., \& Mueser, K. T. (2014). Employment, mental health, internalized stigma, and coping with transphobia among transgender individuals. Psychology of Sexual Orientation and Gender Diversity, 1(2), 146-158. https://doi.org/10.1037/sgd0000029

Moradi, B., Mohr, J. J., Worthington, R. L., \& Fassinger, R. E. (2009). Counseling psychology research on sexual (orientation) minority issues: conceptual and methodological challenges and opportunities. Journal of Counseling Psychology,56 (1), 5-22. doi: 10.1037/a0014572 
Morgenroth, T., Ryan, M. K., \& Peters, K. (2015). The motivational theory of role modeling: How role models influence role aspirants' goals. Review of General Psychology, 19(4), 465-483. https://doi.org/10.1037/gpr0000059

Movement Advancement Project (2020). Missouri's Equality Profile. Retrieved from https://www.lgbtmap.org/equality-maps/profile state/MO

National Center for Education Statistics. U.S. department of education. Retrieved from https://nces.ed.gov/surveys/sass/tables/sass0708_035_s1s.asp

National Center for Transgender Equality (2017). 2015 U.S. Transgender Survey: Missouri State Report. Washington, DC: Author. Available at USTransSurvey.org

Neibergall, N., Swanson, A., \& Sánchez, F. J. (2019). Hormones, sexual orientation, and gender identity. In L. Welling \& T. K. Shackelford (Eds.), The Oxford handbook of evolutionary psychology \& behavioral endocrinology (pp. 201-214). New York: Oxford University Press.

O’Neil, M. E., McWhirter, E. H., \& Cerezo, A. (2008) Transgender identities and gender variance in vocational psychology. Journal of Career Development, 34(3), 286-308. doi:// 10.1177/0894845307311251

NA. (2014). Born this way: Stories of young transgender children. Retrieved from http://www.cbsnews.com/news/born-this-way-stories-of-young-transgenderchildren/

Newfield, E., Hart, S., Dibble, S., \& Kohler, L. (2006). Female-to-male transgender quality of life. Quality of life research : an international journal of quality of life aspects of treatment, care and rehabilitation, 15(9), 1447-1457. https://doi.org/10.1007/s11136006-0002-3 
Newton, J. H. (2001). The burden of visual truth: The role of photojournalism in mediating reality. Mahwah, NJ: Lawrence Erlbaum

Nolan, I. T., Kuhner, C. J., \& Dy, G. W. (2019). Demographic and temporal trends in transgender identities and gender confirming surgery. Translational andrology and urology, 8(3), 184-190. https://doi.org/10.21037/tau.2019.04.09

Nuru, A. K. (2014). Between layers: Understanding the communicative negotiation of conflicting identities by transgender individuals. Communication Studies, 65(3), 281-297.

Padula, W. V., Heru, S., \& Campbell, J. D. (2016). Societal Implications of Health Insurance Coverage for Medically Necessary Services in the U.S. Transgender Population: A Cost-Effectiveness Analysis. Journal of general internal medicine, 31(4), 394-401. https://doi.org/10.1007/s11606-015-3529-6

Pardo, T. B. (2008). An exploratory study of identity conceptualization and development in a sample of gender non-conforming biological females (Unpublished Master's Thesis) Cornell University.

Parent, M. C., \& Sánchez, F. J. (Eds.). (2019). The physical health of boys and men: Integrating biomedical and psychological science [Editorial; Special issue]. Psychology of Men \& Masculinities, 20(2), 161-165. https://doi.org/10.1037/men0000210

Pariseau, E. M., Chevalier, L., Long, K. A., Clapham, R., Edwards-Leeper, L., \& Tishelman, A.C. (2019). The relationship between family acceptance-rejection and transgender youth psychosocial functioning. Clinical Practice in Pediatric Psychology, 7(3), 267-277. https://doiorg.proxy.mul.missouri.edu/10.1037/cpp0000291.supp (Supplemental)

Patton, M. Q. (2002). Qualitative research and evaluation methods (3rd ed). Thousand 
Oaks, CA: Sage.

Pflum, S. R., Testa, R. J., Bongar, B., Balsam, K. F., \& Goldblum, P. B. (2015). Social support, trans community connectedness, and mental health symptoms among transgender and gender nonconforming adults. Psychology of Sexual Orientation and Gender Diversity, 2, 281-286.

Phillips, J. (2006). Transgender on screen. New York, NY: Palgrave Macmillan.

Philipsen, G. (2010). Some thoughts on how to approach finding one's feet in unfamiliar cultural terrain. Communication Monographs, 77(2).

Pleck, J. H. (1981). The myth of masculinity. Cambridge, MA: MIT Press.

Pleck, J. H. (1995). The gender role strain paradigm: An update. In R. F. Levant \& W. S. Pollack (Eds.), A new psychology of men (pp. 11-32). New York: Basic Books

Ramirez-Valles, J., Kuhns, L. M., \& Manjarrez, D. (2014). Tal como comos/Just as we are: An educational film to reduce stigma toward gay and bisexual men, transgender individuals, and persons living with HIV/AIDS. Journal of Health Communication, 19(4), 478-492.

Ryan, C., Russell, S.T., Huebner, D., Diaz, R., \& Sanchez, J. (2010). Family acceptance in adolescence and the health of LGBT young adults. Journal of Child and Adolescent Psychiatric Nursing, 23, 205-213.

Sánchez, F. J. (2016). Masculinity issues among gay, bisexual, and transgender men. In Y. J. Wong \& S. R. Wester (Eds.), APA handbook on the psychology of men and masculinities (pp. 339-356). Washington, DC: American Psychological Association. https://doi.org/10.1037/14594-016 
Sánchez, F. J., Greenberg, S., Liu, W. M., \& Vilain, E. (2009). Reported effects of masculine ideals on gay men. Psychology of Men \& Masculinity, 10(1), 73-87. https://doi.org/10.1037/a0013513

Sears, J. T., \& Williams, W. L. (1997). Overcoming heterosexism and homophobia: Strategies that work. Columbia University Press.

Schilt, K. (2010). Just one of the guys? Transgender men and the persistence of gender inequality. The University of Chicago Press.

Schunk, D. H., \& Meece, J. L. (2006). Self-efficacy beliefs of adolescents. Information Age Publishing

Scott, A. O. (2011, December 20). Finding a Safe Harbor in Male Identity. The New York Times. Available at https://www.nytimes.com/2011/12/21/movies/albert-nobbsmovie-review.html

Schrock, D., Holden, D., \& Reid, L. (2004). Creating emotional resonance: Interpersonal emotion work and motivational framing in a transgender community. Social Problems, $51(1), 61-81$.

Shapiro, E. (2004). Transcending barriers: Transgender organizing on the Internet. Journal of Gay and Lesbian Social Services: Special Issue on Strategies for Gay and Lesbian Rights Organizing, $16(3 / 4), 165-179$.

Shenton, A.K. (2004). Strategies for ensuring trustworthiness in qualitative research projects. Education for Information, 22, 63-75.

Schunk, D.(2012). Learning theories: An educational Perspective ( $6^{\text {th }}$ Ed). (Pearson Education, Boston, MA)

Singh AA. Transgender youth of color and resilience: Negotiating oppression and finding 
support. Sex Roles. 2013;68(11-12):690 702. http://dx.doi.org/10.1007/s11199012-0149-

z. [Google Scholar]

Singh AA, Meng S, Hansen A. "It's already hard enough being a student": Developing affirming college environments for trans youth. Journal of LGBT Youth. 2013;10(3):208-223. http://dx.doi.org/10.1080/19361653.2013.800770. [Google $\underline{\text { Scholar }]}$

Singh, A. A., Hays, D. G., \& Watson, L. (2011). Strategies in the face of adversity: Resilience strategies of transgender individuals. Journal of Counseling \& Development, $89,1,20-27$.

Smith, D. E. (1987). The everyday world as problematic. Boston: Northeastern University Press

Snyder, C. R. Harris, C., Anderson, J.R. Holleran, S. A., Irving, L. M., Sigmon, S. T., et al. (1991). The will and the ways: Development and validation of an initial differences measure of hope. Journal of Personality and Social Psychology, 60, 570-585

Stets, J. E., \& Burke, P. J. (2000). Identity theory and social identity theory. Social Psychology Quarterly, 63, 224-237.

Stieglitz, K. A. (2010). Development, risk, and resilience of transgender youth. Journal of the Association of Nurses in AIDS Care, 21, 192-206. doi:10.1016/j.jana.2009.08.004

Strack, Robert W.; Magill, Cathleen \& McDonagh, Kara (2004). Engaging youth through photovoice. Health Promotion Practice, 5(1), 49-58.

Strauss, A., \& Corbin, J. (1994). Grounded theory methodology. Handbook of qualitative research, 17, 273-85.

Strauss, A., \& Corbin, J. M. (1997). Grounded theory in practice. Sage. 
Stryker, S. (2008). Transgender history. Berkeley, CA: Seal Press.

Sullivan H.S. (ed.). (1953). The Interpersonal Theory of Psychiatry. New York: W. W. Norton.

Sue, D. W. (2017). COUNSELING THE CULTURALLY DIVERSE: Theory and practice, eighth edition. S.1.: JOHN WILEY \& SONS.

Tajfel, H., \& Turner, J. C. (1985) The social identity theory of intergroup behavior. In S. Worchel \& W. G. Austin (Eds.), Psychology of intergroup relations (2nd ed., pp. 7-24). Chicago: Nelson-Hall.

Testa, R. J., Habarth, J., Peta, J., Balsam, K., \& Bockting, W. (2015). Development of the gender minority stress and resilience measure. Psychology of Sexual Orientation and Gender Diversity, 2, 65-77. http://dx.doi.org/10.1037/sgd0000081

Testa, R. J., Jimenez, C. L., \& Rankin, S. (2014). Risk and resilience during transgender identity development: The effects of awareness and engagement with other transgender people on affect. Journal of Gay \& Lesbian Mental Health, 18, 31- 46. http://dx.doi.org/10.1080/19359705.2013.805177

Teti M., Majee W., Cheak-Zamora N., Maurer-Batjer A. (2017) Understanding Health through a Different Lens: Photovoice Method. In: Liamputtong P. (eds) Handbook of Research Methods in Health Social Sciences. Springer, Singapore

Teti, M., Pichon, L., Kabel, A., Farnan, R., \& Binson, D. (2013). Taking pictures to take control:Photovoice as a tool to facilitate empowerment among poor and racial/ethnic minority women with HIV. Journal of the Association of Nurses in AIDS Care, 24, 539553. doi:10.1016/j. jana.2013.05.001

Tongco , M. D. C. ( 2007 ) Purposive sampling as a tool for informant selection 
Ethnobotany Research \& Applications , 5, 147 - 158 .

Toomey RB, Ryan C, Diaz RM, Card NA, Russell ST. 2010. Gender-nonconforming lesbian, gay, bisexual, and transgender youth: school victimization and young adult psychosocial adjustment. Dev. Psychol. 46:1580-89

Toomy, A. (2018, October 22). LGBT posters spark concern at Gentry middle school.

Retrieved from https://www.abc17news.com/news/lgbt-posters-spark-concern-at-gentry$\underline{\text { middle-school/818984799 }}$

Transgender Law Center. (2019, April 30). Equality maps. Retrieved from https://transgenderlawcenter.org/equalitymap

Trans Student Educational Resources. (n.d.). LGBTQ+ definitions. Retrieved from http://www.transstudent.org/definitions

2015 U.S. Transgender Survey: Missouri State Report. (2017). Washington, DC: National Center for Transgender Equality.

van Manen, Max (1990). Researching lived experience: Human science for an action sensitive pedagogy. London, ON: University of Western Ontario.

Vygotsky, L. (1978). Mind in Society. London: Harvard University Press.

Wallerstein, N., \& Bernstein, E. (1988). Empowerment education: Freire's ideas adapted to health education. Health Education Quarterly, 15(4), 379-394.

Wang, C., \& Burris, M. A. (1997). Photovoice: Concept, methodology, and use for participatory needs assessment. Health Education \& Behavior 24(3), 369-387.

Wang, C. C. (1999). Photovoice: A participatory action research strategy applied to women's health. Journal of Women's Health, 8(2), 185-192.

Wang, C. C., Cash, J. L., \& Powers, L. S. (2000). Who knows the streets as well as the 
homeless? Promoting personal and community action through photovoice. Health Promotion Practice, 1, 81-89.

Warbelow, S., Oakley, C., \& Kutney, C. (2018). State Equality Index. Washington, DC: Human Rights Campaign Foundation. Retrieved from https://www.hrc.org/campaigns/state-equality-index

Waterman, A. S. (1999). Identity, the identity statuses, and identity status development: A contemporary statement. Developmental Review, 19(4), 591-621.

Whittle, S. (1998). The trans-cyberian mail way. Social \& Legal Studies, 7, 389-408.

Wilchins, R. (2002). Deconstructing trans. In J. Nestle, C. Howell, \& R. Wilchins (Eds.), Genderqueer: Voices from beyond the sexual binary (pp. 55-63). Los Angeles: Alyson Books.

Wilchins, R. (2004). Queer theory, gender theory: An instant primer. Los Angeles: Alyson Books

Woodgate, Roberta L.; West, Christina H. \& Tailor, Ketan (2014). Existential anxiety and growth: An exploration of computerized drawings and perspectives of children and adolescents with cancer. Cancer Nursing, 37(2), 146-159.

Worthington, R. L., Dillon, F. R., \& Becker-Schutte, A. (2005). Development, reliability and validity of the LGB Knowledge and Attitudes Scale for Heterosexuals (LGB-KASH). Journal of Counseling Psychology, 52, 104-118. doi: 10.1037/00220167.52.1.104

Wu, Katherine J. (2016). Between the gender lines: the science of transgender identity. Retrieved from: http://sitn.hms.harvard.edu/flash/2016/gender-lines-science-transgenderidentity/

Zemsky, Beth, and Ronni L. Sanlo. "Do policies matter?" New Directions for Student 
Services 2005.111 (2005): 7-15.

Zimet, G.D., Dahlem, N.W., Zimet, S.G. \& Farley, G.K. (1988) The Multidimensional Scale of Perceived Social Support. Journal of Personality Assessment, 52, 30-41 
Appendix A: Flyer

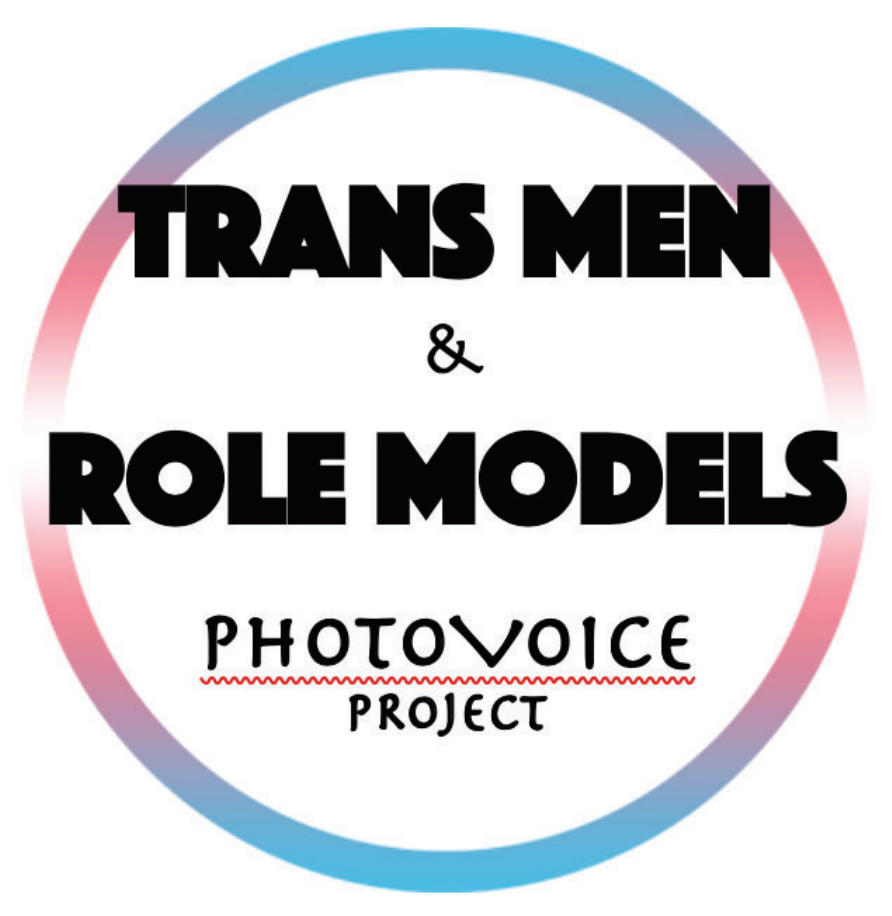

\section{Trans Male Volunteers Needed!}

Researchers at the University of Missouri Department of Counseling Psychology are exploring trans men's experiences with role models. To participate, you will be asked to engage in a photography project, with you as the photographer! Participants will engage in 3 group meetings, each lasting approximately 2 hours. Participants will collectively develop topics, photograph prompts, and discuss themes. Participants will be eligible to receive $\$ 80$ in Visa gift cards. Meetings will occur in a community space with private rooms. Any reservations made for the space will exclude any reference to the research topic/theme.

This study has been approved by the University of Missouri Institutional Review Board. If you are interested, please contact the principal investigator at the University of Missouri:

Jennah Strathausen, M.Ed. inbv86@mail.missouri.edu

573-246-0152
Francisco J. Sánchez, Ph.D Associate Professor sanchezf@missouri.edu 
Appendix B: Personal Information Questionaire

\section{Personal Information Questionnaire}

1) What is your Ethnic identity?

White (Non-Hispanic) _ African American
Hispanic/Latino
Native American
Other [Specify:

2) How old are you?

3) What was your total household income before taxes during the past 12 months?

\begin{tabular}{|c|c|}
\hline Less than $\$ 25,000$ & $\$ 75,000$ to $\$ 99,999$ \\
\hline$\$ 25,000$ to $\$ 34,999$ & $\$ 100,000$ or more \\
\hline$\$ 35,000$ to $\$ 49,999$ & \\
\hline$\$ 50,000$ to $\$ 74,999$ & \\
\hline
\end{tabular}

4) Are you a U.S. citizen? Yes _ No

a) If no, what is your nationality?

5) Were you born in the U.S.? __ Yes__ No

a) If no, how long have you lived in the U.S.?

6) Which statement best describes how you identify your sexual orientation?

Exclusively heterosexual

Predominately heterosexual, but occasionally bisexual or gay

Mostly heterosexual, but more than just occasionally bisexual or gay Bisexual

Mostly gay, but more than just occasionally bisexual or heterosexual

Predominately gay, but occasionally bisexual or heterosexual

Exclusively gay

Other:

7) Which statement best describes how you identify your gender? 
Cisgender

Transgender male

Transgender female

Gender Queer

Gender Non-conforming

8) Level of Education:

$\begin{array}{ll}\text { Less than } 12^{\text {th }} \text { Grade } & \text { High School Diploma/Equivalent } \\ \text { Technical-Vocational Training } & \text { Some College } \\ \text { Associate's Degree } & \text { Bachelor's Degree } \\ \text { Graduate/Professional Degree } & \end{array}$

9) Are you currently in a romantic relationship? __ Yes __ No

If yes, please answer all the questions on the rest of this page.

If no, please skip to the next page.

a) For how long have you been in this relationship?

b) What is the gender identity of your partner? Male Female MTF FTM Other

c) What is your partner's age?

d) Do you currently live with your partner? Yes No

e) Would you characterize your relationship as closed/monogamous? Yes No

10) Are you currently undergoing hormone treatment? __ Yes __ No

a) If yes, when did you begin treatment? 
Appendix C: Informed Consent

Consent TO SERVE AS A SUBJECT IN RESEARCH:

The Influence of Role Models on Trans Men’s Identity Development

Photovoice Participatory Action Research

1. I agree to be a part of a study by Jennah Strathausen, M.Ed., University of Missouri- Columbia. Other people may help her.

2. I understand that:

a) I can take part in this research project only if I want to participate. I may stop at any time and nothing bad will happen to me. I do not have to answer any questions I don't want to answer.

b) I will be asked to use my camera phone to take photos representing topic related to role models. Photo prompts will be developed collaboratively by the focus group. If I do not have access to a camera on my phone, I will be loaned a digital camera.

c) This will be my role in the study: I will take part in photovoice as a research subject. I will participate in three meetings and take a set of photos. In the first meeting, I will learn about photovoice, discuss the topic of role models, and identify an audience for the project. In the second meeting I will participate in a conversation about the ethics of photography and collaborate with group members to develop prompts related to concerns, strengths, social issues and health barriers in the trans masculine community. I will be asked to take pictures responding to these prompts. I will have two weeks to take the pictures and upload them to a Dropbox account prior to the third meeting. The researcher will be available to assist individuals with uploading images if necessary. During the third meeting I will talk about my pictures and why I chose them. I understand that I will 
not have to answer any questions that make me feel uncomfortable. I may be asked to help plan for a forum for a public viewing of the photographs. All the meetings will last approximately 2 hours.

d) I will be given a set of pictures to keep.

e) I do not have to answer any questions during the meetings if I do not want to.

f) I will be asked to take pictures in the community. It is possible that I could see people doing things that break the law. It is also possible that someone could get upset if I take their picture. To make sure that I do not get in harm's way, I will be told to ask people if it is okay to take pictures of them and if they agree to have their picture taken, I will then ask them to sign a consent form. I will be told to avoid taking pictures that include activities that are against the law.

g) I understand that the three meetings will be audio recorded and the recordings will be written out. However, no one will know that I was a participant because: (1) My name will not be mentioned on the tapes, nor will it be written down; (2) the recordings will be kept for 7 years after the project is done and then they will be destroyed. The recordings and what are written will be kept in a locked file and no one except Jennah Strathausen and her assistants will see them.

h) The results of this study may be read by other people, but I will not be named.

i) I know that the pictures I take, and what I say about the pictures, may be seen by other people.

3. I have had a chance to ask any questions I have about the study. If I have any other questions, I can contact Jennah Strathausen (573-246-0152) or Dr. Francisco Sanchez (573)-882-7732. 
4. It is okay for Jennah Strathausen, and the people working with her to tell others what they learned from this project, but I will not be mentioned by name. The information will be about the whole group and not just about me.

5. I will receive an $\$ 80$ Visa gift card for participating in all parts of Photovoice project. I know I will not get the full amount if I do not go to all of the meetings and/or if I do not take pictures. I will get a $\$ 15$ gift card for going to the first meeting, \$25 for participating in the second meeting and an additional $\$ 40$ for uploading my photographs and attending the third meeting. This means that if I participate in all three meetings and upload my photos, I will receive an $\$ 80$ gift card. 6. This study has been approved by the MU campus Institutional Review Board (IRB) (project \# 0000000). I may contact the IRB office at 482 McReynolds Hall, Columbia, MO 65211; telephone: (573) 882-3181.

If I understand the terms above and agree to participate, I will provide verbal consent. 


\section{Appendix D: Photo Release \\ The Influence of Role Models on Trans Men's Identity Development \\ Photovoice Photograph Consent Form}

May I take your picture?

What am I being asked to do?

** You are being asked to give me your permission to take your picture

Why are you taking these pictures?

** The theme for this project is, "Trans Men's Role Models." As a participant of this project I am taking pictures of how role models are present in my life or my community. These pictures will help us understand the impact of role models on the trans masculine community.

Will people know that I had my picture taken for this project?

** Your name will never be revealed in any of the project discussions, presentations, or exhibits. Still, there is a chance that someone might recognize you.

What will I get for having my picture taken for your project?

** All pictures will be kept in a secure place by one of the researchers and me. If you wish, I will send you a copy of the picture I take. If you would like a copy, please write your name and email address where you would like the picture sent at the end of this form.

Do I have to allow you to take my picture?

** No. You do not have to allow me to take your picture.

Has this project been approved? 
** Yes. This project has been approved by the University of Missouri Institutional Review Board

Who can I contact if I have any questions about the project?

** If you ever have any questions or concerns please contact Jennah Strathausen (573-246-0152) or Dr. Francisco Sánchez (573)-882-7732.

If you are willing to have your picture taken, please read the following agreement statement very carefully. Then, please sign and date this form and return it to me.

\section{Agreement Statement:}

By signing this consent form, I agree to have my picture taken. I also understand and agree that unless otherwise notified in writing, Jennah Strathausen assumes that permission is granted to use my picture(s) for project related discussions, exhibits and presentations.

Your signature:

Date:

Photographers signature:

Date:

If you would like a copy of your picture(s) please print your email address:

Thank You!

Appendix E: Consent to Use Photographs 
Acknowledgement of Release I, , grant Jennah

Strathausen, and the University of Missouri the right use photographs that I have taken for exhibition and publication purposes. I authorize Jennah Strathausen, her assigns and transferees to use and publish the same in print and/or electronically or display and/or promotional purposes. I have read and agree to the above:

Signature:

Printed Name:

Date: 
Appendix F: Photovoice Brochure (Frontside)

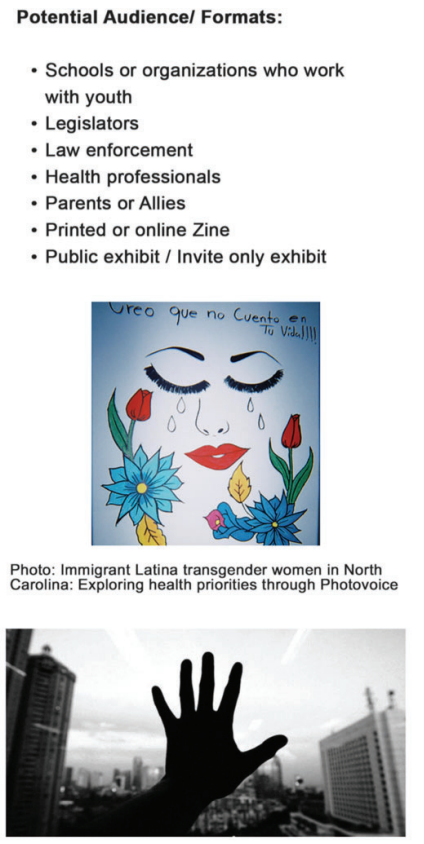

Photo: Mapping Flood POI using OSM \& Photovoice,
Jakarta, India

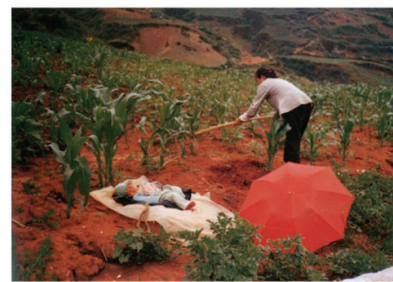

Photo: Chinese Village Women as Visual Anthropolo-
gists". Photograph by Li Qiong FenChengjian. (Wang gists". Photograph by Li Qiong FenChengjian. (Wan
\&urris, 1996)

This study has been approved by the University of Missouri Institutional Review the principal investigator at the Univertact Missouri:

Jennah Strathausen, M.Ed. jnbv86@mail.missouri.edu 573-246-0152

Francisco J. Sánchez, Ph.D. Associate Professor sanchezf@missouri.ed $573-882-7732$

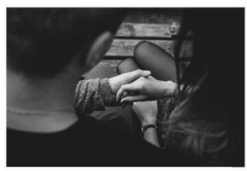
Photo: "Noojamadaa (Let's Heal)" Photovoice project
on intimate partner violence. Northern Ontario School
Trans Men

\& Role Models PHOTOVOICE PROJECT

"Photovoice is a method that enables people to define for themselves and others, including policy makers, what is worth remembering and what needs to be changed." - Carolyn Wang

Appendix G: Photovoice Brochure (Backside) 
Photovoice: A research method where community members use photography to express their views on their

community concerns, assets, health barriers or social issues.

\section{Goals of Photovoice:}

1. Record \& reflect upon community strengths and concerns

2. Promote dialogue and knowledge about important community issues using large \& small group discussions

3. Reach community stake holders
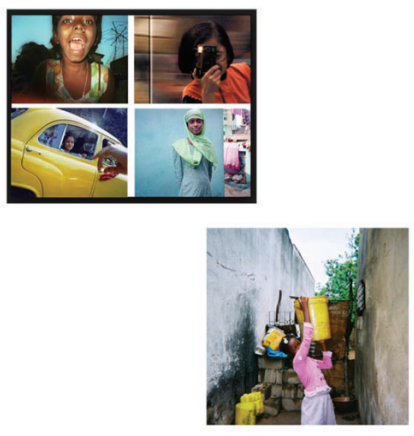

Photos: Born into Brothels: Redlight District Calcutta,
Steps in a Photovoice Project:

1. Meet with other community members

2. Identify an audience of community leaders

3. Pose initial themes for taking pictures

4. Photograph themes

5. Discuss photographs and identify themes

6. Share photographs with policy makers/community leaders

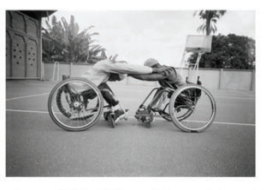

Photo: "Able Voices" Two athletes in wheelchairs

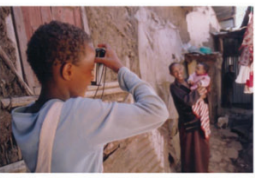
Photo: Anamuh Arts for Dialogue.
https: //www.anamuh.org/index.php/2017/01/19/phot
ovoice/

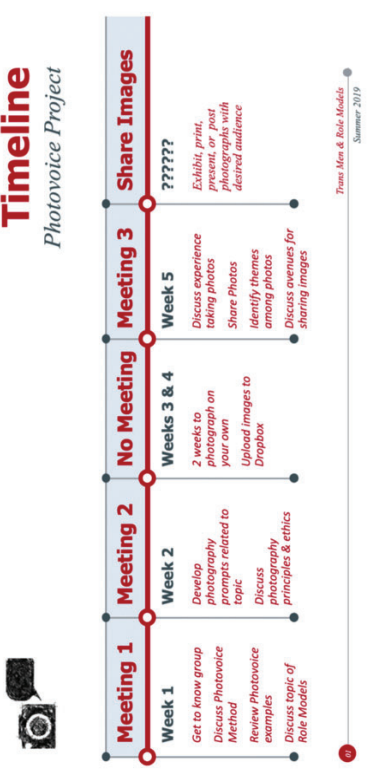

Appendix H: PowerPoint Slides for Session 1 

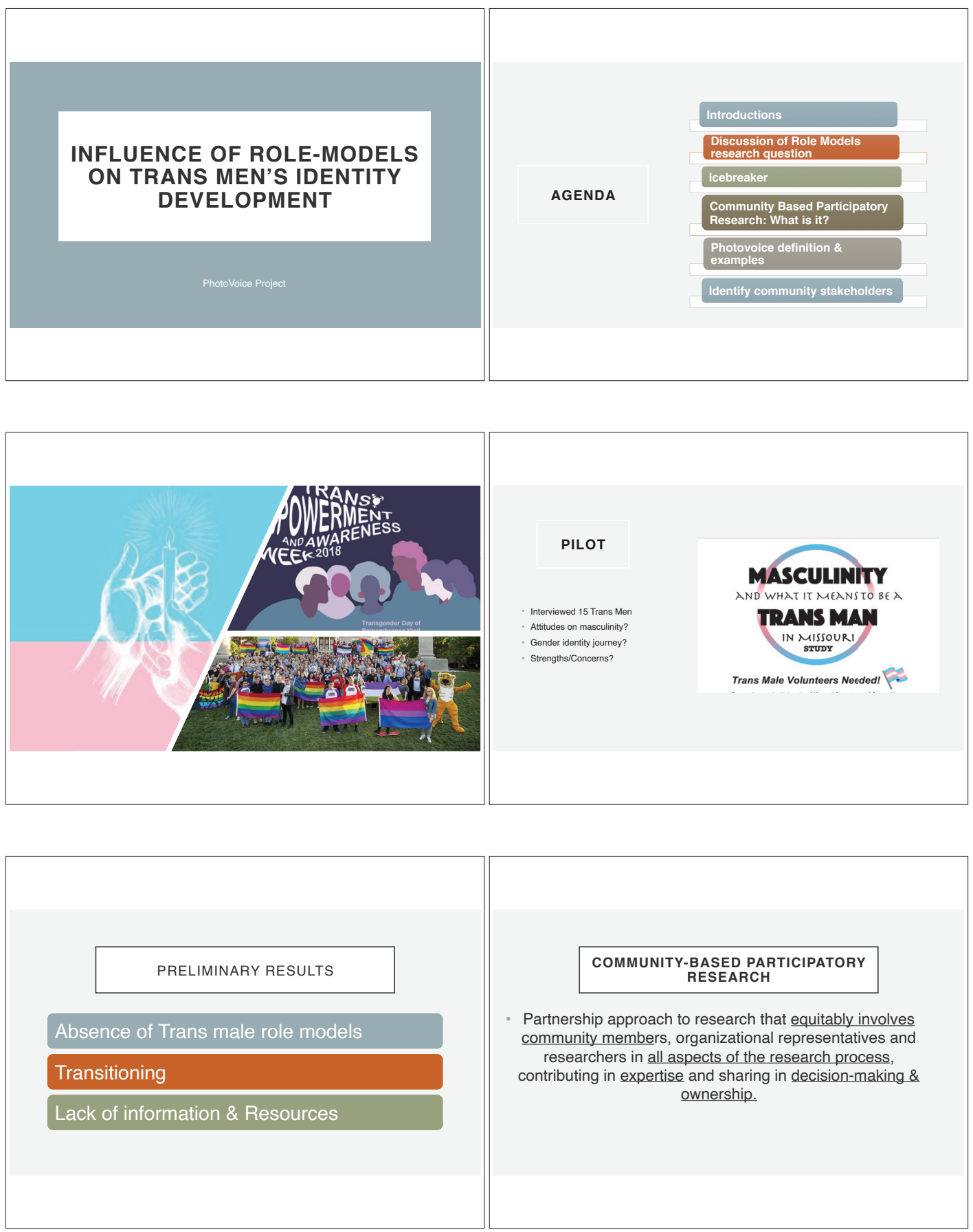


\section{PRINCIPLES OF CBPR}

1. Community recognized as unit of identity

-2. Build on community strengths \& resources

3. Collaborative partnerships in all research phases

-4. Integrate knowledge \& action for mutual benefit

5. Promote co-learning \& empowerment

6. Cyclical \& Incremental

-7. Uses positive \& Ecological models to address health

8. Disseminate knowledge/findings to all partners

BUILD ON COMMUNITY STRENGTHS \& RESOURCES

- You have a wealth of knowledge \& information from lived experience

KNOWLEDGE + ACTION $=$ MUTUAL BENEFIT

- Not only to add the the scientific body of knowledge

Knowledge gained should be applied to to the advancement of interventions or policies that benefit the community

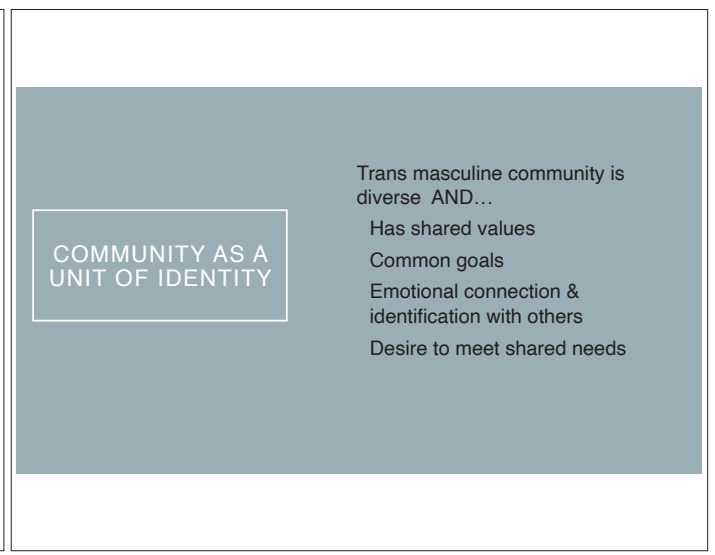

COLLABORATIVE PARTNERSHIPS IN ALL STAGES

Shared decision making \& accountability

Recognize inherent inequalities between researchers \& communities

Address imbalances through communication, building trust \& mutually respectful relationships

Research questions, data collection \& analysis EMPOWERMENT

All partners bring a wealth of diverse experiences, skills, and perspectives to the research process 

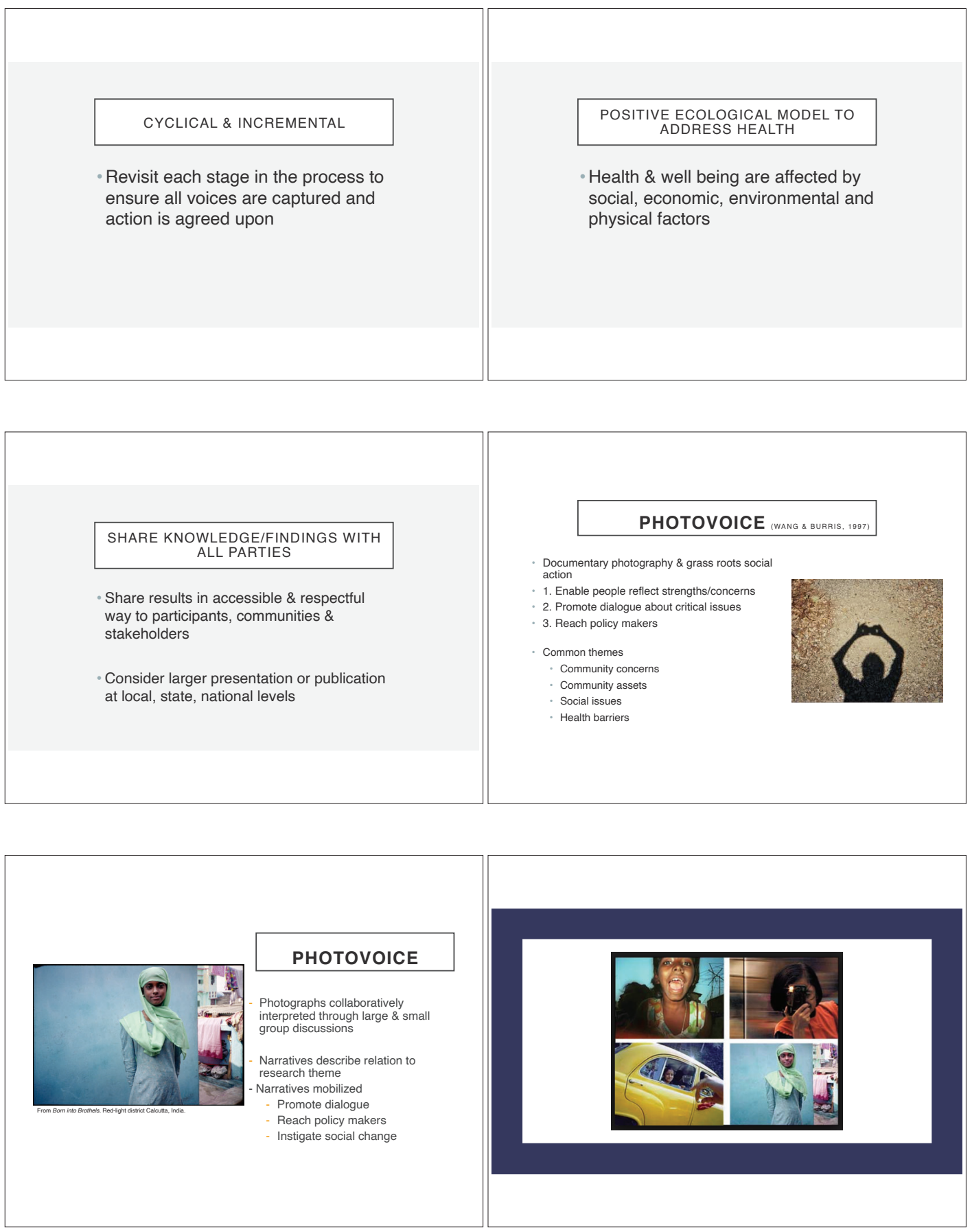

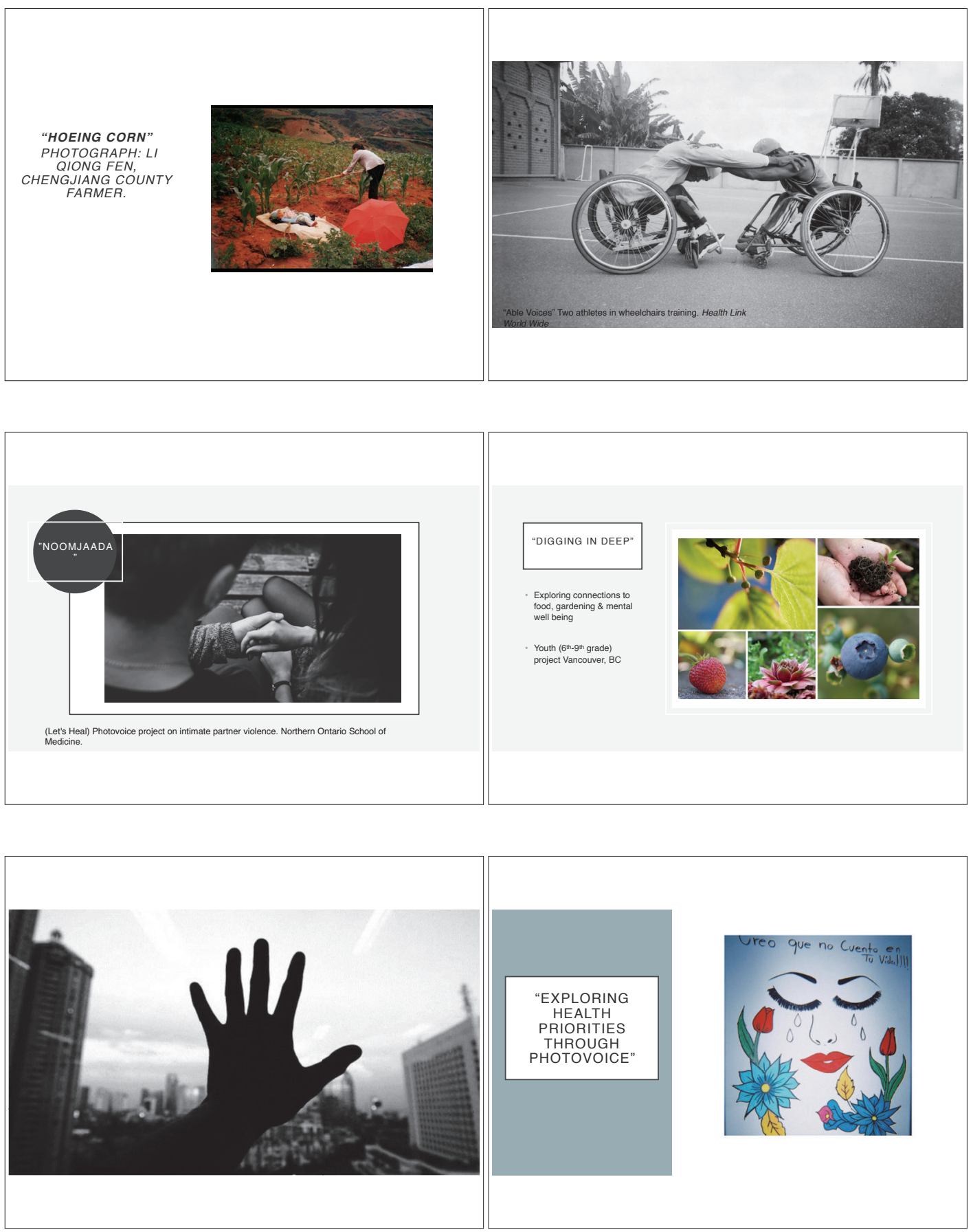

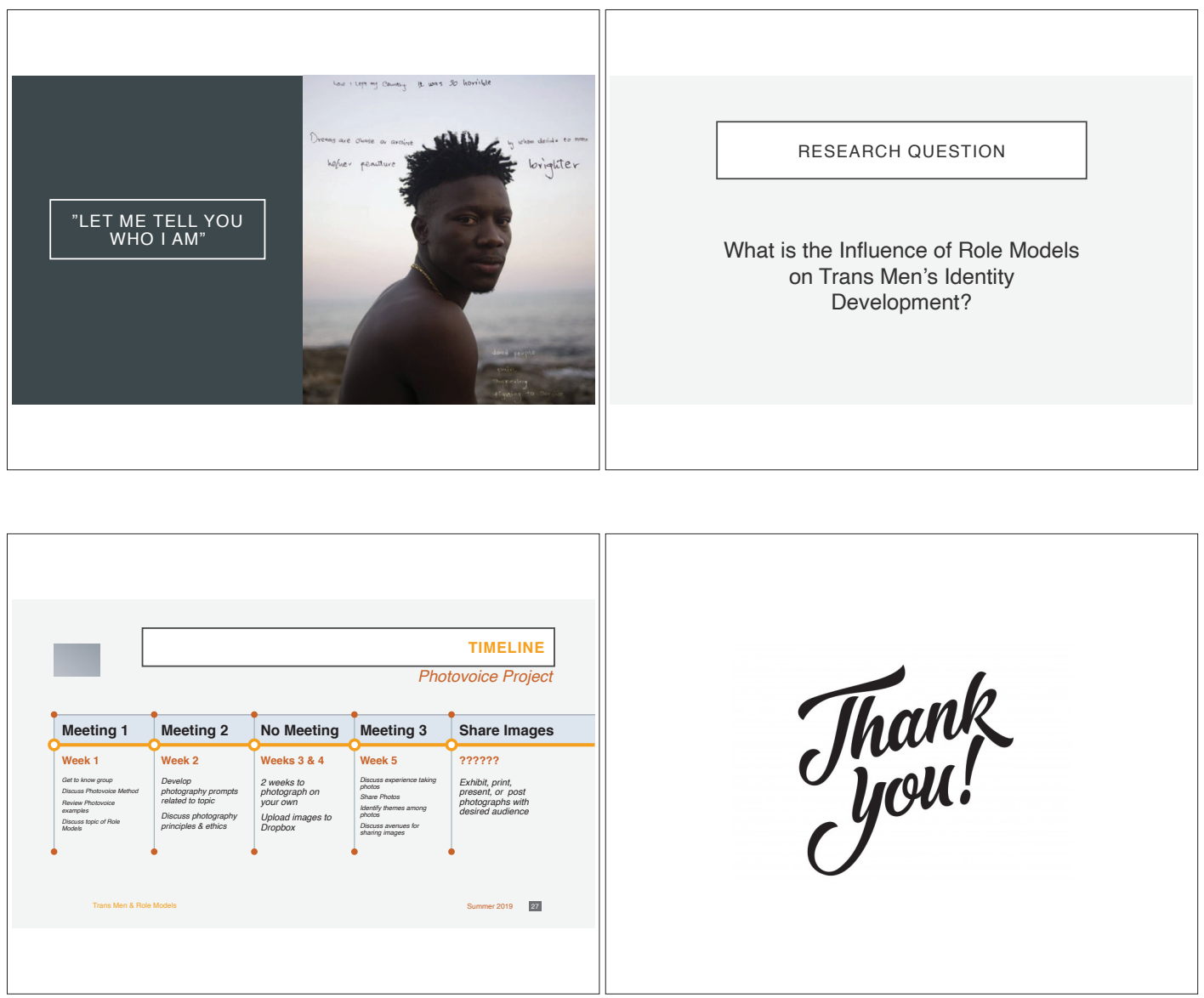
Appendix I: PowerPoint Slides for Session 2
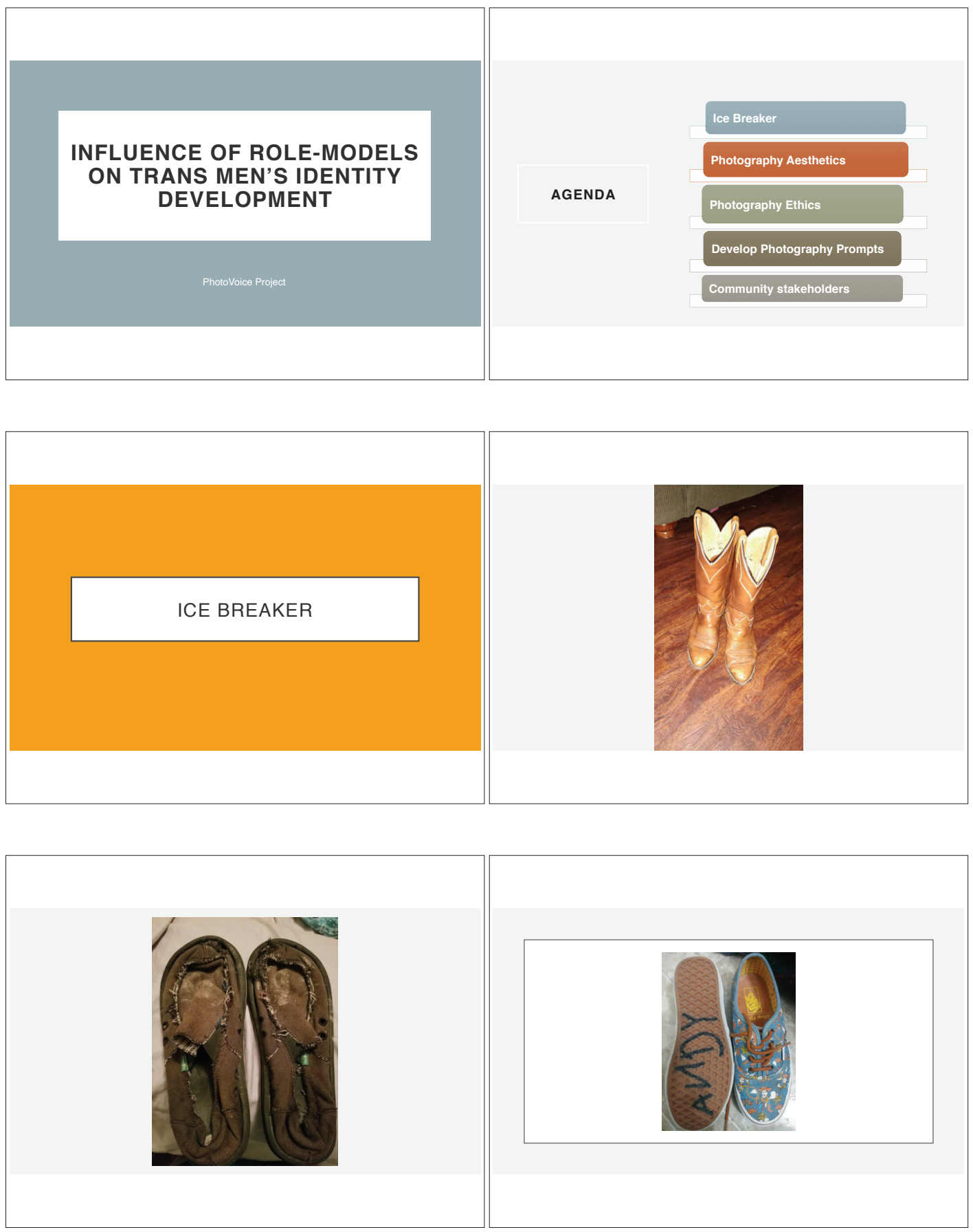

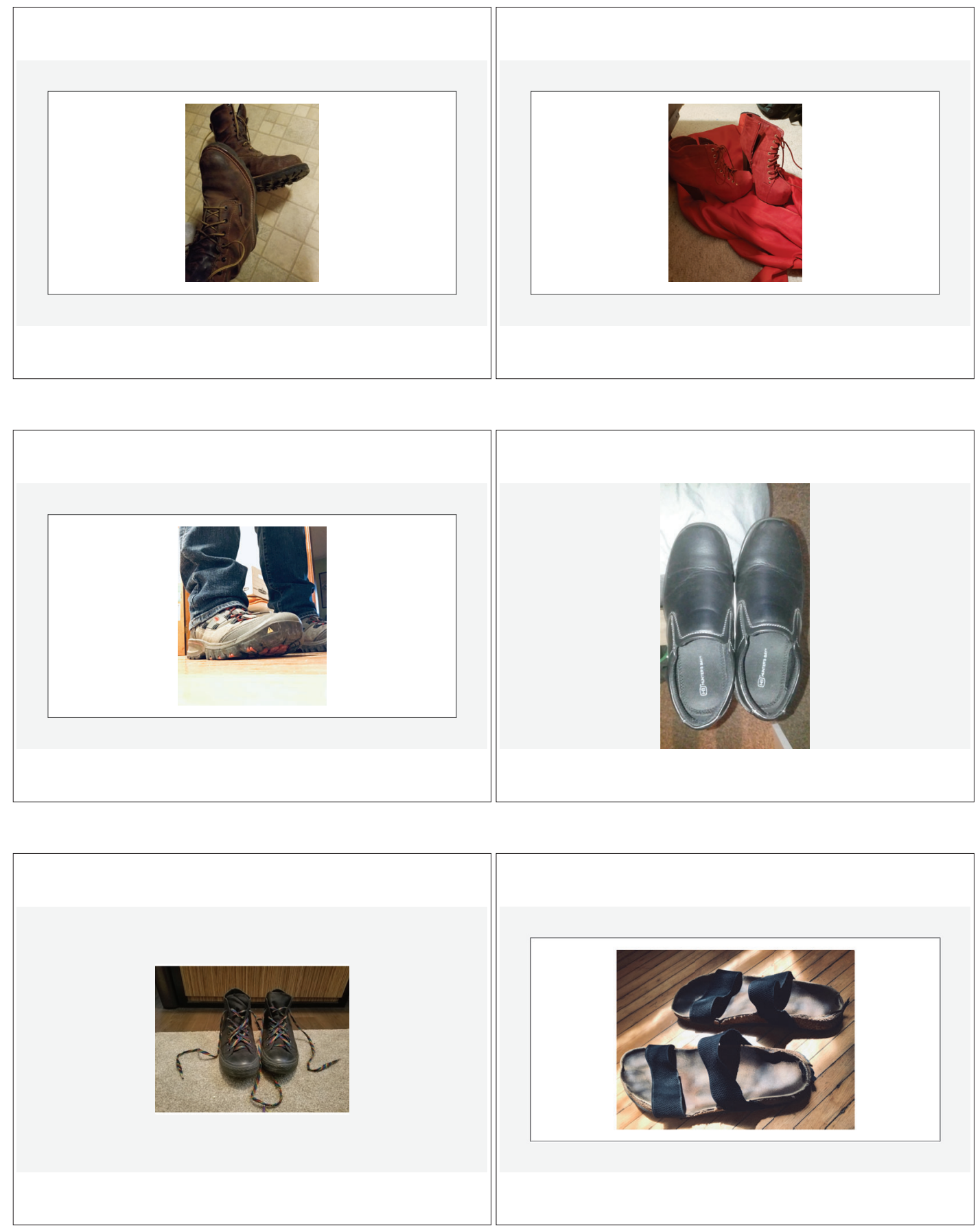

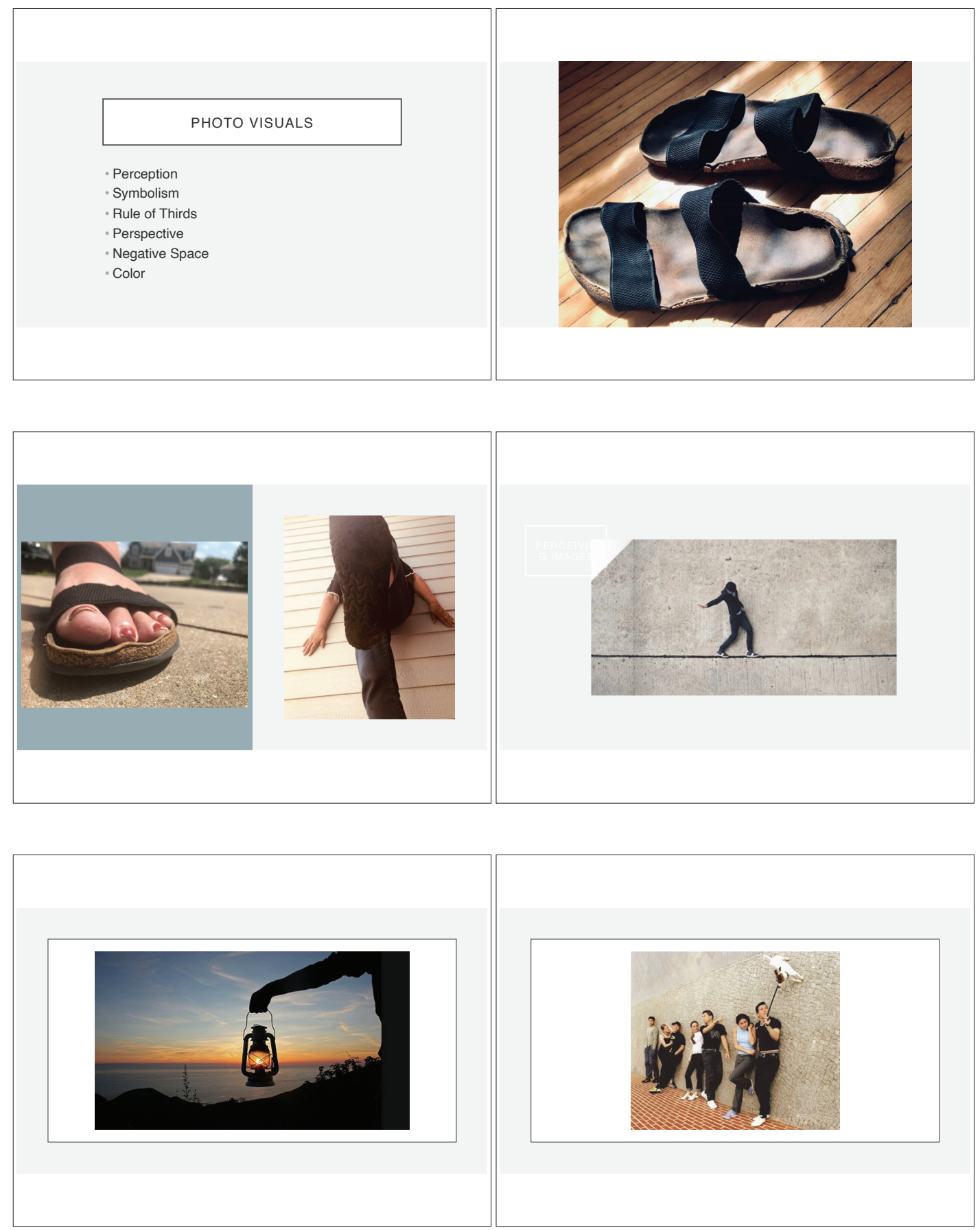

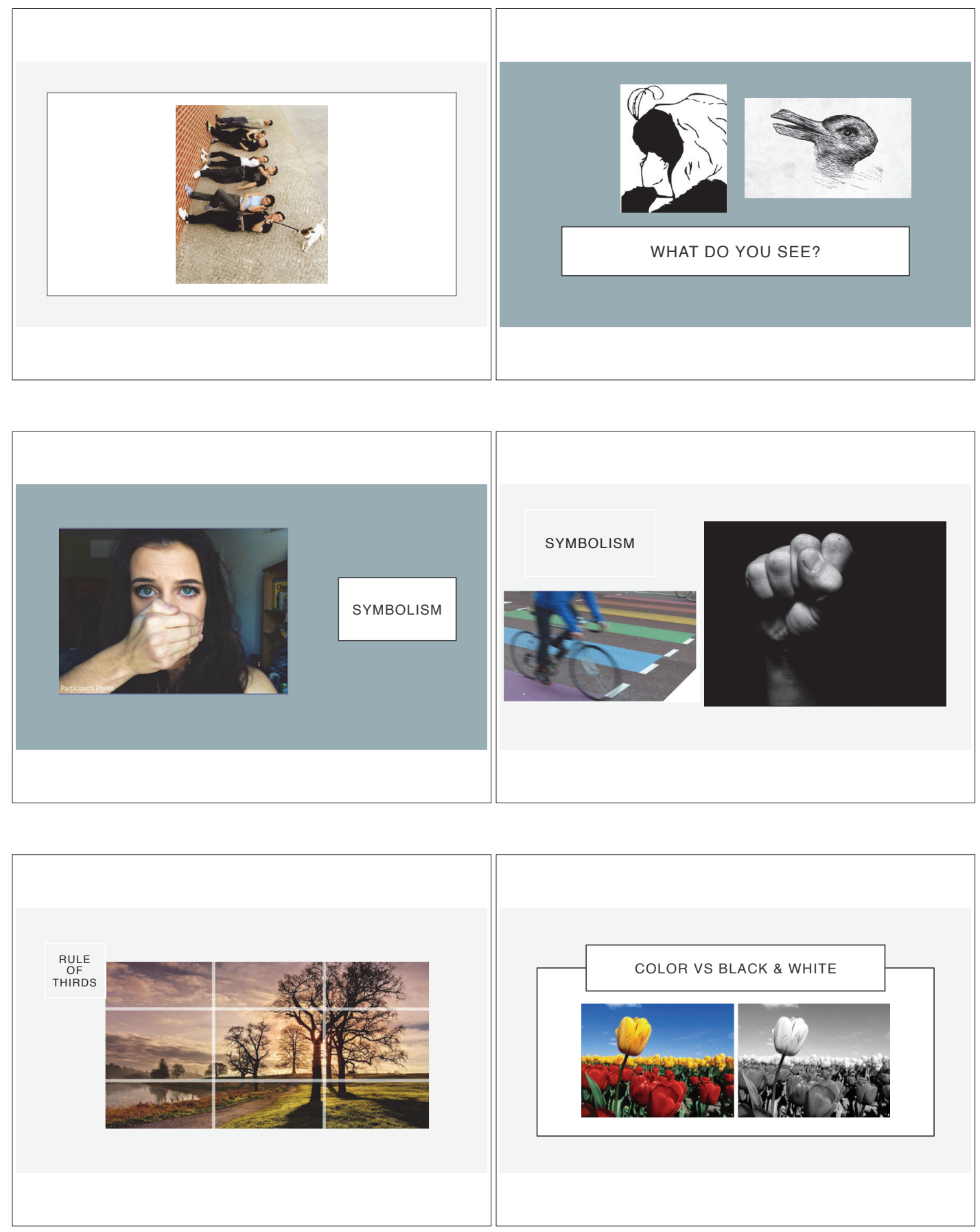

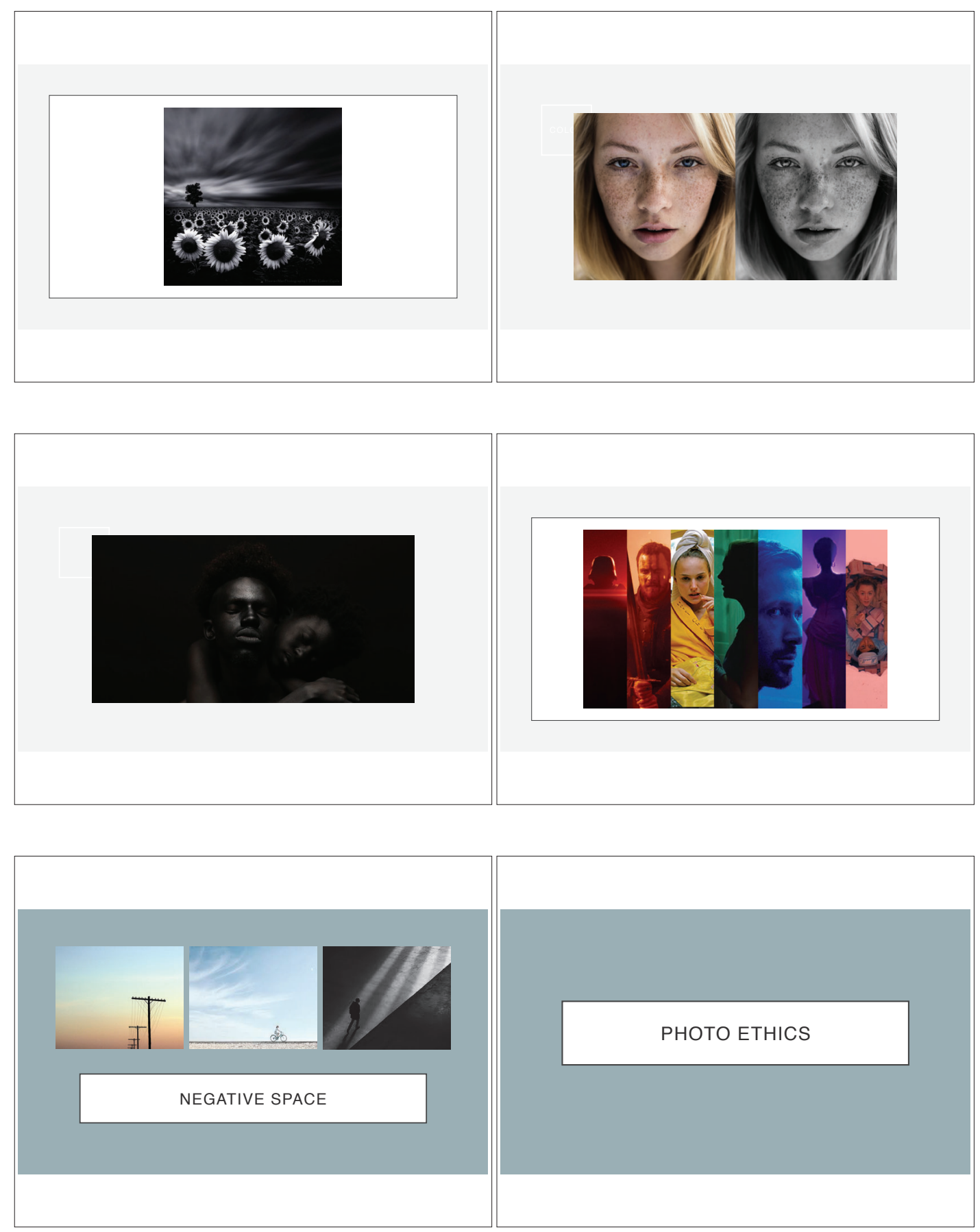

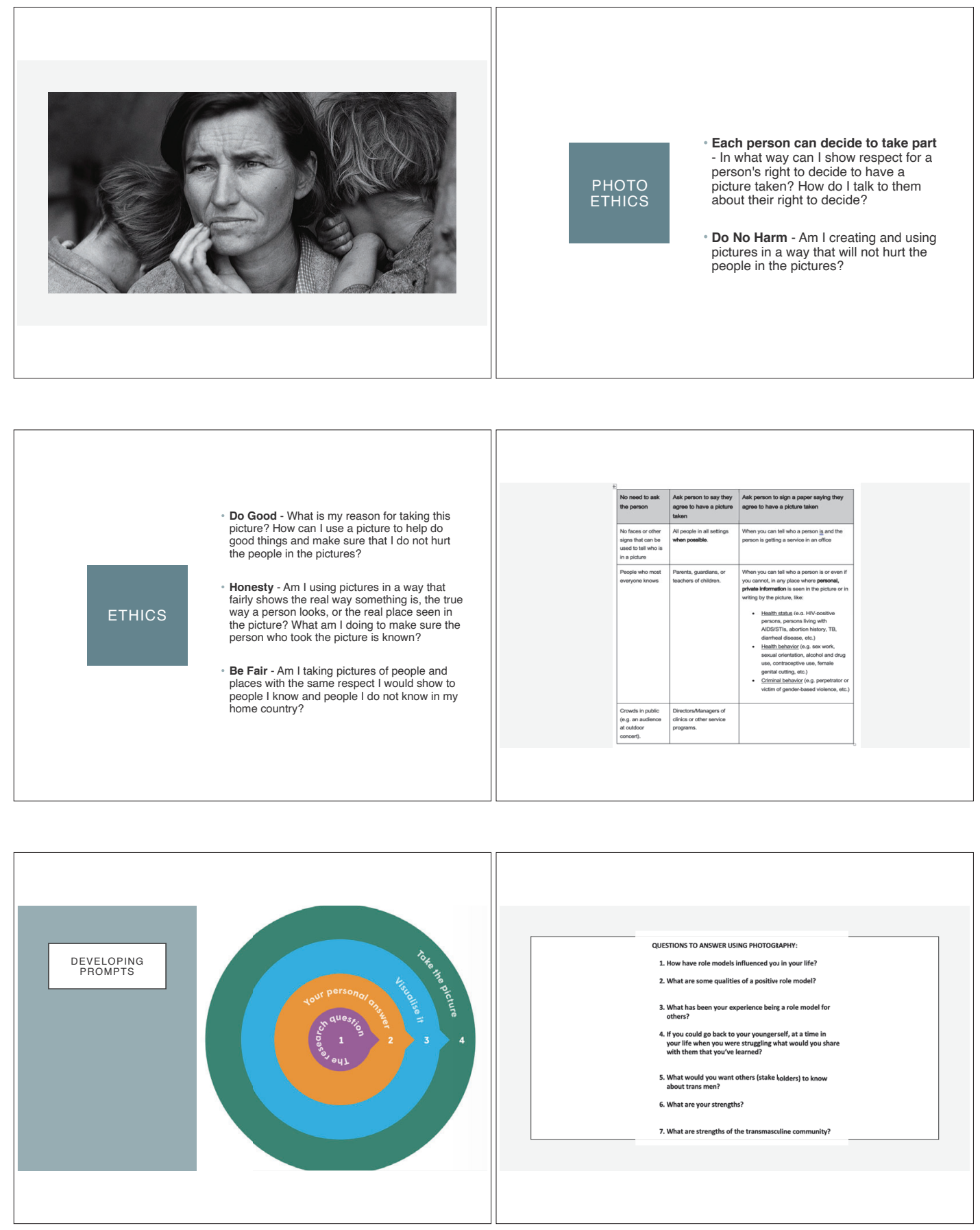

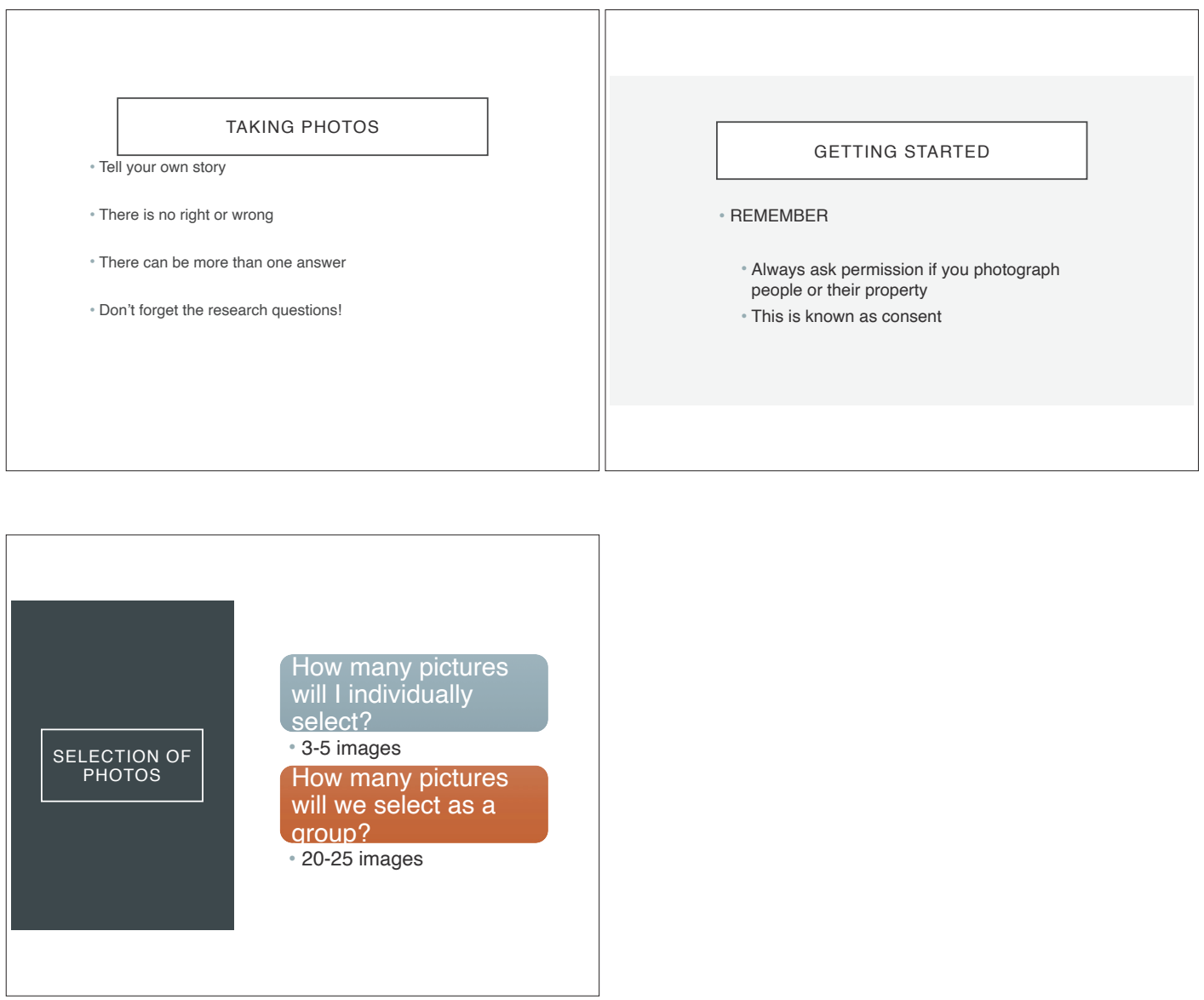
Appendix J: PowerPoint Slides for Session 3
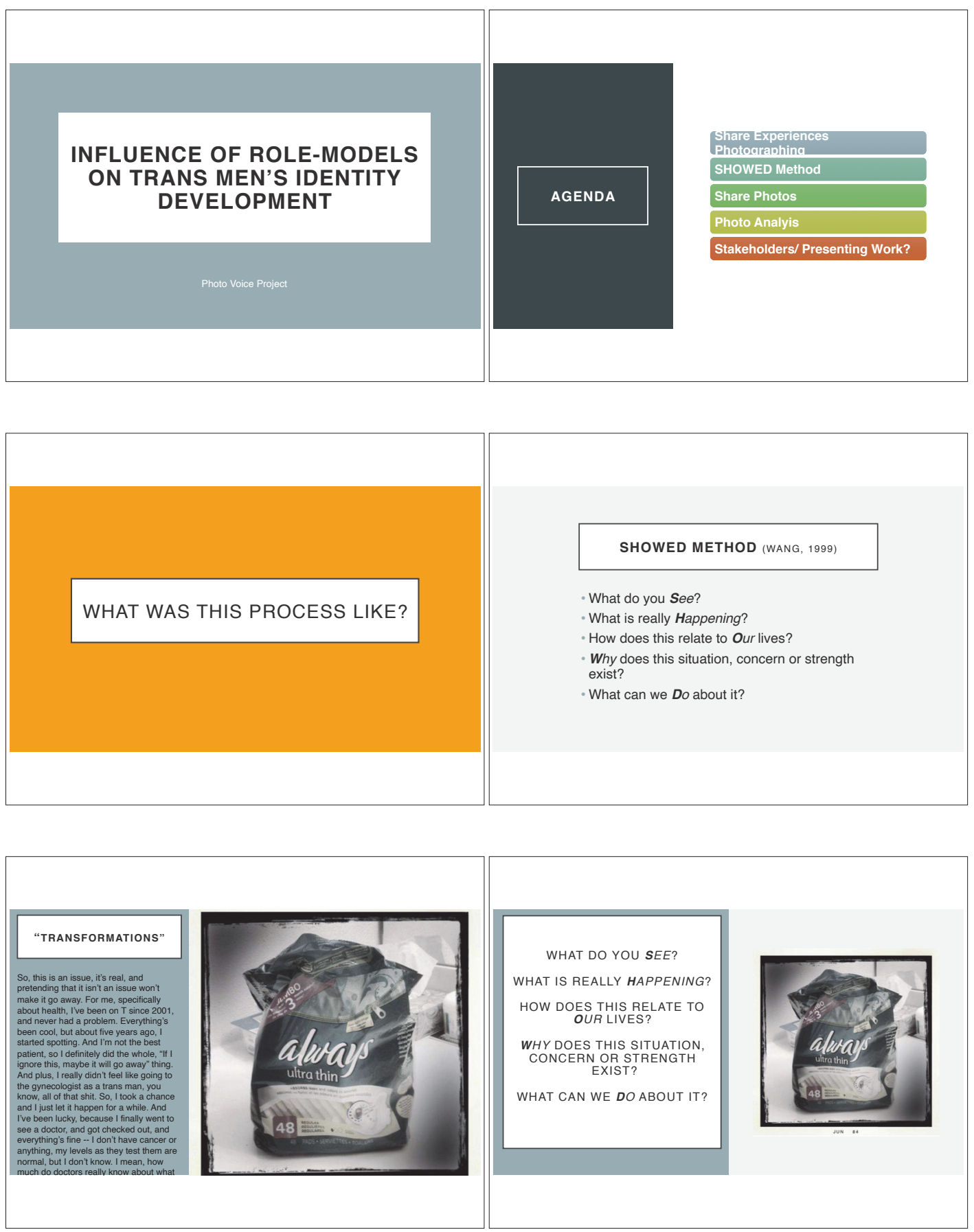

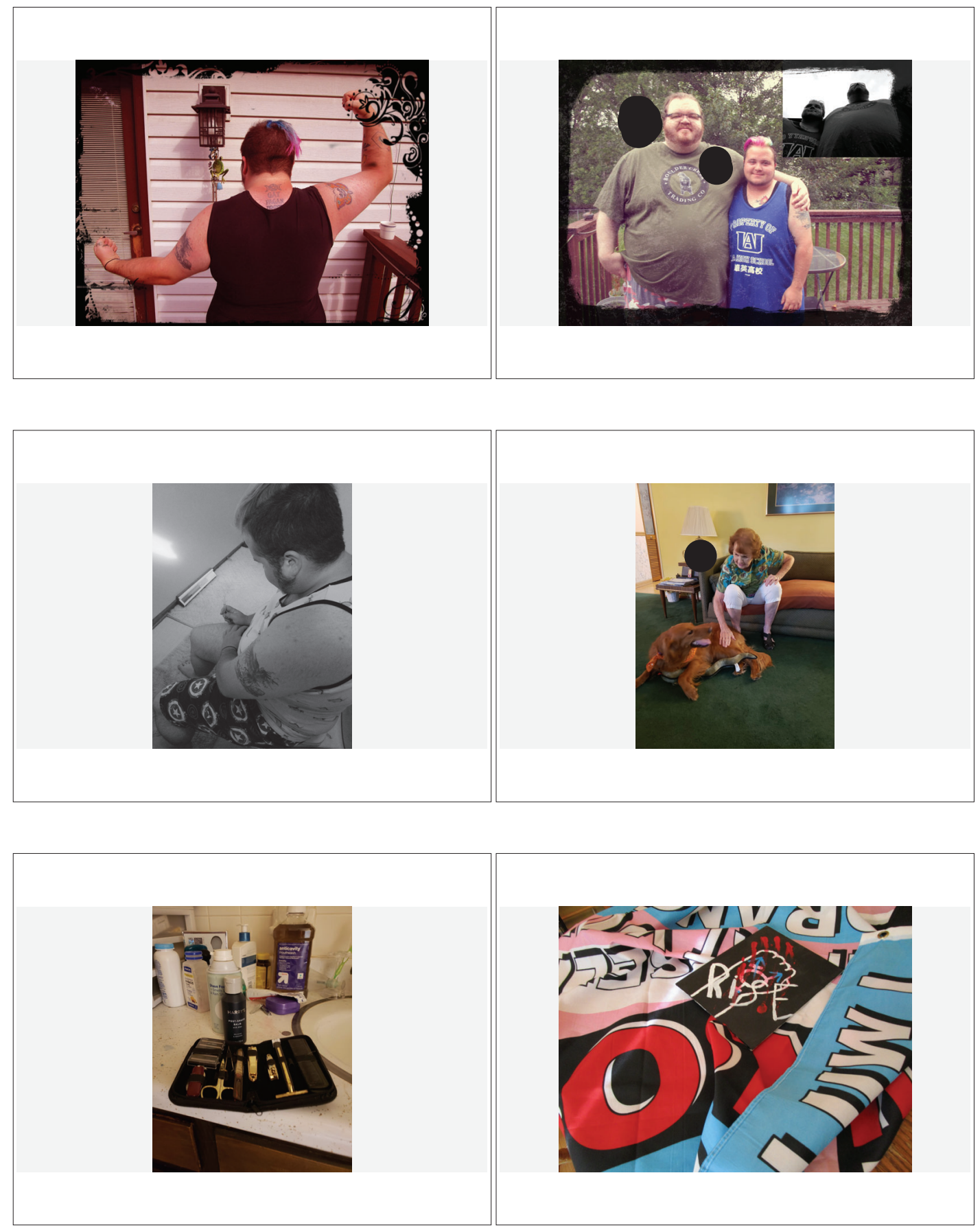

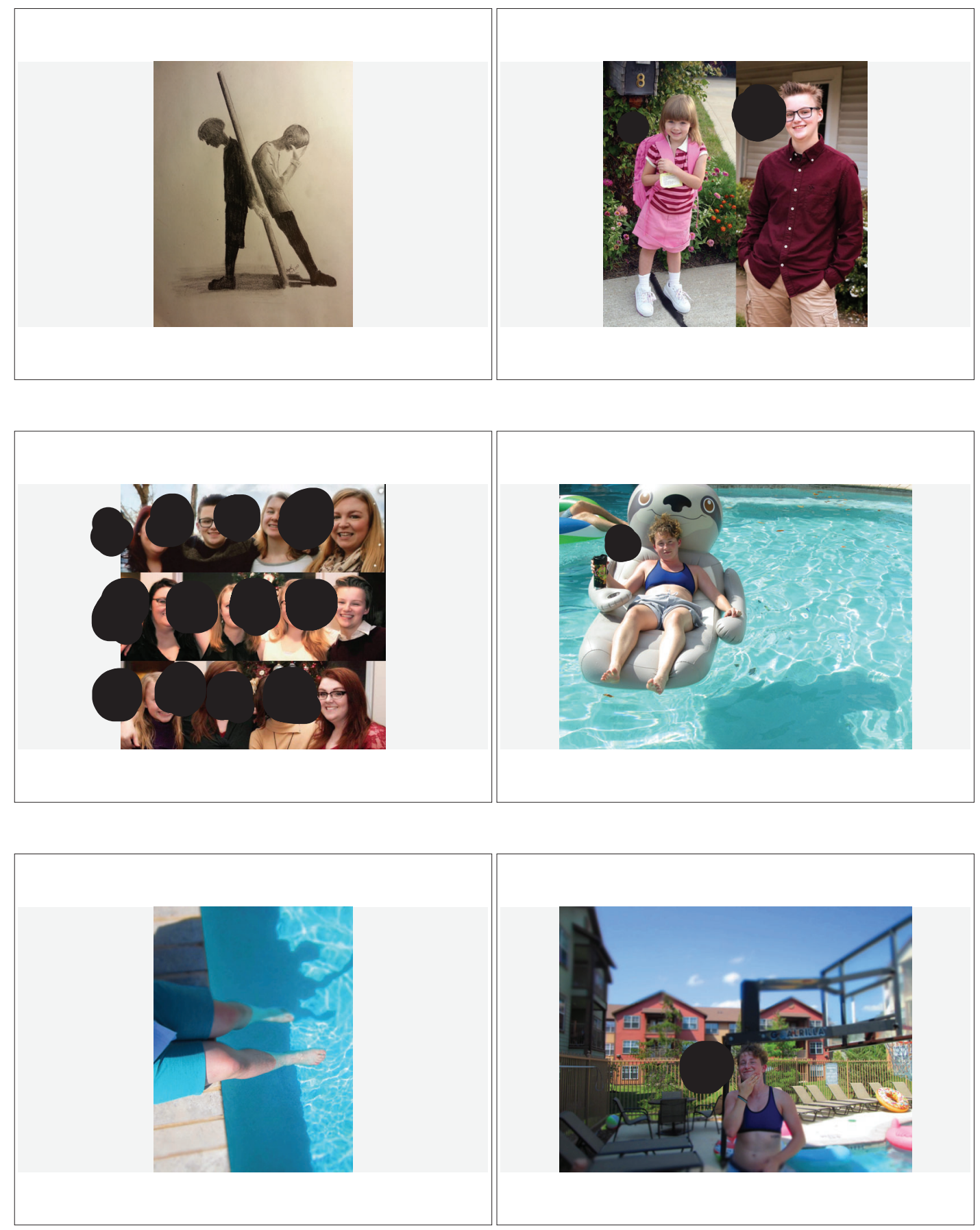

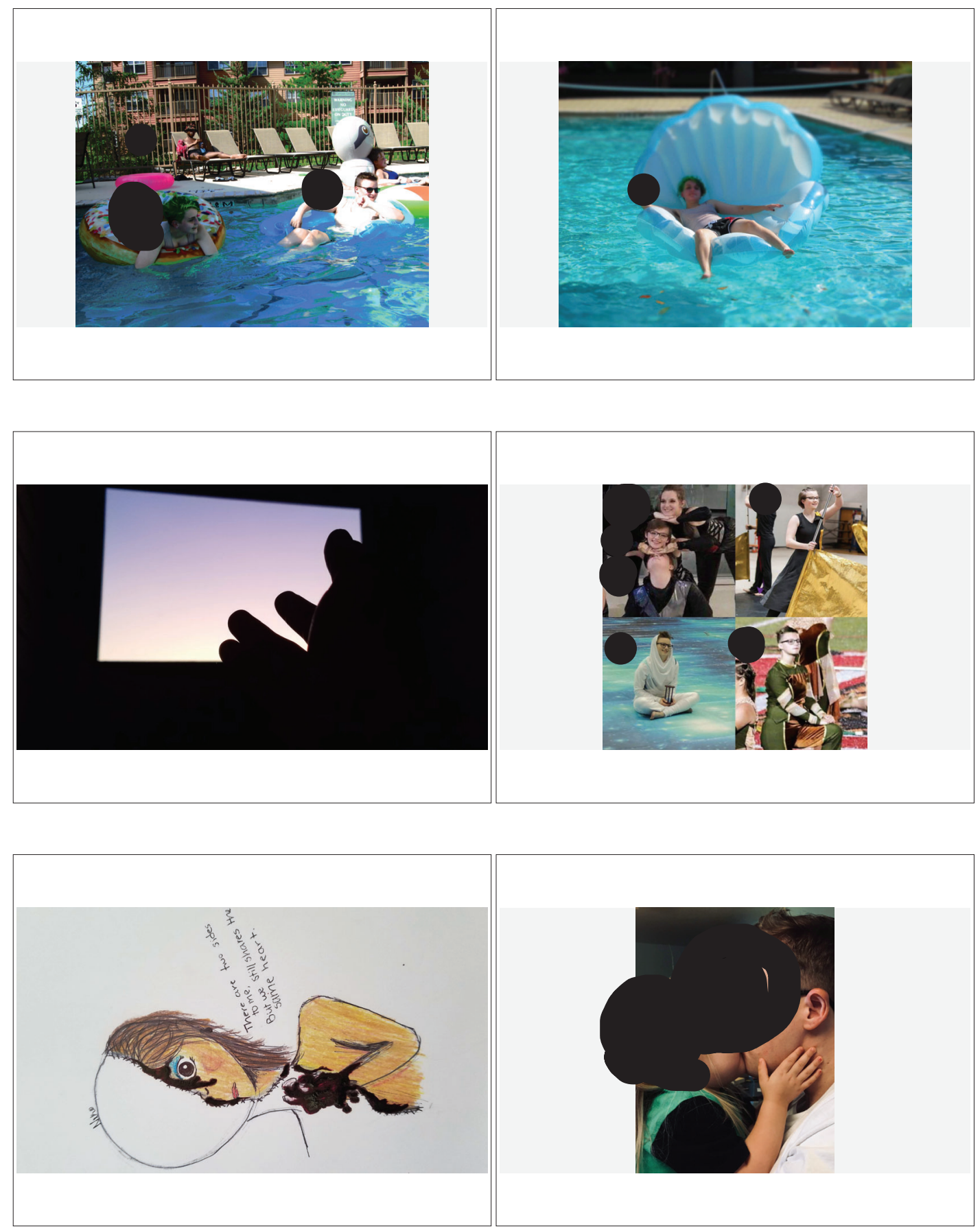

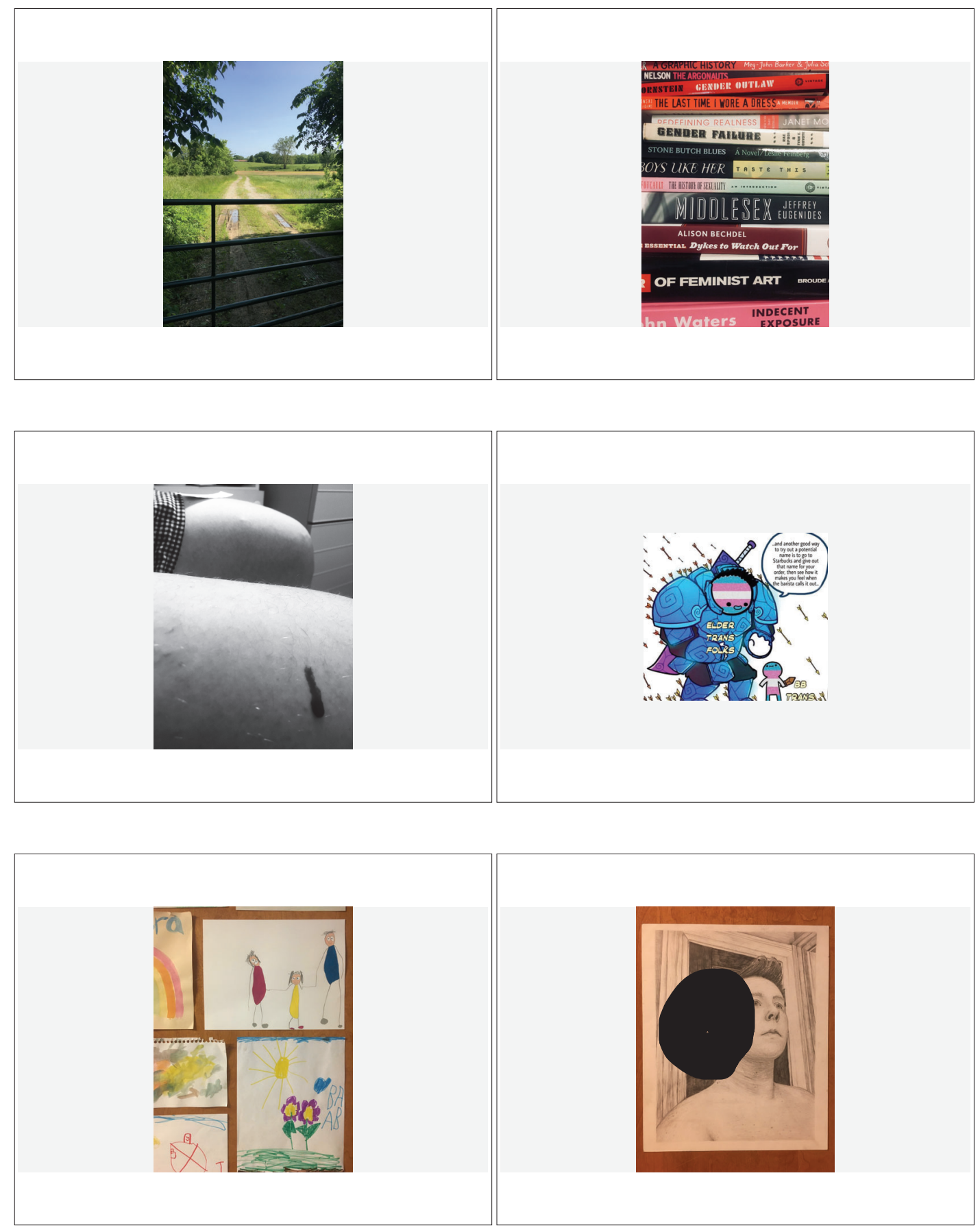

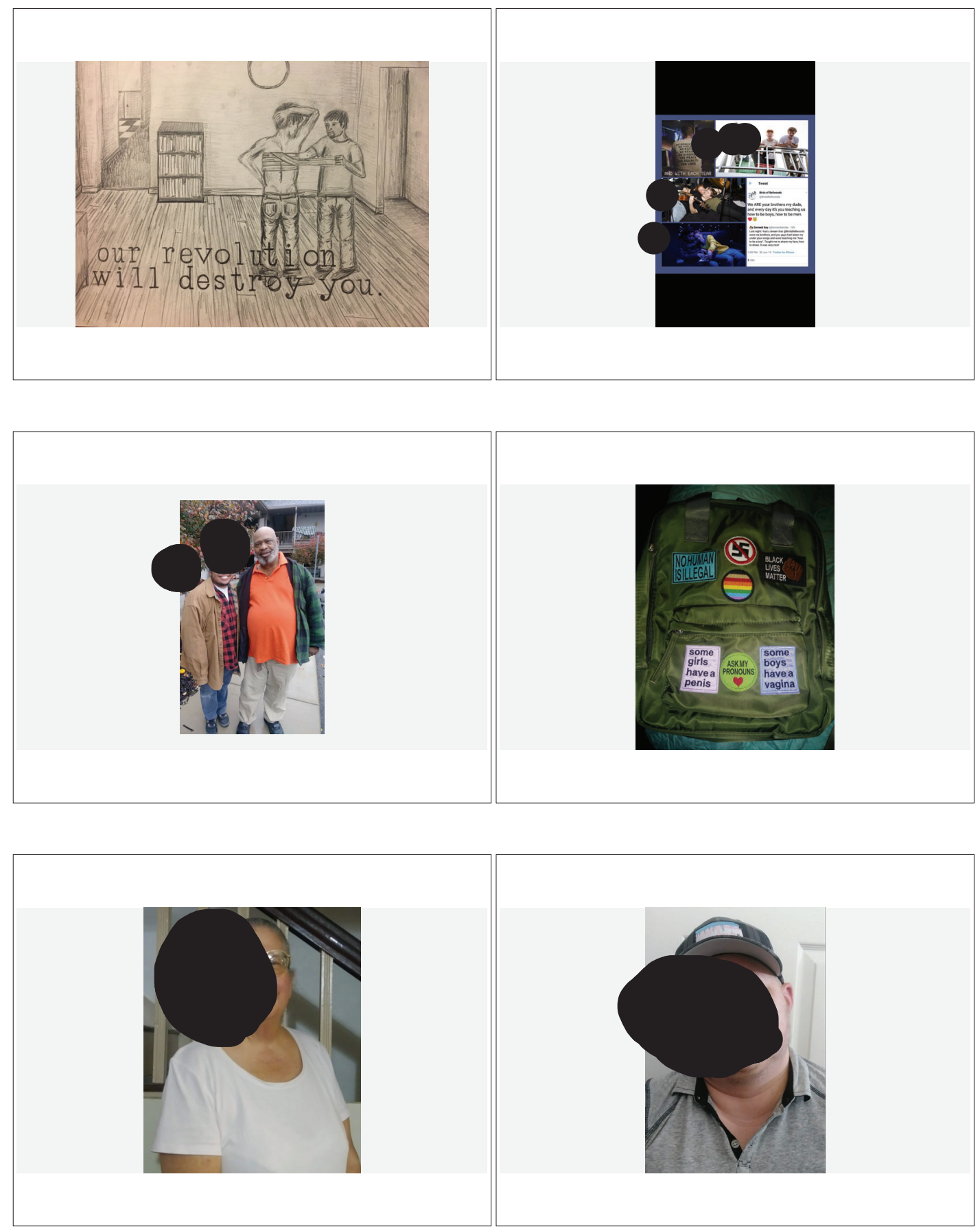

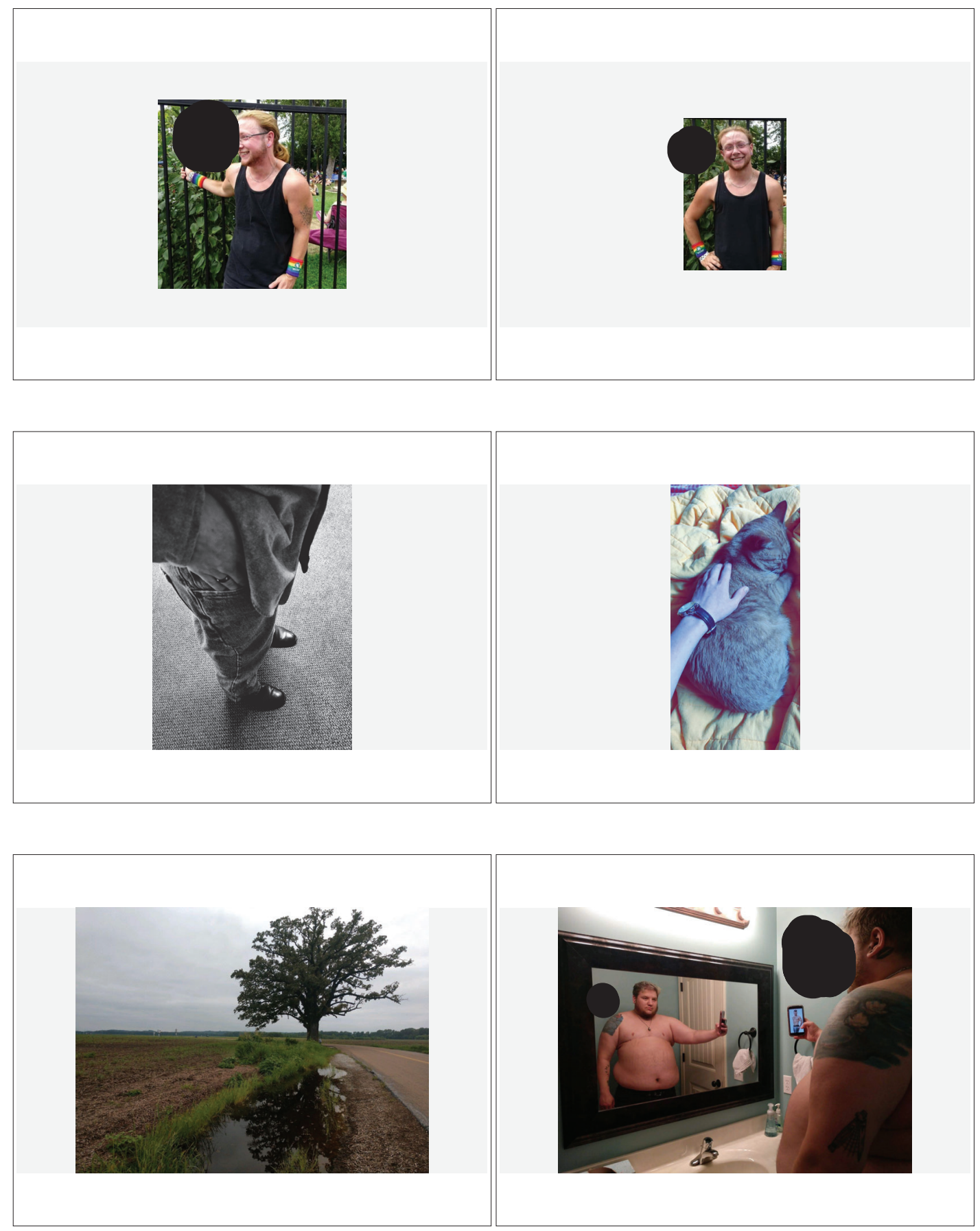

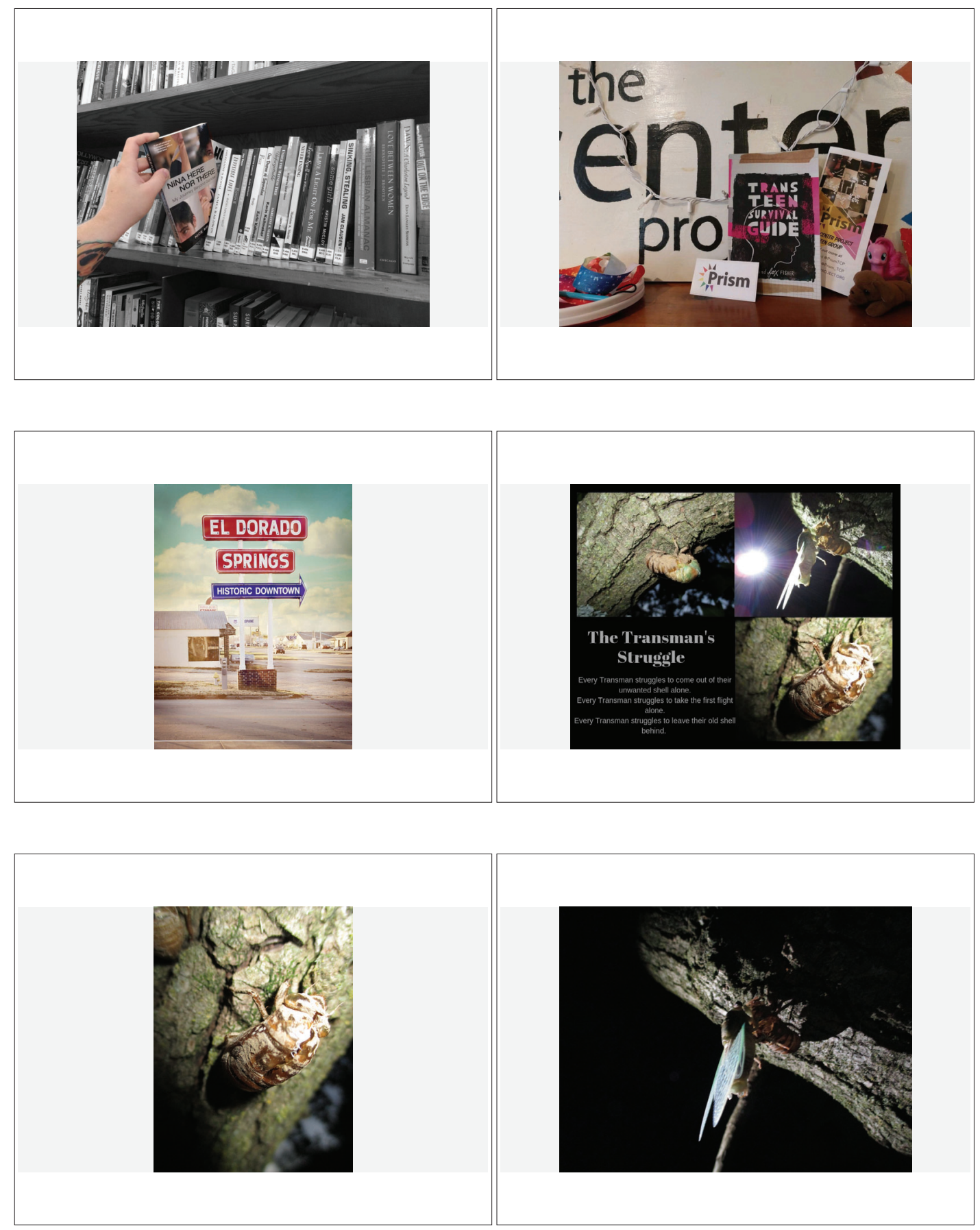

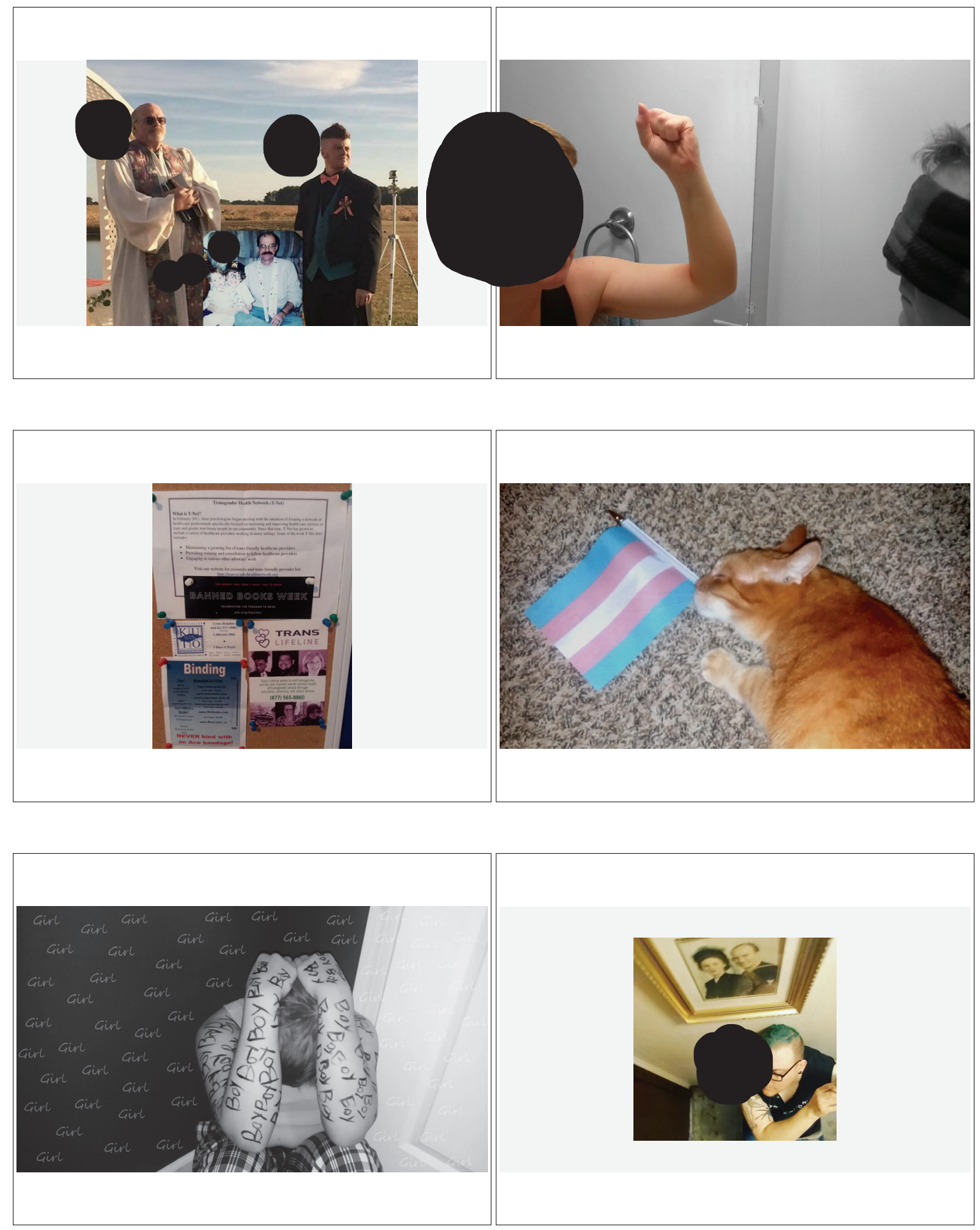

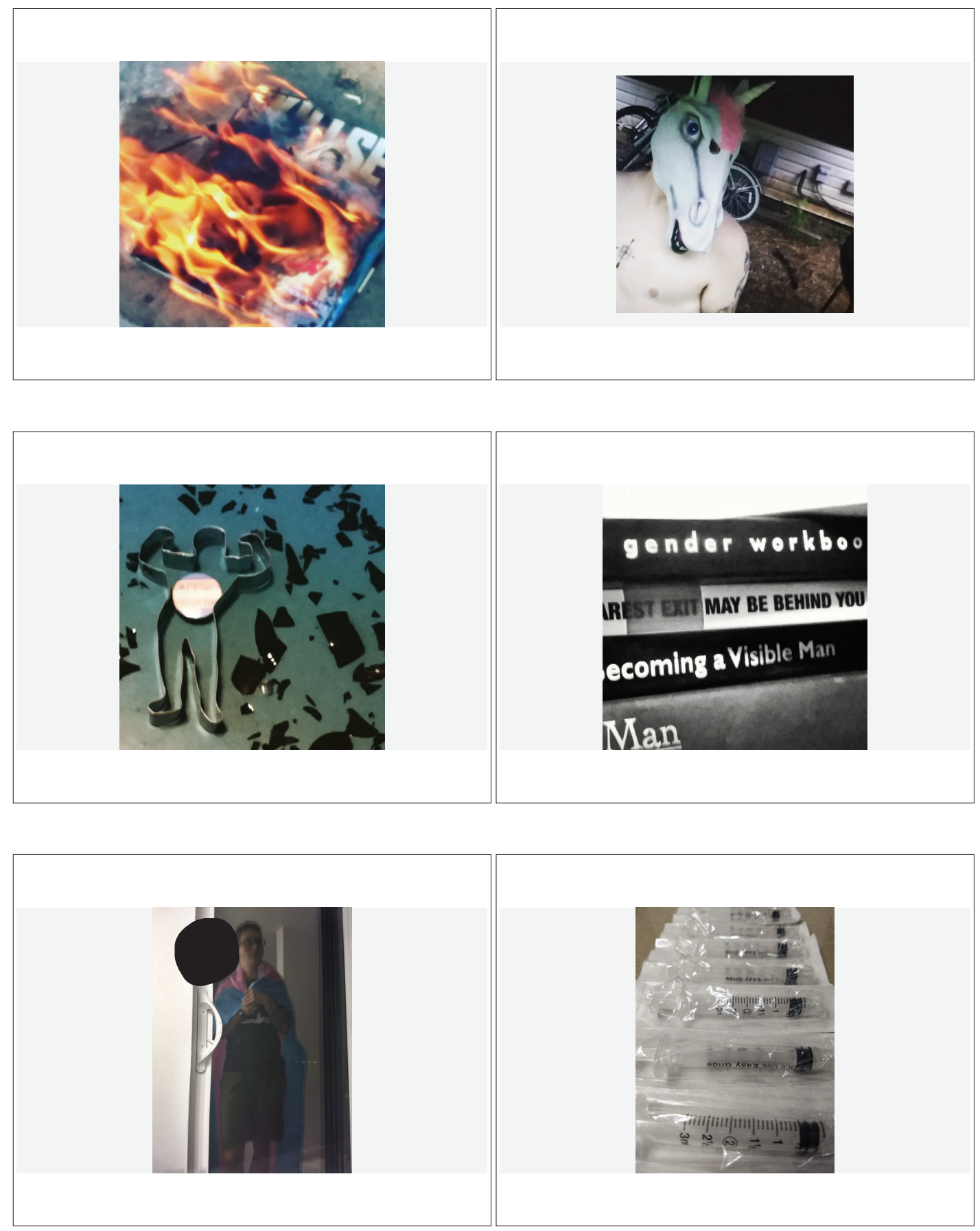

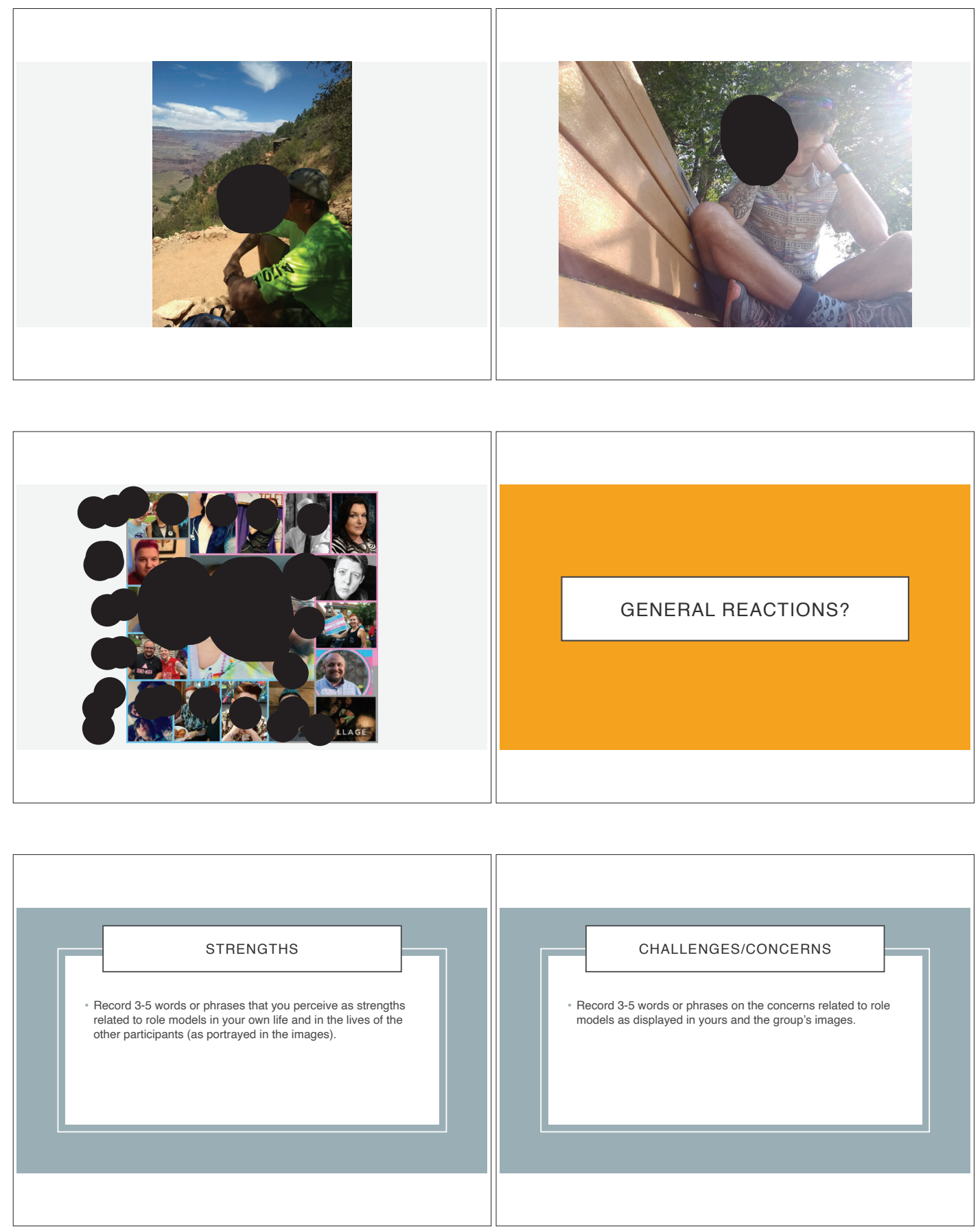


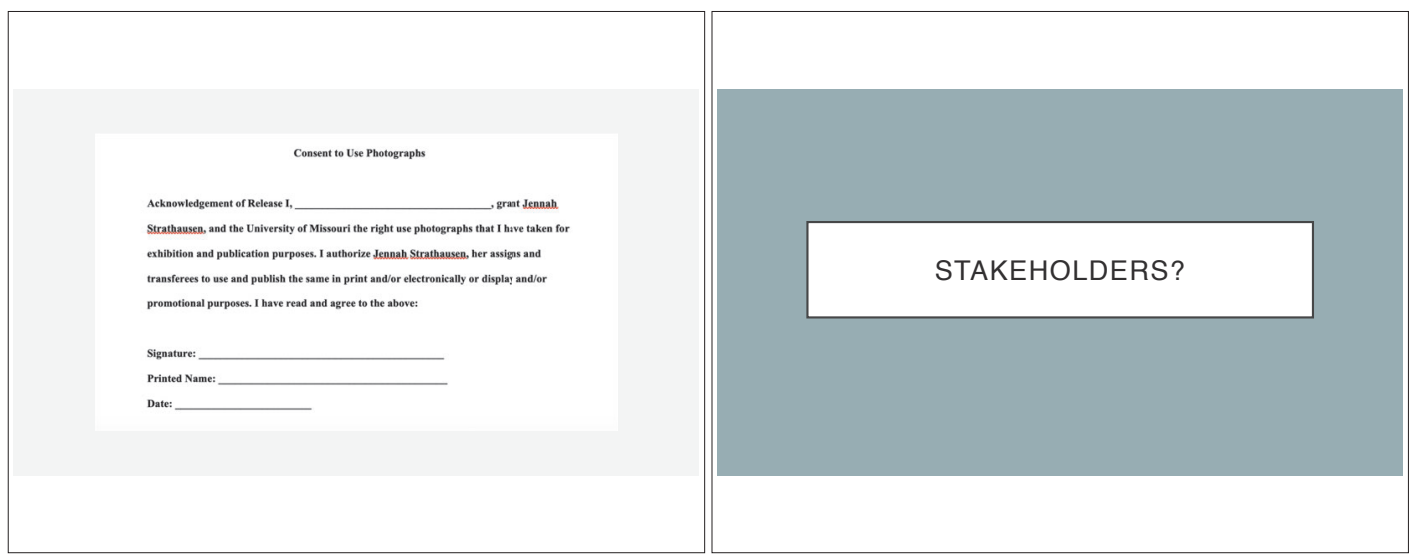


Appendix K: Researchers' Statement of Reflexivity

Jennah: Cisgender, woman, white, mom, academic, no religious affiliation, formerly working class, presently middle class, grad student

Biases: negative views of religiosity \& social/political conservatism, feminist. Background/Belief in photojournalism as a powerful tool for social change \& hope the project will garner public attention ( participants may have different desires for their level of visibility)

- Early frustration with delayed/inconsistent communication from multiple participants (May have unrealistic expectations for participants time investment given their personal situations/ responsibilities)

\section{Expectations:}

1. Participants will identify their time of transition as "adolescence"

2. Coming out/transitioning will have significantly improved their well being

3. They will be influenced by multiple marginalized statuses

4. Resilience will be a theme

5. Trans masculine role models will be mostly online vloggers

6. In person mentors will be more impactful than celebrities

Felice: Asian (Chinese), cisgender female, heterosexual, working class background, grad student

- Trans male friend from Kuwait, so provided some exposure to how trans males navigate religion and culture affected identity.

Biases:

- Family has conservative views about sex and gender, e.g. "unnatural" "why change bodies?"

- Besides interactions with trans male friend, lack of familiarity with trans individuals

- How are they different than LGB people?

- Privileged people had more access to transitioning

-people from rural parts of country tend to be too conservative and religious

Expectations:

- Older generation (pre 1990's) will have had a more difficult time than younger generation.

- Eastern cultures will view more negative

- Transmen with rural backgrounds will have harder time reconciling sex and gender more so than those who grew up in the city 


\section{VITA}

Jennah Strathausen was raised in Hilo, Hawaii, USA, and Lawrence, Kansas, USA, where she graduated from Lawrence High School. Jennah studied photojournalism at the University of Missouri (MU) and graduated in 2007. For the next five years Jennah worked as a freelance photographer in Missouri and Los Angeles, before returning to MU to pursue a graduate degree in Counseling Psychology. In 2014, Jennah completed her M.Ed. in Career Counseling.

At MU, Jennah developed interests in multicultural psychology and particularly LGBTQ quality of life issues and transgender identity development. Jennah pursued her LGBT research interests under the mentorship of Francisco J. Sánchez. She taught a course in Positive Psychology, and co-taught courses in Counseling Methods and Group Counseling.

As a graduate clinician, Jennah provided group and individual therapy at the MU Counseling Center, provided brief substance abuse interventions through BASICS and the Wellness Resource Center. She served as an MU Disability Center counselor and graduate researcher for three years. Jennah supervised beginning counselors in the MU Career Center.

Jennah will begin pre-doctoral internship in professional psychology at the Washington State University Counseling and Psychological Services in July 2020; and she is scheduled to earn her Ph.D. in Counseling Psychology in May 2021. Throughout her career, Jennah plans to apply teaching supervision, and clinical skills to the advancement of cross-cultural communication and inclusivity. 